DISSERTAÇÃO DE MESTRADO EM ENGENHARIA ELÉTRICA DEPARTAMENTO DE ENGENHARIA ELÉTRICA

\title{
DESENVOLVIMENTO DE SOLUÇÕES VISUAIS, DE USABILIDADE, DE MONITORAMENTO E DE INTERAÇÃO AUTOMÁTICA PARA PLATAFORMAS DE EDUCAÇÃO A DISTÂNCIA
}

\author{
LUCIANO ROSA DE ALMEIDA
}

ORIENTADOR: JOÃO PAULO CARVALHO LUSTOSA DA COSTA

DISSERTAÇÃO DE MESTRADO EM ENGENHARIA ELÉTRICA

$$
\text { PUBLICAÇÃO: }
$$

BRASÍLIA / DF, 27 de março de 2017. 
UNIVERSIDADE DE BRASÍLIA

FACULDADE DE TECNOLOGIA

DEPARTAMENTO DE ENGENHARIA ELÉTRICA

\author{
DESENVOLVIMENTO DE SOLUÇÕES VISUAIS, DE \\ USABILIDADE, DE MONITORAMENTO E DE INTERAÇÃO \\ AUTOMÁTICA PARA PLATAFORMAS DE EDUCAÇÃO A \\ DISTÂNCIA
}

\title{
LUCIANO ROSA DE ALMEIDA
}

DISSERTAÇÃO DE MESTRADO ACADÊMICO SUBMETIDA AO DEPARTAMENTO DE ENGENHARIA ELÉTRICA DA FACULDADE DE TECNOLOGIA DA UNIVERSIDADE DE BRASILIA, COMO PARTE DOS REQUISTIOS NECESSÁRIOS PARA OBTENÇÃO DO GRAU DE MESTRE.

APROVADA POR:

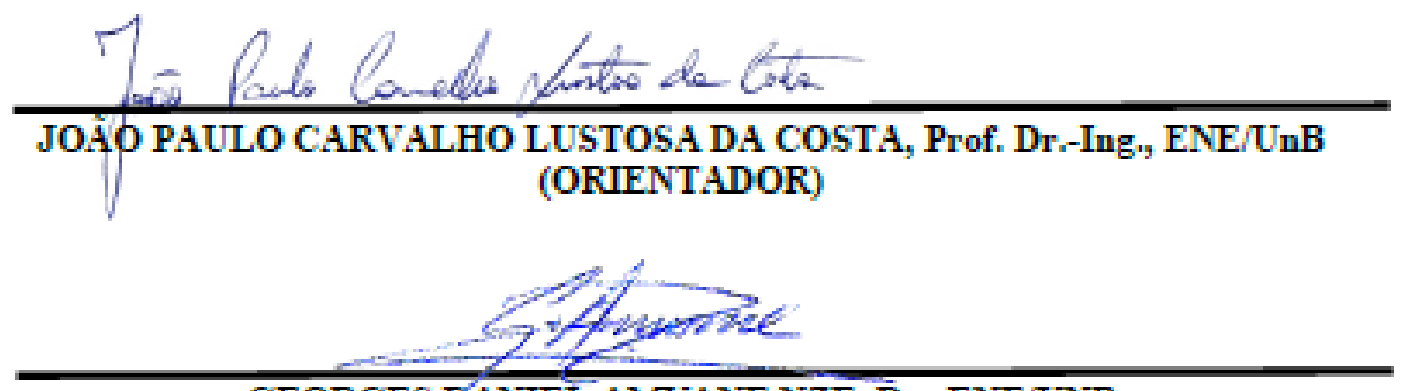

GEORGES DANIEL AMVANE NZE, Dr., ENE/UNB

(EXAMINADOR INTERNO)

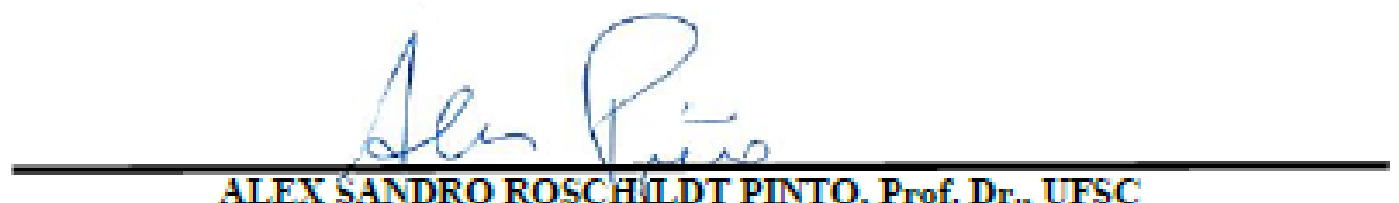

ALEX SANDRO ROSCHILDT PINTO, Prof. Dr., UFSC

(EXAMINADOR EXTERNO)

Brasilia, 27 de março de 2017. 


\section{Ficha catalográfica}

Rosa de Almeida, Luciano

DESENVOLVIMENTO DE SOLUÇÕES VISUAIS, DE USABILIDADE, DE MONITORAMENTO E DE INTERAÇÃO AUTOMÁTICA PARA PLATAFORMAS DE EDUCAÇÃO A DISTÂNCIA / Luciano Rosa de Almeida; orientador JOÃO PAULO CARVALHO LUSTOSA DA COSTA. -- Brasília, 2017. $69 \mathrm{p}$.

Dissertação (Mestrado - Mestrado em Engenharia Elétrica) -- Universidade de Brasília, 2017.

1. Educação a Distância. 2. Mensagens automáticas.

3. Moodle plugin. 4. Ferramentas de interatividade no ensino a distância. I. CARVALHO LUSTOSA DA COSTA, JOÃO PAULO, orient. II. Título.

\section{REFERÊNCIA BIBLIOGRÁFICA}

\section{CESSÃO DE DIREITOS}

AUTOR: LUCIANO ROSA DE ALMEIDA

TÍTULO: DESENVOLVIMENTO DE SOLUÇÕES VISUAIS, DE USABILIDADE, DE MONITORAMENTO E DE INTERAÇÃO AUTOMÁTICA PARA PLATAFORMAS DE EDUCAÇÃO A DISTÂNCIA

GRAU: Mestre $\quad$ ANO: 2017

É concedida à Universidade de Brasília permissão para reproduzir cópias desta dissertação de mestrado e para emprestar ou vender tais cópias somente para propósitos acadêmicos e científicos. $\mathrm{O}$ autor reserva outros direitos de publicação e nenhuma parte dessa dissertação de mestrado pode ser reproduzida sem autorização por escrito do autor.

\section{LUCIANO ROSA DE ALMEIDA}

Campus Universitário Darcy Ribeiro, Gleba A, Faculdade de Tecnologia.

CEP: $70790-120$ 


\section{AGRADECIMENTOS}

Agradeço ao meu professor Dr. João Paulo Carvalho Lustosa da Costa pelo apoio no crescimento acadêmico que ganhei nesse período de aprendizagem e novas experiências. Aos professores Dr. Georges Daniel Amvame Nze, Dr. Alex Sandro Roschildt Pinto e Dr. Ricardo Zelenovsky que compõem a banca dessa dissertação.

Aos professores Dr. Edison P. de Freitas, Dra. Edna D. Canedo, Dr. Rafael T. de Sousa Júnior e Giovanni Del Galdo pela ajuda nos trabalhos publicados, aos meus colegas Eliakim Zacarias e em especial a Juliano Prettz, o qual muito me auxiliou na reta final. Agradeço a Escola Nacional de Administração Publica - ENAP (Acordo de Cooperação 30/2014) e a Secretaria de Orçamento - SOF (Cooperação Acordo 30/2014), do Ministério do Planejamento, Orçamento e Gestão, pelo tempo em que participei do projeto em suas dependências e finalmente a CAPES pelo apoio financeiro recebido nesse período. 


\section{RESUMO}

\section{DESENVOLVIMENTO DE SOLUÇÕES VISUAIS, DE USABILIDADE, DE MONITORAMENTO E DE INTERAÇÃO AUTOMÁTICA PARA PLATAFORMAS DE EDUCAÇÃ̃O A DISTÂNCIA}

Autor: Luciano Rosa de Almeida

ORIENTADOR: João Paulo Carvalho Lustosa da Costa

Programa de Pós-graduação em Engenharia Elétrica

Brasília, 27 de março de 2017.

Os avanços tecnológicos nos sistemas de informação e comunicação estão permitindo o acesso à educação para milhões de participantes, independentemente da sua localização geográfica. Nesse sentido, as escolas de educação a distância necessitam cada vez mais de suporte e ferramentas tecnológicas, para implantação de plataformas mais robustas e interativas. Neste trabalho são propostas diversas soluções customizadas para integrar o ambiente virtual de ensino incluindo aspectos visuais de plataformas de Educação a Distância, ferramenta de apoio na usabilidade como o tour virtual e ferramentas de monitoramento e de acompanhamento do comportamento de participantes dos cursos e de interações por meio de envio de mensagens automáticas para os participantes. A parceria entre a Universidade de Brasília e a Escola Nacional de Administração Pública (Enap) possibilitou a criação dessas ferramentas e aperfeiçoamento do novo layout da plataforma, que contribuiu e auxiliou para que fosse possível o incremento em mais de 30 \% nas ofertas de turmas em cursos de Educação a Distância e também um salto de 20.553 capacitações no ano 2012 para 110.936 em 2016. Para validar as contribuições e atingir o objetivo proposto neste trabalho, foram utilizados, como estudo de caso, dados oriundos da base de dados do ambiente virtual Enap - Moodle, relatórios de gestão e de ferramentas externas de monitoramento como o google analytics. Os resultados do uso deste plugin no ambiente real da Enap mostram um aumento de $14 \%$ a mais de acessos em dias de mensagens em relação aos dias que não são enviadas mensagens, o que indica que o plugin proposto é particularmente bem-sucedido para lidar com os casos da falta de motivação dos participantes do curso a acessar e, consequentemente, aumentar o tempo do aluno em interações com o ambiente virtual.

Palavras-chave: Educação a Distância, Mensagens automáticas, Moodle plugin, ferramentas de interatividade no ensino a distância. 


\title{
ABSTRACT
}

\section{DEVELOPMENT OF VISUAL, USABILITY, MONITORING AND AUTOMATIC INTERACTION SOLUTIONS FOR DISTANCE EDUCATION PLATFORMS}

\author{
Supervisor: Prof. Dr.-Ing. JOÃO PAULO CARVALHO LUSTOSA DA COSTA \\ Department of Electrical Engineering / University of Brasília \\ Graduate Program in Electrical Engineering \\ Brasilia, March 27, 2017.
}

Technological advances in information and communication systems are enabling access to education for millions of participants, regardless of their geographic location. In this sense, distance education schools increasingly require support and technological tools to deploy more robust and interactive platforms. This work proposes several customized solutions to integrate the visual teaching environment including visual aspects of distance education platforms, a usability support tool such as the virtual tour and tools for monitoring and monitoring the behavior of course participants and interactions through sending Automatic messages to participants. The partnership between the University of Brasília and the National School of Public Administration (Enap) enabled the creation of these tools and improvement of the new layout of the platform, which contributed to and helped to increase the offer of more than $30 \%$ distance education courses and also a jump from 20,553 trainings in 2012 to 110,936 in 2016. To validate the contributions and achieve the goal proposed in this work, we used, as a case study, data from the Enap virtual environment database - Moodle, Management reports and external monitoring tools like google analytics. The results of using this plugin in Enap real environment show an increase of $14 \%$ more hits in message days compared to days that are not sent messages, which indicates that the proposed plugin is particularly successful in dealing with cases of the lack of motivation of the course participants to access and, consequently, increase the student's time in interactions with the virtual environment.

Keywords: Distance Learning, Automatic Messages, Moodle plugin, interactive tools in distance learning. 


\section{SUMÁRIO}

1 - INTRODUÇÃ

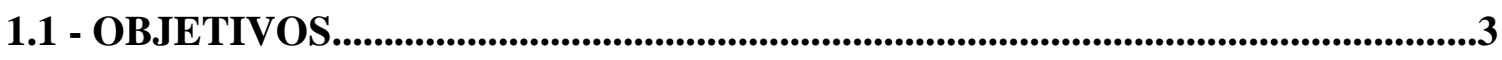

1.1.1 - Objetivo Geral.........................................................................................................3

1.1.2 - Objetivo Específico...............................................................................................3

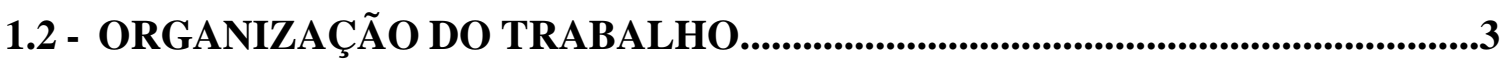

\section{2 - CONCEITOS DE EDUCAÇÃO A DISTÂNCIA NO CONTEXTO DA}

COOPERAÇÃO UNB - ENAP........................................................................................5

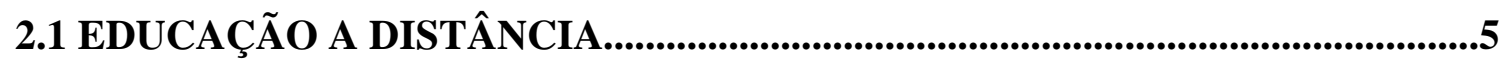

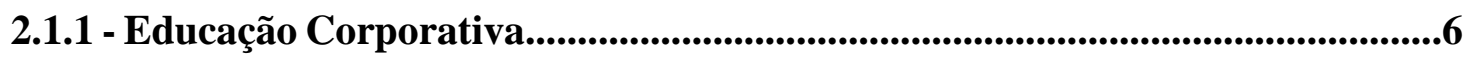

2.1.2 - Contextualização da Evasão na Educação a Distância........................................7

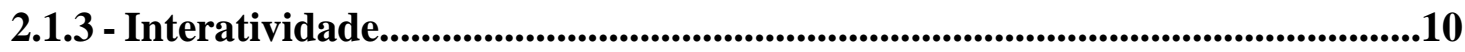

2.2 - VISÃO GERAL DO TERMO DE COOPERAÇÃO...............................................11

2.3 - ATIVIDADE DESEMPENHADAS NO PROJETO.........................................12

2.4 - TECNOLOGIA DE APOIO À EDUCAÇÃO À DISTÂNCIA.........................13

2.4.1 - E-Learning..........................................................................................................14

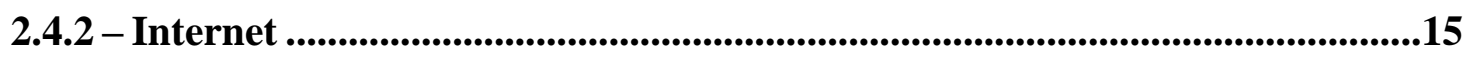

2.4.3 - Implantação do E-Learning........................................................................16

2.4.4 - SGAs e AVAs: Conceitos e Distinções .......................................................19

2.4.5 - Principais Ambientes Virtuais de Aprendizagem ...........................................21

\section{3 - CONCEPÇÃO E DESENVOLVIMENTO DE FERRAMENTAS}

PERSONALIZADAS..............................................................................................25

3.1 - MUDANÇAS DO VISUAL DA ESCOLA VIRTUAL DA ENAP .........................25

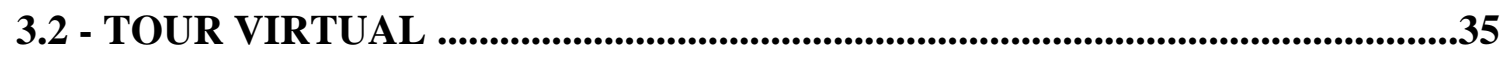

3.3 - FERRAMENTA DE MONITORAMENTO DO COMPORTAMENTO

E DO DESEMPENHO DOS ALUNOS ...................................................................38

3.4 - IMPACTO DA INTERFACE E DO MONITORAMENTO ...............................45

4 - FERRAMENTA DE INTERAÇÃO AUTOMÁTICA POR MEIO DO ENVIO DE MENSAGENS . 
4.1- IMPACTO DA FERRAMENTA .56

5 - CONCLUSÕES ............................................................................................62

5.1 - TRABALHOS FUTUROS .........................................................................64

REFERÊNCIAS BIBLIOGRÁFICAS.....................................................................65 


\section{LISTA DE TABELAS}

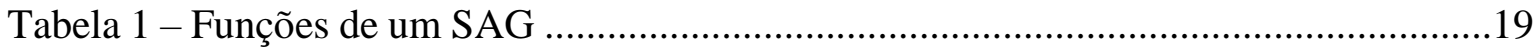

Tabela 2 - Funções e atividades na plataforma MOODLE ..............................................26

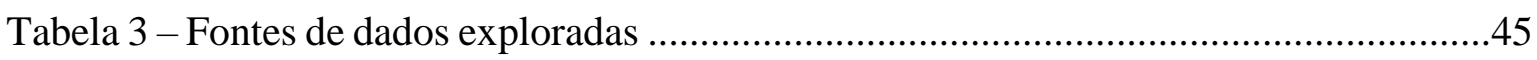

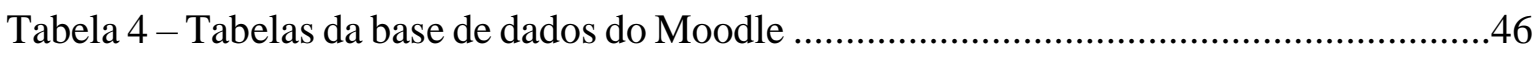

Tabela 5 - Informações da demanda 2009 e 2012 .............................................................47

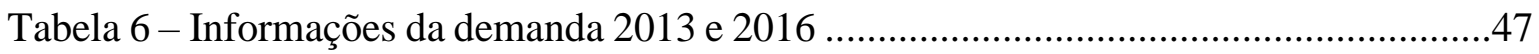

Tabela 7 - Total e Porcentagem de acessos em dias em que não foram enviadas

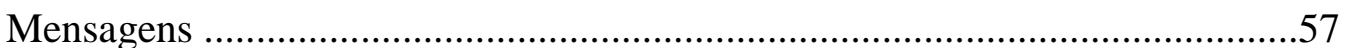

Tabela 8 - Total e Porcentagem de acessos em dias com mensagens automáticas são enviadas pelo plugin .............................................................................5

Tabela 9 - Mostra que as médias dos cursos com e sem mensagens ....................................60

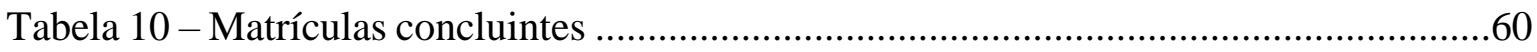

Tabela 11 - Relação entre turmas com 20 dias e turmas com 34 dias de duração de curso ..60 


\section{LISTA DE FIGURAS}

Figura 1 - Índices alunos por modalidade de cursos em EaD em 2014 -2015 ........................1

Figura 2 - Modelo da relação aprendizagem/permanência .............................................. 9

Figura 3 - Tela inicial com histórico de cursos do aluno ..................................................27

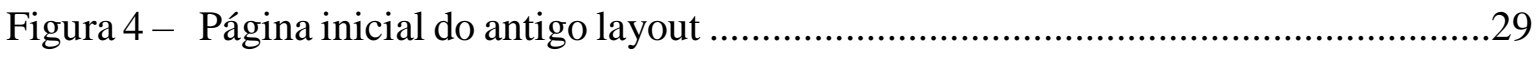

Figura 5 - Tela de abertura de curso novo layout ..............................................................

Figura 6 - Módulos dos cursos no layout antigo .................................................................

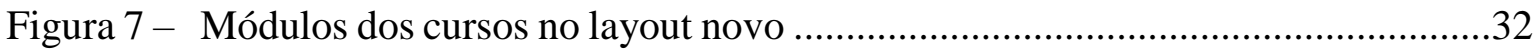

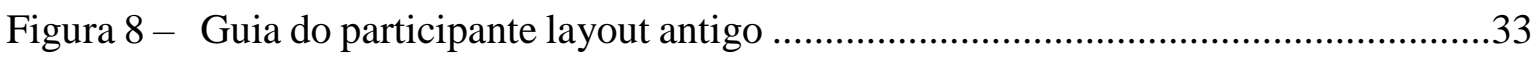

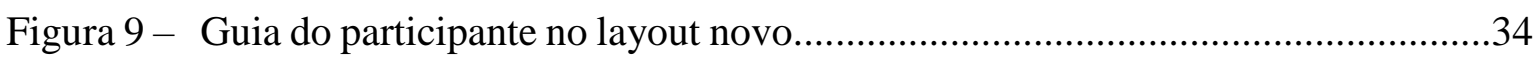

Figura 10 - Apresentação do guia do participante...............................................................

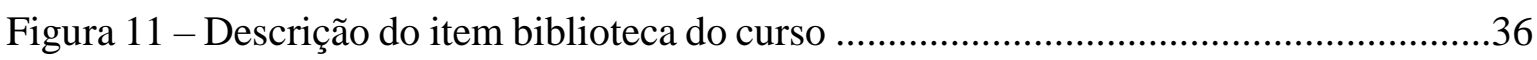

Figura 12 - Apresentação dos módulos dos cursos ................................................................

Figura 13 - Apresentação do guia do participante .................................................................37

Figura 14 - Apresentação dos comandos de navegação do guia ...........................................38

Figura 15 - Fluxo das informações que compõem o relatório de desempenho

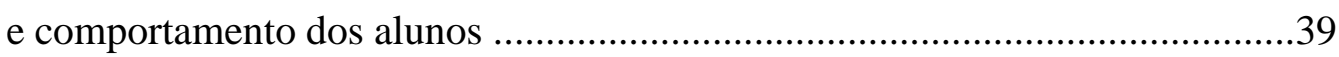

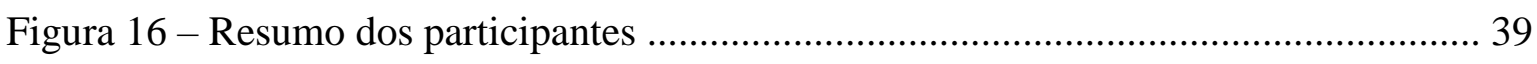

Figura 17 - Gráfico com a quantidade de acesso por dia e histórico de

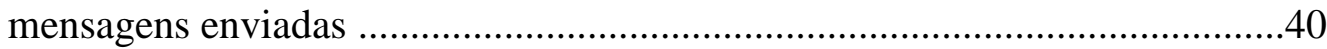

Figura 18 - Gráfico de participação por atividades ............................................................41

Figura 19 - Gráficas participações por tipo de atividades ...................................................42

Figura 20 - Registro de tempo online por status do aluno ............................................... 43

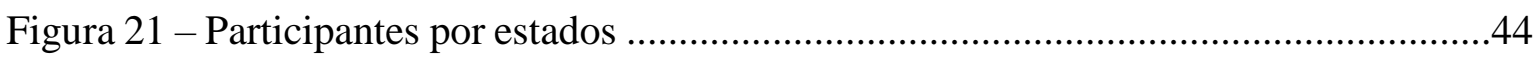

Figura 22 - Gráfico total de matrículas por esfera de poder em 2016 ................................48

Figura 23 - Gerenciador de e-mail para envio manual de mensagens ...............................50

Figura 24 - Fluxo de operação do plug-in de envio de mensagem ......................................51

Figura 25 - Processos de interação do usuário com o plugin de mensagem automática ......53

Figura 26 - Tela de seleção com as condições para enviar mensagens para os alunos ..........54

Figura 27 - Listas de mensagens registradas em determinar curso ......................................55

Figura 28 - Exemplo de mensagens recebidas pelo participante no final do curso ................56

Figura 29 - Visualização dos picos de acesso do Google Analytics ...................................59 


\section{ACRÔNIMOS}

AVA

$\mathrm{BD}$

CGEAD

EC

ENAP

FUB

NTIC

MP

PCA

SGC

SGBD
Ambientes Virtuais de Aprendizagem

Banco de Dados

Coordenação Geral na Educação a Distância

Educação corporativa

Escola Nacional de Administração Pública

Fundação Universidade de Brasília

Novas Tecnologias de Informação e

Comunicação

Ministério do Planejamento

Principal Componente Analysis

Sistema de Gerenciamento de Cursos

Sistema de Gerenciamento de Banco de Dados 


\section{INTRODUÇÃO}

Educação a Distância (EaD) está em constante expansão no Brasil. Em 2015, mais de 5 milhões de brasileiros realizaram cursos a distância, segundo o Anuário Estatístico de Educação Aberta e a Distância no Brasil (Abed, 2015). O censo de 2015 contabilizou 5.048.912 alunos de EaD, com 1.108.021 em cursos totalmente a distância e semipresenciais e 3.940.891 em cursos livres ou corporativos. Foram registrados 1.180 .296 a mais que o ano anterior conforme podemos ver na figura 1.

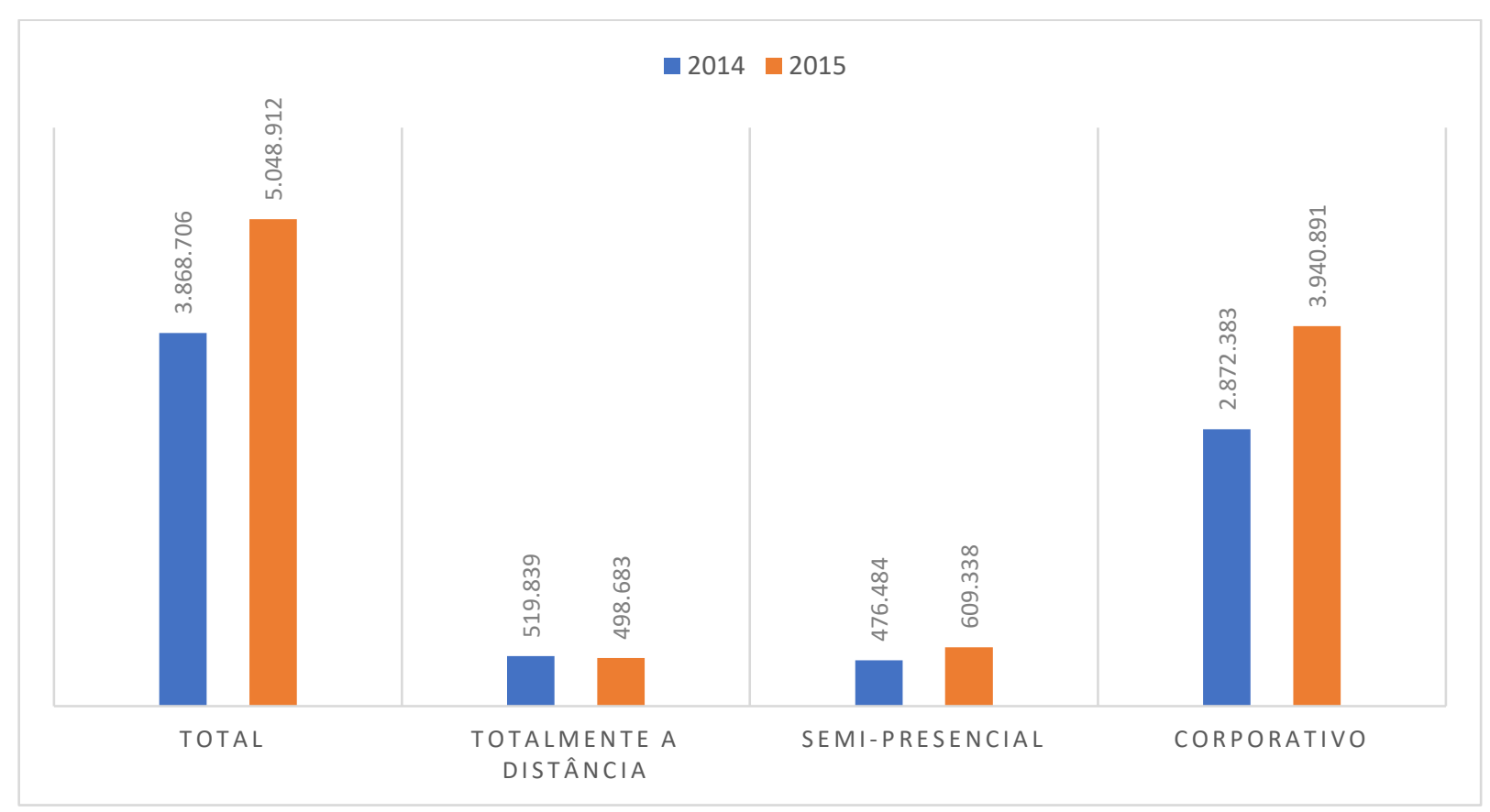

Figura 1 - Índices de alunos por modalidade de cursos em EaD em 2014 -2015.

Fonte: CensoEaD 2015.

Em cursos técnicos, de graduação e pós-graduação lato sensu são ofertados integramente no formato EaD há mais de 1.100 .000 estudantes (Abed, 2015). Em cursos de graduação presenciais até $20 \%$ da carga horária total pode ser realizada a distância, de acordo com a legislação vigente (Mec, 2004).

A necessidade de formação, a expansão e interiorização da educação, a crescente demanda por cursos de $\mathrm{EaD}$, os índices de reprovação e as taxas de evasão neste tipo de formação mostram-se elevados conforme dados do censo $\mathrm{EaD}$ de 2015, 40 \% das instituições apresentam taxas entre 
$26 \%$ - $50 \%$ de evasão (Abed, 2015). O termo reprovação é usado para definir a situação do aluno que apesar de finalizar o programa conforme critérios das instituições de ensino, não consegue atingir aproveitamento mínimo para aprovação no curso. Já evasão define os alunos desistentes, que não completam o programa de ensino.

Com plena ampliação de ofertas de cursos e aumento das matrículas, é indiscutível que as Tecnologias de Informação e Comunicação (TIC), em especial o uso de computadores e a Internet os quais ocupam uma boa parcela do tempo das pessoas diariamente, deram um grande impulso ao ensino a distância, apesar disso até o momento não tiveram impacto significativo na motivação dos alunos em participar de atividades ligadas a $\mathrm{EaD}$ e consequentemente ajudar na diminuição da evasão nessa modalidade de ensino.

$\mathrm{Na}$ educação a distância, as TICs buscam estimular uma nova composição dos espaços de aprendizagem e o papel dos professores e alunos, resumindo, refletir sobre a construção e reconstrução de diferentes concepções de educação. É possível se projetar novas ferramentas e ambientes de comunicação e criar novas formas de interação para estimular a participação e autonomia dos alunos, libertando-se dos paradigmas tradicionais da educação.

Os Ambiente Virtuais de Aprendizagem (AVA) possibilitam essa quebra de paradigma e através da combinação de diversas tecnologias é possível organizar conteúdos de forma atrativa, o que facilita a aprendizagem e a interação (Dillenburg e Teixeira, 2011). Franco et al. (2003) e Sarmento et al. (2011), ressaltam a importância de que nos AVAs são possíveis incorporar ferramentas da Web, como por exemplo sistema de e-mail, sala de chat, espaços para debates, local para enviar arquivos, sistema de avaliação, relatórios de participação, dentre outros.

Assim, o desafio consiste em desenvolver ferramentas que complementem os AVAs e que auxiliem os gestores a entender o comportamento dos alunos e obter um feedback do mesmo. Através da análise desses comportamentos registrados no ambiente de educação a distância, foi possível coletar informações importantes sobre o comportamento dos participantes até então implícitas na base e revelou a necessidade de novos modelos de sistemas com tarefas especializadas.

Diversos estudos (Bassani, 2006) têm sido realizados no desenvolvimento de ferramentas especializadas em mapear as interações alunos e ambientes de aprendizado, permitindo o 
monitoramento da frequência e produção de cada aluno, acompanhando os processos de avaliações e de aprendizado.

A proposta em questão é demonstrar a importância das melhorias que essas ferramentas, desenvolvidas em volta as necessidades específicas da Coordenação Geral na Educação a Distância (CGEAD) da Escola Nacional de Administração Pública (Enap), trouxe de progresso na produção do ambiente virtual da Enap. O foco principal é apresentar a ampliação da escola proporcionada pela melhoria do AVA, o relatório de Desempenho e Comportamento do Aluno e a análise da ferramenta envio de mensagem automáticas desenvolvido na parceria entre UnB-Enap.

\subsection{OBJETIVOS}

\subsubsection{Objetivo Geral}

O objetivo deste estudo é apresentar as contribuições que as melhorias visuais da plataforma de educação a distância e no desenvolvimento de plugins com tarefas específicas incorporado trouxeram ao ambiente virtual de ensino da Escola Nacional de Administração Pública.

\subsubsection{Objetivo Específico}

Apresentar a evolução das ofertas de cursos após a implantação das melhorias no novo layout do ambiente virtual de aprendizado da Escola Nacional de Administração Pública em parceria com a Universidade de Brásilia. Em segundo momento demonstrar a eficácia das ferramentas desenvolvidas, em específico o sistema de envio de mensagens automáticas, explorar a base de dados do ambiente virtual e relacionar as informações extraídas com outras fontes de informações da Enap.

\subsection{ORGANIZAÇÃO DO TRABALHO}

Tendo determinado a finalidade do estudo e as definições que servem como a base da pesquisa, os seguintes capítulos focam na revisão da literatura, descrição do procedimento de investigação e os resultados da pesquisa, e finalizam em um resumo que inclui as conclusões e recomendações para um estudo mais aprofundado. Para um melhor entendimento, este trabalho é organizado em capítulos na seguinte sequência. 
O capítulo 2 traz uma revisão da literatura onde estão explicitados conceitos importantes para entender o funcionamento da pesquisa, onde tratamos dos fundamentos de educação a distância, educação corporativa e suas particularidades em organizações do governo federal, destacando a motivação para o desenvolvimento dessa modalidade de ensino e importância do aperfeiçoamento das plataformas de ensino a distância.

No capítulo 3, é descrito o ambiente virtual da Enap, destacando a importância de utilizar uma plataforma Moodle, que é um sistema de código aberto e flexível. São apresentadas soluções visuais e as diferenças entre o layout antigo e o novo layout desenvolvido para a escola. Demonstra o guia virtual Tour, que auxilia na orientação e na usabilidade dos recursos e componentes do AVA. Exibe o relatório de monitoramento do comportamento e do desempenho dos alunos, que sintetiza informações importantes de uma turma em um determinado curso. E por fim apresenta o impacto das melhorias após a remodelagem do layout da escola virtual e o desenvolvimento de soluções costumizadas em parceria UnB-Enap comparado com os 4 anos anteriores ao acordo de cooperação.

Já no capítulo 4, detalha-se a ferramenta de envio de mensagens e apresentam-se as análises dos resultados obtidos com as ferramentas de envio de mensagens automáticas e a extração de informações referentes a atividade dos alunos em relação ao estímulo da ferramenta e sua relação com as notas e os índices de conclusões.

No Capítulo 5 são descritas as considerações finais e as principais contribuições da parceria de cooperação UnB-Enap, no desenvolvimento e aperfeiçoamento da plataforma de EaD no que tange as melhorias visuais e de estrutura dos cursos, assim como impacto das ferramentas desenvolvidas sobre o comportamento dos alunos. Além disso, fornece o entendimento dos resultados obtidos nos estudos de casos aplicados e proposições para trabalhos futuros, baseados nos assuntos aqui abordados. 


\section{CONCEITOS DE EDUCAÇÃO A DISTÂNCIA NO CONTEXTO DA COOPERAÇÃO UNB - ENAP}

Este capítulo, inicialmente, busca conceituar Educação a Distância, apresentando suas principais características e referenciais. A relação entre educação corporativa, mais especificamente a educação a distância em ambiente corporativos, que é o caso da Enap, que oferece treinamento e capacitação para órgãos do governo federal.

No item seguinte, é tratado pontos importantes e de grande impacto na educação a distância no que se refere a evasão e a interação dos alunos com o ambiente de ensino.

Nos tópicos seguintes, é possível ter uma visão geral do termo de cooperação entre Enap e UnB, das atividades desempenhadas no projeto, assim como apresenta as tecnologias desenvolvidas e implantadas no ambiente virtual de aprendizado.

Em cursos a distância, especificamente através da Web, as várias ferramentas que compõem um AVA são essenciais como espaço de disseminação de conhecimento. Uma análise cuidadosa dos dados gerados nas interações realizadas nesses espaços virtuais contribui para que o professor controle e gerencie seus alunos, a fim de motivá-los a participar de suas atividades de aprendizagem e alcançar sucesso nos estudos.

\subsection{EDUCAÇÃO A DISTÂNCIA}

Este tópico destaca conceitos sobre Educação a distância, sua contribuição na área de educação corporativa focada no poder público. No subtópico seguinte é apresenta o impacto e as características da evasão na modalidade de educação a distância. Por fim falamos sobre a interatividade e sua importância no aprendizado dos alunos de educação a distância.

Educação a Distância é uma forma de educação que conta com o apoio de novas tecnológicas. Possui a capacidade de atingir uma grande quantidade de alunos ao mesmo tempo e surge como uma modalidade alternativa para superar limites de tempo e espaço. É o aprendizado planejado que ocorre normalmente em um lugar diferente do local do ensino, exigindo técnicas especiais de criação de cursos e de instruções, com comunicação por meio de TICs, disposições organizacionais e características especiais de ensino (Moore e Kearsley, 2007). 
Segundo (Keegan, 1996), entre as características da educação a distância estão: A separação entre professores e alunos durante o processo de ensino e aprendizagem, constante ou na maior parte do tempo. A existência de uma organização educacional, tanto no planejamento e preparação dos materiais como nos serviços de apoio aos alunos, que diferencia o $\mathrm{EaD}$ de um autoestudo privado.

O uso de vários meios de comunicação para unir professores e alunos e fornecer conteúdo educacional; A possibilidade de uma comunicação bidirecional entre professores e alunos, para que o aluno possa concentrar-se ou mesmo iniciar o diálogo; A possibilidade de encontros ocasionais ou por meios eletrônicos, para fins didáticos, ou socialização entre os participantes do ambiente educacional.

Essas características levaram a Educação a distância a expandir as oportunidades educacionais para um maior número de indivíduos, independentemente da sua posição geográfica ou limitações socioeconômicas, democratizando a (Unesco, 2002). É uma realidade que foi aceita e é incentivada por órgãos governamentais (Costa, 2007), pois possui um formato que permite levar a educação para locais remotos, horários de estudo flexíveis e proporciona o envolvimento de um número maior de participantes. Outra característica importante é a possibilidade de uma comunicação de via dupla entre professores e alunos, de modo que os alunos possam participar ou até mesmo iniciar o diálogo. A possibilidade de encontros ocasionais, pessoalmente ou por meios digitais com a finalidade de troca de conhecimento.

\subsubsection{EDUCAÇÃO CORPORATIVA}

Conforme Abbad (2007), a Educação a Distância (EaD) é sugerida como um dos mecanismos viáveis para o desenvolvimento e aprimoramento das competências das organizações. A EaD está sendo adotada por diversas escolas de governo de países da Europa, da América do Norte e Brasil, tanto nos programas de qualificação e formação profissional de servidores públicos e comunidade com interesse na área pública (Abbad, 2007).

Mesmo com a constatação de resistências, a aprendizagem em torno da EaD tem mobilizado as instituições de ensino (públicas e privadas) a adotar o uso intensivo de tecnologias em rede e ambientes virtuais de aprendizagem. Para as instituições públicas, tem-se o desafio da expansão da educação no Brasil e, para as instituições privadas, a busca crescente de adequação às 
necessidades de treinamento e desenvolvimento no mundo do trabalho. (Valente e Arantes, 2011).

A utilização das TICs nas escolas de governo transformou o modo de pensar e de fazer educação corporativa (EC). Hoje é possível perceber, ser difícil formular estratégias de treinamento em larga escala, especialmente em um pais com as dimensões geográficas como as do Brasil sem a interface da EaD.

De acordo com Abbad (2007), a educação corporativa no Brasil, impulsionada pela educação a distância, aumentou as oportunidades de aprendizagem ao longo da vida profissional de seus funcionários, colaboradores, parceiros e demais componentes da cadeia de valor. Investimento em treinamento tem se mostrado eficaz para que os colaboradores obtenham um melhor conhecimento das organizações onde atuam e tem se tornado um dos fatores de retenção de talentos nas empresas.

No contexto do serviço público, a Enap fez um esforço adicional para sensibilizar os profissionais de educação e de gestão de pessoas para o papel indispensável da educação à distância na promoção de oportunidades de aprendizagem continuada aos funcionários públicos e o acesso ao estudo a qualquer momento e em qualquer lugar.

\subsubsection{CONTEXTUALIZAÇÃO DA EVASÃO NA EDUCAÇÃO A DISTÂNCIA}

A evasão é objeto bastante debatido e avaliado devido a sua relevância nos resultados de programas de ensino a distância. A evasão se caracteriza geralmente quando por um abandonou em definitivo do aluno independente do período de curso, sem cumprir os requisitos pedagógico do curso (Abbad et al., 2006; Vargas, 2004).

Walter (2006), em uma revisão dos estudos da área, encontrou resultados de diversos estudos que mostraram uma taxa elevada de abandono nos cursos a distância. Entre esses estudos, verificou-se quais as principais causas da evasão e também os fatores que contribuíram para a permanência dos participantes. A pesquisa relatou uma taxa de desistência de aproximadamente $50 \%$ e identificou como razões: falta de tempo; falta de condições de estudo no lar e no local de trabalho; falta de organização pessoal; problemas com a tecnologia; e falta de atenção as expectativas.

Dados de revisões de literatura sobre o fenômeno apontam para níveis preocupantes, já que a taxa de desistência nos cursos corporativos brasileiros ultrapassa $30 \%$ (AbraEAD, 2015). O que mostra 
que os avanços tecnológicos cada vez mais difundidos no campo da educação a distância não foram capazes de impedir a evasão (Sales, 2011).

Almeida (2007 apud ABBAD, 2010) aponta que a falta de suporte das instituições pode levar à evasão, da mesma forma a falta de apoio a aprendizagem incidem diretamente sobre os índices de evasão, apresentado por Vasconcelos (2008 apud ABBAD, 2010).

Fernandes (2005) pesquisou 50 instituições de ensino superior no Brasil e apurou a relação entre a taxa de abandono (18\% em cursos semipresenciais e $28 \%$ em cursos inteiramente a distância), as tecnologias utilizadas, a plataforma de ensino e o design dos cursos. Tomados em conjunto, estas variáveis contribuem para a explicação de $34 \%$ da variabilidade das taxas de evasão dos cursos investigados.

Dentre os fatores relacionados ao aluno e a sua situação, destacam-se: falta de tempo para estudar, problemas financeiros, local de trabalho que não possibilita tempo para o estudo , problemas relativos à profissão, dificuldade de deslocamento do trabalho para casa, a incapacidade de conciliar as atividades do cotidiano com as tarefas necessárias para o curso, a falta de experiência como estudante em cursos de ensino à distância, a dificuldade de escrever textos e mensagens, a falta de conhecimento para usar recursos da Internet, problemas com a tecnologia falta de conhecimento para baixar documentos e recursos de áudio e vídeo, além da falta de apoio de outros alunos para alcançar bons resultados de aprendizagem, falta de experiências com computadores, natureza e complexidade do curso (Almeida, 2007 apud ABBAD, 2010).

A partir das pesquisas já citadas, verifica-se entre as características que influenciam o aluno em abandonar os cursos em EaD, a falta de habilidades do estudante de fazer uso das ferramentas eletrônicas disponibilizadas, a inabilidade de organizar o tempo de estudo e a ausência de autodisciplina.

As pesquisas também indicam que os indivíduos que experimentam maiores dificuldades em relação ao manejo dos elementos eletrônicos do curso possuem maiores chances de evasão dos programas educacionais (Abbad et al., 2006; Almeida, 2007; Lucena et al., 2012) ou em ambientes corporativos (Sales et al., 2011).

Em seu estudo, Zerbini $(2003,2007)$ propõe a investigação de algumas variáveis antecedentes da evasão, tais como características de cunho individual do estudante; de acordo com a pesquisadora, 
tais variáveis contribuem para a compreensão da evasão e da persistência em treinamentos a distância.

Em relação às variáveis do curso relacionadas à evasão, a literatura relata que problemas relacionados ao desempenho do tutor, como falta de apoio ao aluno, falta de feedback, falta de conhecimentos ou inabilidade para transmiti-los, são descritos como uma das causas para o abandono de cursos (Abbad et al., 2006; Vargas, 2004). Apesar desses e de outros achados, os estudos empíricos na área ainda são pouco extensos e conclusivos, de modo que assim se justifica a realização de investigações que se proponham a avaliar o fenômeno da evasão, a exemplo deste relato.

Estas variáveis definem os fatores que envolvem o status social do aluno, atributos tais como sexo, idade, habilidades pessoais, experiências anteriores, junto com suas expectativas de desenvolvimento pessoal e profissional associados à motivação no desenvolvimento acadêmico. Esses elementos estão interligados continuamente, portanto a importância e influência de cada uma delas muda de acordo com o tempo no âmbito da instituição de ensino.

A Figura 2 resume este modelo, que evidencia a influência de ambos os aspectos pessoais e sociais existentes antes de entrar no curso universitário, contato com o enfoque acadêmico, forma de ensino e integração institucional.

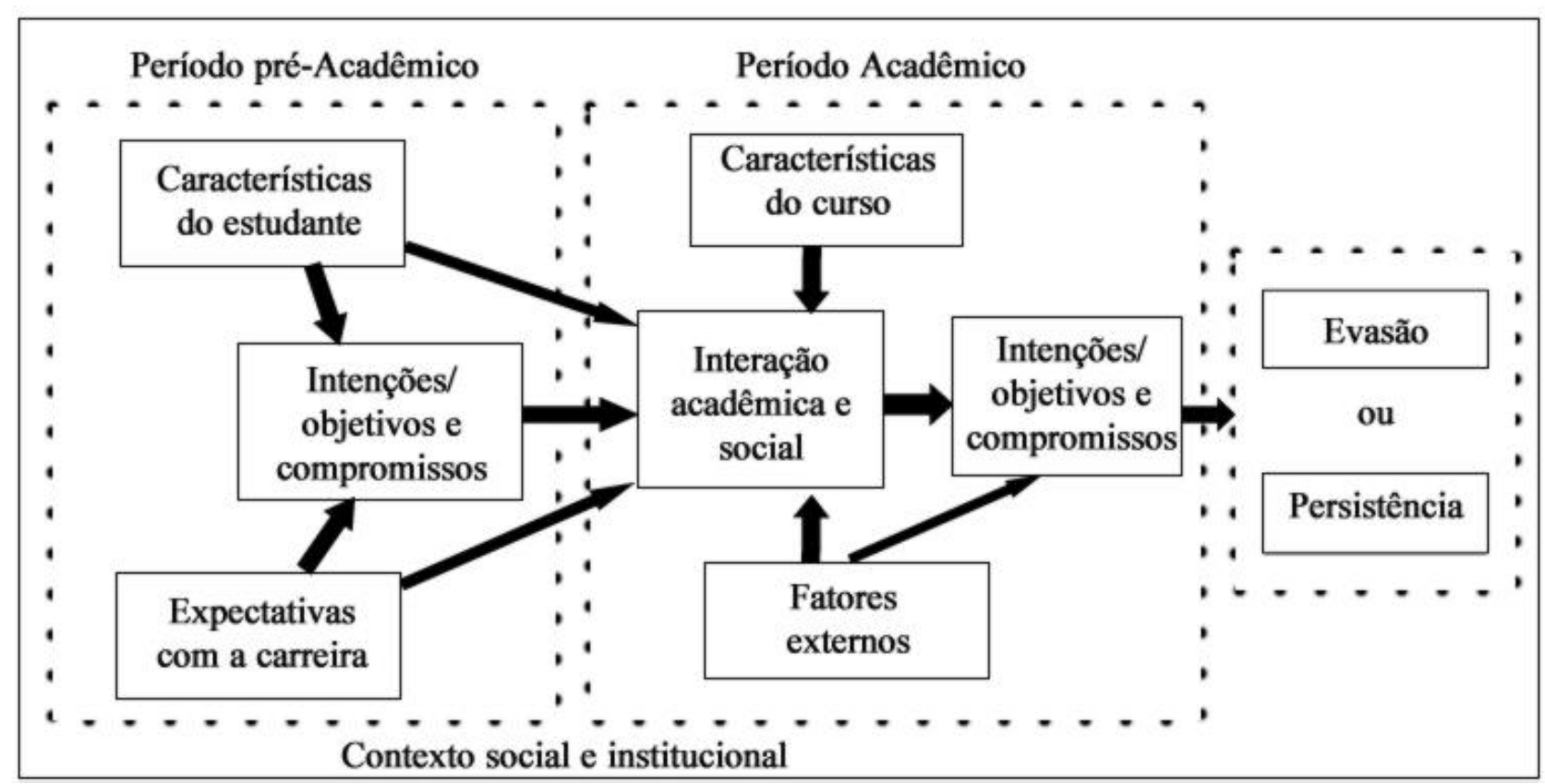

Figura 2 - Modelo da relação aprendizagem/permanência.

Fonte: Adaptado (Tinto, 1997 apud Andriola, 2006) 
Note-se a necessidade de uma avaliação cuidadosa dos modelos descritos, devido a dinâmica observada em relação a esses fatores e seus efeitos. Fatores como elementos sociais podem ser superados a partir das condições motivacionais ou perspectivas de carreira, bem como as ações metodológicas e pedagógicas podem ser associada a motivação (Adachi, 2009).

\subsubsection{INTERATIVIDADE}

O conceito de interatividade é largamente utilizado em $\mathrm{EaD}$ e tem despertado o interesse de instituições e alunos nos últimos anos. O fator Internet intensifica essa concepção com novas possibilidades tecnológicas de comunicação e transmissão de informações. Para Sale (2005) a interatividade é fundamental em EaD para que seja possível atingir uma aprendizagem de alto nível, basicamente porque o retorno pode ser bidirecional e em tempo real.

A interatividade não é um conceito simples e resumido, uma vez que com o avanço contínuo da tecnologia vêm novas formas de interação são criadas e obrigam a revisão periódica desses conceitos. No EaD, é ainda mais evidente, uma vez que as ferramentas educacionais adotadas são diversivicadas e precisam ser avaliadas constatementes quanto a eficácia .

Já alguns autores decompõem a interatividade em classes, que vão das mais reativas, nas quais o aluno tem pouco controle sobre o conteúdo, até as mais proativas, no qual o aluno passa a ter maior autonomia (Sims, 1999).

Para Machado (1997), a interatividade de fato é proporcionar ao usuário respostas autônomas e criativas.

Ainda vale destacar que a definição de interatividade é diferente nas várias áreas de seu uso. Segundo Waisman (2005), na Engenharia a interatividade pode ser, simplesmente, escolher uma opção no menu da televisão, optar por um idioma no DVD ou clicar em um link no navegador para mudar de página na internet. Para a Comunicação, a interatividade está ligada à ação do receptor de modicar o conteúdo e a mensagem. Quando se tratam das áreas de Educação e Psicologia, interatividade pode ser entendida como uma troca de mensagens entre duas pessoas ou entre uma pessoa e uma máquina. 
Essas definições combinam a interatividade em vários níveis ou dimensões com diferentes tecnologias, o que torna claro que existem várias formas de interatividade que não podem ser classificadas com os mesmos critérios e características (Jensen1999).

No caso da ferramenta de Almeida (2016), utiliza-se da interatividade através de envio de mensagens, de forma a provocar o aluno participante de cursos a distância em acessar e interagir com o ambiente de ensino virtual. Os eventos são interligados e monitorados, a situação do aluno é verificada diariamente conforme critérios pré-estabelecidos.

\subsection{VISÃO GERAL DO TERMO DE COOPERAÇÃO}

Este tópico apresenta o termo de cooperação entre a Universidade de Brasília e Escola Nacional de Administração Publica (Enap), assim como contribuição dessa parceria para atingir a missão da escola no seu campo de atuação.

A Escola Nacional de Administração Pública (Enap), é uma fundação pública ligada ao Ministério do Planejamento, Orçamento e Gestão - MP, caracteriza-se por ser uma escola pública que tem a missão de desenvolver as habilidades dos servidores públicos para aumentar a capacidade do governo na gestão de políticas públicas. Ela tem uma demanda para aumentar o volume de formação e incrementar os padrões educacionais, como forma de estabelecer referência para outras escolas do governo do país.

A Enap também mantém muitas atividades de cooperação internacional, que se caracterizam pela articulação de projetos estratégicos e de intercâmbio de boas práticas. Dessa forma, a escola mantém relações com a comunidade internacional, o que contribui para a experiência do Brasil na administração pública e fomenta inovações que podem contribuir para a melhoria da Enap, enquanto Escola de Governo e na transformação da realidade brasileira (Enap, 2016).

As competências estatutárias da Escola, dispostas no Decreto ${ }^{\circ}$ 6.563, de 11 de setembro de 2008, e alteradas pelo Decreto ${ }^{\circ}$ 8.091, de 03 de setembro de 2013, consistem em:

I. Elaborar e executar programas de formação inicial, de aperfeiçoamento de carreiras, de desenvolvimento técnico-gerencial e de capacitação permanente de agentes públicos;

II. Prospectar e difundir conhecimento sobre gestão pública;

III. Fomentar e desenvolver pesquisa na área de gestão pública; 
IV. Prestar assessoria técnica na elaboração de estratégias e projetos de desenvolvimento Institucional, e para a formulação, implementação e avaliação de políticas públicas;

V. Desenvolver e manter projetos de cooperação nacional e internacional;

VI. Coordenar e supervisionar os programas de capacitação gerencial de pessoal civil executados pelas escolas de governo da administração pública federal direta, autárquica e fundacional, conforme o art. $6^{\circ}$, parágrafo único, do Decreto $n^{\circ} 5.707$, de 23 de fevereiro de 2006; e

VII. Instituir e coordenar sistema de escolas de governo da União, nos termos do art. $3^{\circ}$, caput, inciso XIII, do Decreto no 5.707, de 2006.

Impulsionada por esses desafios, em 2010, a Escola realizou um estudo para avaliar o contexto nacional e internacional vinculado à educação a distância, levando em conta a necessidade de avançar na simplificação de seu processo de desenvolvimento de cursos e incorporação de tecnologias, fortalecendo assim seu papel de inovação e coordenação junto às demais escolas de governo do país (Enap, 2016).

Com esse fim, a escola que busca parcerias com instituições públicas que contribuam com uma busca por soluções tecnológicas acessíveis, eficientes e flexíveis, apoiados por um modelo educacional coordenado de ações entre as instituições, permitindo o compartilhamento de esforços destinados a ações de formação e capacitação no serviço público.

A Enap em parceria com Fundação Universidade de Brasília (FUB) desenvolve um projeto (Acordo de Cooperação 30/2014), de modo a empregar todo o potencial de professores e pesquisadores da UnB, especificamente na área de pedagogia, web design, informação e tecnologia da informação, a serviço da melhoria da qualidade da gestão das ações ligadas à educação mediada por tecnologias. É também objeto desta parceria a transferência de tecnologias a Enap visando a adequada utilização das tecnologias e técnicas desenvolvidas, associadas ao desenvolvimento, oferta e gestão da Escola Virtual Enap (Enap, 2016).

\subsection{ATIVIDADE DESEMPENHADAS NO PROJETO}

Nesta seção são destacadas as principais atividades desenvolvidas e as contribuições na implementação de soluções personalizadas que integram o ambiente virtual de aprendizagem da Enap. 
Dentre as diversas tarefas desempenhadas destacamos o processo de desenvolvimento das soluções customizadas, os ajustes do layout novo da escola virtual da Enap, integrando transições e inserções assíncronas através de JavaScript (Ajax). No desenvolvimento do Relatório de Desempenho e Comportamento do Aluno integramos ao relatório informações extraídas do plugin de envio de mensagens automáticas e do plugin minutos online responsável pela contagem de tempo em que o aluno permanecia conectado no sistema. A contribuição ao sistema Tour foi possível adequar o layout a diferentes resoluções de delas. E como destaque principal o sistema de envio de mensagens automáticas o qual foi reestruturada a base de dados, layout do cadastro de mensagens e melhorias na integração com o Moodle.

O desenvolvimento de novas soluções inicia com uma série de entrevistas juntos aos membros da CGEAD, com a finalidade de levantar os requisitos que estarão em conformidade com as necessidades da coordenação. Após esse levantamento são realizadas as análises das informações e a prototipação da solução.

Com o protótipo aprovado é repassado a CGEAD todos os requisitos e recursos necessários para sua implementação, logo após encaminhado para a etapa de homologação / aprovação pela CGEAD.

Homologada a solução, inicia-se a codificação, testes, correções e implantação em ambiente de produção.

Finalizados todos os processos é analisado e documentado os impactos das soluções desenvolvidas, a fim de se comprovar a eficácia no ambiente virtual, quais os benefícios que o desenvolvimento de tal solução trouxe para a escola e para os alunos participantes.

\subsection{TECNOLOGIAS DE APOIO À EDUCAÇÃO A DISTÂNCIA}

Este tópico apresenta o e-Learninge e a Internet como as principais tecnologias de apoio á educação a distância, suas caracteriscas como meio de propagação do ensino e as condições para sua implantação nas instituições de ensino. 


\subsubsection{E-learning}

$\mathrm{O} e$-Learning é uma ferramenta tecnológica de apoio a $\mathrm{EaD}$ por meio da Internet, favorece condições que fortalecem um ambiente produtivo e prático de educação permanente para a divulgação de informações necessárias ao desempenho dos funcionários de uma organização, principalmente dentro do contexto atual, globalizado e de alta competitividade. Assim, ao longo do tempo, o treinamento corporativo em sala de aula, conforme conhecemos hoje em dia, será apenas uma parte - e em certos casos uma pequena parte - da abordagem adotada pelas organizações para a educação de seus funcionários. À medida que os trabalhos vão ficando mais complexos e as qualificações que eles exigem, mais extensas, os executivos estão começando a questionar os pressupostos tradicionais que fundamentaram os programas corporativos de treinamento e desenvolvimento (Meister, 1999).

Segundo Hall (2001) o e-Learning é o aprendizado que entrega eletronicamente o conteúdo de aprendizagem, em parte ou completamente via web browser, navegadores e intranet.

As organizações precisam de uma estrutura exclusivamente implementada conforme as suas necessidades para que possa desenvolver a aprendizagem permanente dos funcionários através do e-learning. Conforme Rosenberg (2002), existem alguns critérios de grande importância no que se refere à utilização da internet para o e-learning, como é mostrado abaixo:

- $\mathrm{O}$ e-Learning é transmitido via rede, permitindo uma rápida atualização, armazenamento e recuperação que possibilita a disseminação instantânea do conhecimento;

- Precisa de Internet;

- Fornece aprendizado que vai além dos tradicionais.

\subsubsection{Internet}

Com o surgimento da internet, foi possível superar uma série de limitações em relação ao tempo e ao espaço. Tratando-se de uma rede mundial de computadores trabalhando entre si, com a finalidade de compartilhar informações de modo acessível a qualquer pessoa. Podemos incluir nesse contexto a dstribuição das formas simples de $\mathrm{EaD}$, as quais citamos os conteúdos em vídeos e materiais escritos, 
A rede mundial é composta entre vários computadores espalhados pelo planeta inteiro, transformando em uma poderosa ferramenta, com diversos recursos e serviços, um meio de comunicação diferenciado que permite a passagem de documentos escritos, sons e imagens, seja entre pessoas ou organizações (Stewart, 1998).

Existem diversas vantagens, das mais diversas ordens, há a possibilidade de grupos específicos de pessoas ou grupos isolados dos diversos tipos, sendo assim existem profissionais com funções diversas e cargos semelhantes, ocupando várias informações em pontos diversos do mundo, essas necessitam de uma orientação para o desenvolvimento das atividades, podendo compartilhar e trocar várias experiências.

Para Bittencourt, Lezana e Neves Jr. (2002) as características que fazem da Word Wide Web (www) um processo com grande potencial para contribuir com a EaD são as seguintes:

a) Ambiente acessível: permite ser acessado por usuários com pouco conhecimento no uso de computadores;

b) Capacidade multiplataforma: utilização das diferentes plataformas, com diferentes hardware e software;

c) Capacidade hipertexto e hipermídia: a capacidade da Web para apresentar as informações em formato não linear (documento hipertexto ou on-line) é parte da sinopse de seu êxito;

d) Capacidade multimídia: na rede de Internet podem ser distribuídos documentos multimídia, possibilitando ao tutor/professor enriquecer o material instrucional;

e) Disponibilidade gratuita: clientes, servidores, aplicações auxiliares para vídeo e áudio de formatos diversos; ferramentas para a elaboração de hipermídia e de gestão de serviços; todo ele para diferentes plataformas hardware/software (Windows, Mac, Unix);

f) Disponibilidade de conteúdo: a Internet é a maior e mais diversa fonte de recursos de informação disponível atualmente no mundo;

g) Capacidade de servir como um sistema uniformizado de informação, com protocolo aberto na Internet, para facilitar a aprendizagem entre os usuários;

h) Oferece flexibilidade de horário: admitir que o aluno/funcionário estude o material institucional disponibilizado na WWW no momento em que lhe for mais adequado. (Royo et al, 1996 apud Bittencourt e Lezana, 1997, p. 44-45). 
Com a popularização da Internet pode se contribuir no processo da atualização, capacitação e qualificação das mais diversas unidades de uma organização. O desenvolvimento da informatização das empresas já atinge quase que totalmente todos os setores, em um processo que se propaga em grande velocidade de crescimento (Bittencourt e Lezana, 1997).

Nos dias atuais a Internet é o meio da maior parte do acesso ao e-learning, adequando a realidade dos colaboradores e viabilizando a aquisição das diversas habilidades que são essenciais no ambiente que são favoráveis a aprendizagem. Segundo Neves (2002), os dispositivos e os recursos de Internet podem descomplicar o aprendizado no ritmo dos próprios alunos, individualizando o conhecimento e enriquecendo os conteúdos didátivos com a contribuição através de gráficos, vídeos, áudios e computadores.

\subsubsection{Implantação do E-learning}

Em Eboli (2002) salienta-se que as tecnologias utilizadas na educação, permitem que as pessoas aprendam com um nível elevado de aproveitamento e mais rapidamente, se tornem mais competentes para a realização das devidas funções. Neste sentido é preciso avaliar se a empresa está preparada tecnologicamente para os programas de capacitação, desenvolvimento e educação através de plataformas de e-learning:

a) A quantidade pessoas a serem qualificadas é expressiva?

b) As pessoas estão dispersas geograficamente?

c) Existem gastos com estadia para as pessoas que efetuaram a qualificação?

d) Existem equipamentos disponíveis para o desenvolvimento da qualificação dos funcionários na organização, tais como computadores e tecnologia?

e) Os conteúdos a serem abordados estão diretamente ligados a habilidades comportamentais ou técnicas?

f) A qualificação requer objetos físicos e equipamentos?

g) A alta direção da empresa vê a aprendizagem virtual como uma oportunidade de crescimento dos funcionários?

h) Como são as avaliações computer based training - capacitação baseado no 
computador?

i) Qual a percepção dos funcionários sobre a tecnologia usada na qualificação?

É preciso afirmar que é necessário aplicar um exame minucioso nos pacotes disponíveis no mercado, bem como: suporte online, certificação, tutoria e principalmente cursos e qualificações que atendam as estratégias organizacionais, e se existe tempo para a implementação dos cursos ou qualificações, pois a fase de implantação do e-Learningnas empresas é devagar.

Caso no decorrer a etapa de implementação do processo de e-Learningseja detectado que organização não tem um método tecnológico, será necessário desenvolver um planejamento estratégico para implantar algum curso com os elementos necessários, tanto em cursos presencial, quanto semipresencial.

Para Rosenberg (2002, p. 29) "uma verdadeira estratégia de e-Learningcertamente aborda questões de cultura, liderança, justificativa, organização, talento e mudança". O autor menciona determinadas estratégias a serem utilizadas na organização, o que chama de "base estratégica para o e-learning":

a) Capacitação on-line (para instrução) e gerenciamento do conhecimento (para informação);

b) Arquiteturas do aprendizado: o equilíbrio entre e-Learninge outras metodologias, inclusive a capacitação presencial;

c) Infraestrutura: os recursos tecnológicos para fornecer e gerenciar o e-learning;

d) Cultura do aprendizado, propriedade do gerenciamento e gerenciamento da mudança: a concepção de um ambiente que incite o aprendizado;

e) Caso comercial sólido: uma justificativa que apoie o e-learning;

f) Capacitação: a adoção de um modelo organizacional que apoie o desenvolvimento do e-learning.

Segundo Hall (2001) ainda existem seis etapas muito importantes na concepção do processo de EaD na organização:

Etapa 1: Preparação para o e-learning, quando se obtém o bônus com a implantação após de uma análise e de um planejamento criterioso, sendo assim, se torna necessário definir barreiras que a 
empresa precisa sobrepujar na implementação do e-learning, ainda existem três etapas, mostradas abaixo:

Selecionar as dimensões a serem consideradas: dirigentes, stakeholders, conteúdo, tecnologia e aprendizes;

a) Identificar os principais ativos e barreiras para cada dimensão;

b) Considerar as estratégias de implantação: desenvolver uma estratégia para alinhar o $e$ Learningà visão de negócios e objetivos da empresa.

Etapa 2: Desenvolvimento da estratégia, neste ponto o autor descreve três caminhos distintos para o desenvolvimento das estratégias, ou seja, ele relaciona as experiências da organização.

Nível 1: organização com pouca ou quase nenhum tipo de experiência no processo de busca por soluções que beneficiem o acesso às informações;

Nível 2: A empresa que já tem algum tipo de implantação, seja de um ou mais cursos deve arquitetar iniciativas em que o conteúdo seja otimizado ao ponto de ter mais usos ou simulações;

Nível 3: a organização que já implantou mais de dois cursos de e-learning, onde o principal objetivo é sanar diversos problemas para encontrar resultados mais satisfatórios, com base em soluções que utilizam estratégias para um melhor aproveitamento das ferramentas vituais diponíveis.

Etapa 3: Seleção da tecnologia e conteúdo - a empresa deve buscar soluções que consigam atender sua demanda e seu sistema de gestão de aprendizagem da melhor forma, para que se obtenha um controle do gerenciamento das qualificações despendidas aos funcionários. Tal instrumento tende a registrar usuários, interações, cursos e também fornece diversos relatórios e avaliações online, personalização e outros diversos recursos para gestão do ambiente virtual e presencial.

Etapa 4: Venda do e-Learningpara todos na organização - é um método de grande importância a aceitação do programa pela alta direção, ou seja, diversos funcionários, nesse caso é necessário repassar as informações necessárias aos empregados sobre diversos programas a serem desenvolvidos pela empresa como forma de estruturar a qualificação do conhecimento. 
Etapa 5: implementação ampla - nesse caso é necessário uma boa e criteriosa fundamentação dos cursos para que ambos sejam online e possam ser oferecidos aos funcionários. Determinar a estratégia de conexão entre a sala de aula e outras possíveis metodologias.

Etapa 6: Mensurando os benefícios do negócio - nessa etapa se faz necessário um método para analisar e criar diversos parâmetros de medidas a fim de avaliar diversas medidas fundamentais para a implantação da EaD.

Segundo Vianna (1999) é importantíssimo ressaltar que o e-Learning é uma via adotada pelas empresas como solução para qualificação dos seus colaboradores. Porém, para que isto aconteça, é muito importante quebrar as regras da cultura da empresa, sendo preciso uma forte força de vontade comportamental para o sucesso da etapa do conhecimento.

\subsubsection{SGAs e AVAs: conceitos e distinções}

As terminologias SGA (Sistema de Gerenciamento de Aprendizado) ou SGC (Sistema de Gerenciamento de Cursos) são referentes ao conjunto de informações e ferramentas que servem de estrutura para construção de um novo curso em qualquer espaço virtual. Este conjunto de ferramentas compõe uma plataforma utilizada na educação a distância para criação de um curso completamente on-line, ou no caso da modalidade semipresencial.

Segundo Berking e Gallagher (2013), o SGA pode apresentar variadas funções como no quadro a seguir:

Tabela 1 - Funções de um SGA (adaptado de Berking \& Gallagher, 2013, p. 7)

\begin{tabular}{|l|l|}
\hline Funções & Características \\
\hline Estrutura & $\begin{array}{l}\text { Centralização e organização das funções relacionadas a } \\
\text { aprendizagem em um sistema, permitindo acesso a elas por meio } \\
\text { de uma interface de navegação em camadas. }\end{array}$ \\
\hline Segurança & $\begin{array}{l}\text { Proteção contra acesso não autorizado aos cursos, registro de } \\
\text { alunos e funções administrativas. }\end{array}$ \\
\hline Inscrição & $\begin{array}{l}\text { Busca, seleção ou distribuição de cursos por alunos e seus } \\
\text { professores. }\end{array}$ \\
\hline
\end{tabular}




\begin{tabular}{|c|c|}
\hline Distribuição & $\begin{array}{l}\text { Distribuição sob demanda do conteúdo e de experiências de } \\
\text { aprendizagem aos alunos. }\end{array}$ \\
\hline Interação & $\begin{array}{l}\text { Interação do aluno com o conteúdo e comunicação entre alunos, } \\
\text { instrutores e administradores do curso, bem como entre o } \\
\text { conteúdo e o SGA. }\end{array}$ \\
\hline Avaliação & $\begin{array}{l}\text { Gerenciamento de avaliação e coleta, rastreamento e } \\
\text { armazenamento de dados da avaliação }\end{array}$ \\
\hline Controle & $\begin{array}{l}\text { Controle dos dados dos alunos, incluindo seu desempenho no } \\
\text { curso, baseados nos pré-requisitos }\end{array}$ \\
\hline Relatórios & $\begin{array}{l}\text { Extração e apresentação de informações sobre alunos pelos } \\
\text { administradores }\end{array}$ \\
\hline $\begin{array}{l}\text { Armazenamento de } \\
\text { Registros }\end{array}$ & Armazenamento e atualização de dados sobre os alunos \\
\hline Reutilização & $\begin{array}{l}\text { Fácil reaproveitamento do conteúdo e ambiente para a } \\
\text { construção de outros cursos }\end{array}$ \\
\hline Personalização & $\begin{array}{l}\text { Configuração da interface e características do SGA para atender } \\
\text { a necessidades específicas de alunos e administradores }\end{array}$ \\
\hline Integração & Troca de dados com outros sistemas \\
\hline Administração & Gerenciamento centralizado de todas as funções listadas acima \\
\hline
\end{tabular}

A diversificação de funções destacada acima possibilita que diferentes abordagens instrucionais possam ser contempladas e favorece o uso pedagógico de recursos de forma integrada permitindo assim a seleção de ferramentas que facilitam a interação entre os participantes (Dillenbourg et al., 2002). Dessa forma, é possível compreender a crescente adesão de instituições e professores adeptos da modalidade de ensino semipresencial ao SGA como sistema de desenvolvimento de cursos.

Ao escolher as ferramentas e as funções do SGA que utilizará, o professor está criando o AVA do seu curso, ou seja, "um espaço na internet formado pelos sujeitos e suas interações e formas de comunicação que se estabelecem através de uma plataforma" (Behar, 2006).

A construção do Ambiente Virtual de Aprendizado (AVA) é determinada pela forma como será utilizado, quais recursos selecionados e de que forma atividades e conteúdos serão apresentados, objetivando sempre o ensino e a aprendizagem on-line. Cumpre destacar que tal construção não está 
necessariamente vinculada a um SGA, podendo acontecer em blogs ou sites de relacionamento, por exemplo.

Dessa forma, conclui-se que o SGA em si não constitui um AVA, assim como o AVA não precisa ser necessariamente desenvolvido em uma plataforma de SGA.

\subsubsection{Principais Ambientes Virtuais de Aprendizagem}

Para uma análise a fim de comparação entre os ambientes virtuais de aprendizado relacionamos as três plataformas mais utilizadas pelas instituições brasileiras. As plataformas são o TelEduc, Blackboard e o Moodle.

O TelEduc, Blackboard e Moodle são exemplos de ambientes virtuais de aprendizagem, que oferecem diferentes funções na aplicação em EAD servem de facilitador nas atividade e ajudam a superar dificuldades de aprendizagem.

Estes ambientes são utilizados para dar o apoio necessário no desenvolvimento de cursos através da educação a distância, é possível selecionar o conjunto de características de um AVA para que fiquem disponíveis aos curso, bem como a maneira correta de usar essas características para garantir o sucesso da implantação da educação a distância, tanto no ambiente acadêmico, quanto no treinamento coorporativo.

\section{TelEduc}

O TelEduc é um ambiente de educação a distância foi desenvolvido em 1997. Foi desenvolvido baseado em uma proposta de dissertação do Instituto de Computação da Universidade Estadual de Campinas (Unicamp). O desenvolvimento deste AVA foi realizada pelos pesquisadores do Instituto de Computação da Unicamp, juntamente com o Núcleo de Informática Aplicada à Educação (Nied). Esse ambiente foi implementado de forma participativa e todas as ferramentas incorporadas foram projetadas conforme as experiências de usuários que forneciam feedbacks a cada distribuição .

\section{Características e funcionalidades básicas do TelEduc}

- Desenvolvido em PHP, JavaScript e MySQL para ambientes UNIX e LINUX

- Código aberto com licença de software livre na modalidade GNU,

- Plataforma baseada na internet 
- Interface gráfica simples, mas que não pode ser personalizada

- Possui uma abordagem educacional construtivista e de aprendizagem colaborativa

Agrega um grande número de ferramentas e recursos flexíveis que podem ser ligados ou desligados para cada curso como: Dinâmica do curso, agenda, avaliações, atividades perguntas frequentes, enquetes, perfil dos participantes, mural de avisos, chat, webfórum, correio eletrônico, material de apoio, grupos de participantes, estatísticas de acesso, funções administrativas e de configuração.

\section{Blackboard}

O sistema de Blackboard é um software proprietário que constitui um Ambiente Virtual de Aprendizagem que permite a criação de cursos em educação a distância compreende a criação de disciplinas, cursos, introdução de ferramentas de conteúdo e comunicação entre utilizadores, gestão de usuários, estudantes, professores e tutores . Este sistema é utilizado como uma ferramenta de informação e comunicação entre os usuários (alunos, professores e tutores) de um determinado curso. (Blackboard, 2016).

Os cursos de gestão são conduzidos através da internet, permitindo o acesso controlado ao conteúdo e à participação dos alunos em salas de chat e fóruns de discussão. Permite também a personalização de cada ambiente de trabalho do curso. É possível gerenciar anúncios (modificar, inserir e remover) indicando as datas que serão visíveis.

Este sistema é muito flexível e, portanto, pode suportar múltiplas pesquisas nas áreas de ensino, aprendizagem e colaboração.

Os professores podem postar conteúdo de aprendizagem a qualquer hora e em qualquer lugar, com a ajuda de formas intuitivas e um ambiente fácil de usar.

Há fóruns, chats e salas virtuais independentes e por grupos, o que permite uma intensa colaboração e participação no processo de aprendizagem, auxiliando seus alunos a aprender e medir seu progresso publicando questionários e tópicos, podem automatizar a apresentação do conteúdo, definir datas de publicação e duração dos testes. (Blackboard, 2016). 


\section{Moodle}

O Moodle é um software livre de apoio à aprendizagem, desenvolvido em PHP e com banco de dados MySQL, PostgreSQL, Oracle, Access, Interbase, através da colaboração da comunidade virtual. Foi desenhado por um educador, Martin Dougiamas que possui as funções de criador e diretor de desenvolvimento, baseando-se nos princípios do construtivismo social. O Moodle possui licença Open, é livre para ser instalado em qualquer computador, ser usado, modificado e até mesmo ser distribuído sob a condição do GNU. Moodle (2016).

Os materiais e atividades dinâmicas são disponibilizados pelo professor ou gestor da plataforma constituem o grande diferencial do Moodle, uma vez que permitem a interação entre o professor/gestor e os alunos através de:

- Fóruns de debate, partilha de ideias e esclarecimento de dúvidas;

- Gestão de conteúdos e recursos

- Questionários diversos formatos

- Blogs

- Chats - salas de conversação entre os utilizadores; podem ser utilizadas para conversação em tempo real um para um ou em grupo.

- Wikis

- Glossários

- Formação de grupos de estudo e de debates

- Suporte de Gestão através de análises de gráficos interativos online para questionários prepostos.

- Suporte multi-idioma (mais de 75 idiomas são suportados).

- Atualizações frequentes

- Grande variedade de plugins com as mais diversas funcionalidades

Dentre as inúmeras características apresentadas as que mais influenciaram na escolha do Moodle em ser implantado na Escola Virtual da Enap destacamos a grande comunidade ativa no desenvolvimento e de troca de experiências. A possiblidade de costumização de layout, fundamental para a inserção identidade visual da Enap, diferente do TelEduc que é limitado nesse item e também o incentivo governamental para o uso de software livre o que gera grande economia na comparação 
com o Blackboard o qual toda instalação e costumização deve ser paga a desenvolvedores credenciados pelo proprietário da plataforma. 


\section{CONCEPÇÃO E DESENVOLVIMENTO DE FERRAMENTAS PERSONALIZADAS}

Dentre os itens que destacamos nesse capítulo, abordamos a pesquisa e o desenvolvimento do novo layout da escola virtual. No item seguinte apresentamos o Tour, que funciona como um guia de orientação, apresenta aos participantes os principais componentes dos cursos e a forma de navegar pelas atividades. For fim temos a ferramenta de monitoramento do comportamento e do desempenho dos Alunos, que agrupa diversas informação, das mais variadas fontes do AVA e fornece uma visão geral do status da turma durante o período de curso.

O ambiente virtual desenvolvido para a Enap utiliza plataforma Moodle (Modular Object-Oriented Dynamic Learning Environment - em Português, Ambiente de Aprendizagem Dinâmico Modular Orientado a Objeto). É um pacote de software gratuito que, segundo Dougiamas (2000), tem como ideia básica servir como uma ferramenta baseada na Internet que pode ser usada para implementar, modificar e experimentar a maneira mais fácil e flexível possível na implementação de cursos a distância.

O Moodle apesar de ser uma plataforma de educação a distância com muitos recursos, faltam novas ferramentas com finalidades bem especificas, essa carência surge com a necessidade de atender públicos muito especifico, como os da Escola Nacional de Administração Pública.

\subsection{MUDANÇAS DO VISUAL DA ESCOLA VIRTUAL DA ENAP}

Levando-se em consideração que os cursos a distância requerem maior disciplina por parte dos alunos, é imprescindível que os cursos proporcionem uma organização dos materiais no ambiente virtual, facilitando e orientando o aluno na navegabilidade e minimizando as dificuldades de interação com o ambiente virtual.

É importante salientar que o Moodle é uma plataforma de código aberto. Dessa forma, seu acesso é gratuito e seus usuários podem também modificá-lo e distribuir essas modificações ou novos recursos desenvolvidos de forma colaborativa.

O Moodle é altamente adaptável, podendo ser configurado com diversas ferramentas, como 
atividades, blocos e recursos. Os participantes têm funções atribuídas, de acordo com seu login, e assim são determinados os conteúdos e as atividades a que terão acesso, como vemos no quadro 2 a seguir:

Tabela 2 - Funções e atividades na plataforma MOODLE (Araujo, 2011)

\begin{tabular}{|l|l|l|}
\hline Função & Atividade & Detalhamento da Atividade \\
\hline Administrador & Gestão do Moodle & $\begin{array}{l}\text { Cadastro de participantes, criação da } \\
\text { estrutura básica dos cursos, inclusão de } \\
\text { novos recursos do sistema, atualização do } \\
\text { sistema. }\end{array}$ \\
\hline Professor & Docência & $\begin{array}{l}\text { Preparação da ementa, seleção da } \\
\text { bibliografia, planejamento das atividades, } \\
\text { acompanhamento e avaliação dos alunos. }\end{array}$ \\
\hline Tutor & Apoio à docência & $\begin{array}{l}\text { Apoio ao professor no planejamento das } \\
\text { atividades e no acompanhamento dos alunos } \\
\text { em termos de frequência de acesso e de } \\
\text { dificuldades específicas com o conteúdo e } \\
\text { com as atividades. }\end{array}$ \\
\hline Estudante & Participação ativa \\
no curso & $\begin{array}{l}\text { Participação nas atividades propostas, } \\
\text { observância dos prazos, entrega dos trabalhos. }\end{array}$ \\
\hline
\end{tabular}

Essa característica maleável do Moodle possibilita apresentação de seu conteúdo com qualidade e interatividade, cabe destacar o trabalho apresentado em Oliveira (2016), que aborda o papel do design instrucional e estabelece um padrão uniforme, tanto para as páginas iniciais como para os Guias do Participante.

A implementação de todo o processo foi possível graças a criação de um documento na forma de roteiro que tem como objetivo organizar, sistematizar e registrar o processo de produção dos cursos de forma que as diferentes equipes envolvidas possam alinhar-se na mesma linguagem, aprimorar a troca de informação sobre o processo de elaboração de cursos online (Oliveira, 2016). 
Na figura 3 é possível ver o histórico dos cursos aos quais o aluno esteve matriculado, possui também uma barra lateral à direita com opções a que podem ser configuradas pelo administrador e que fornece acesso a recursos conforme privilégios de cada tipo de usuário.

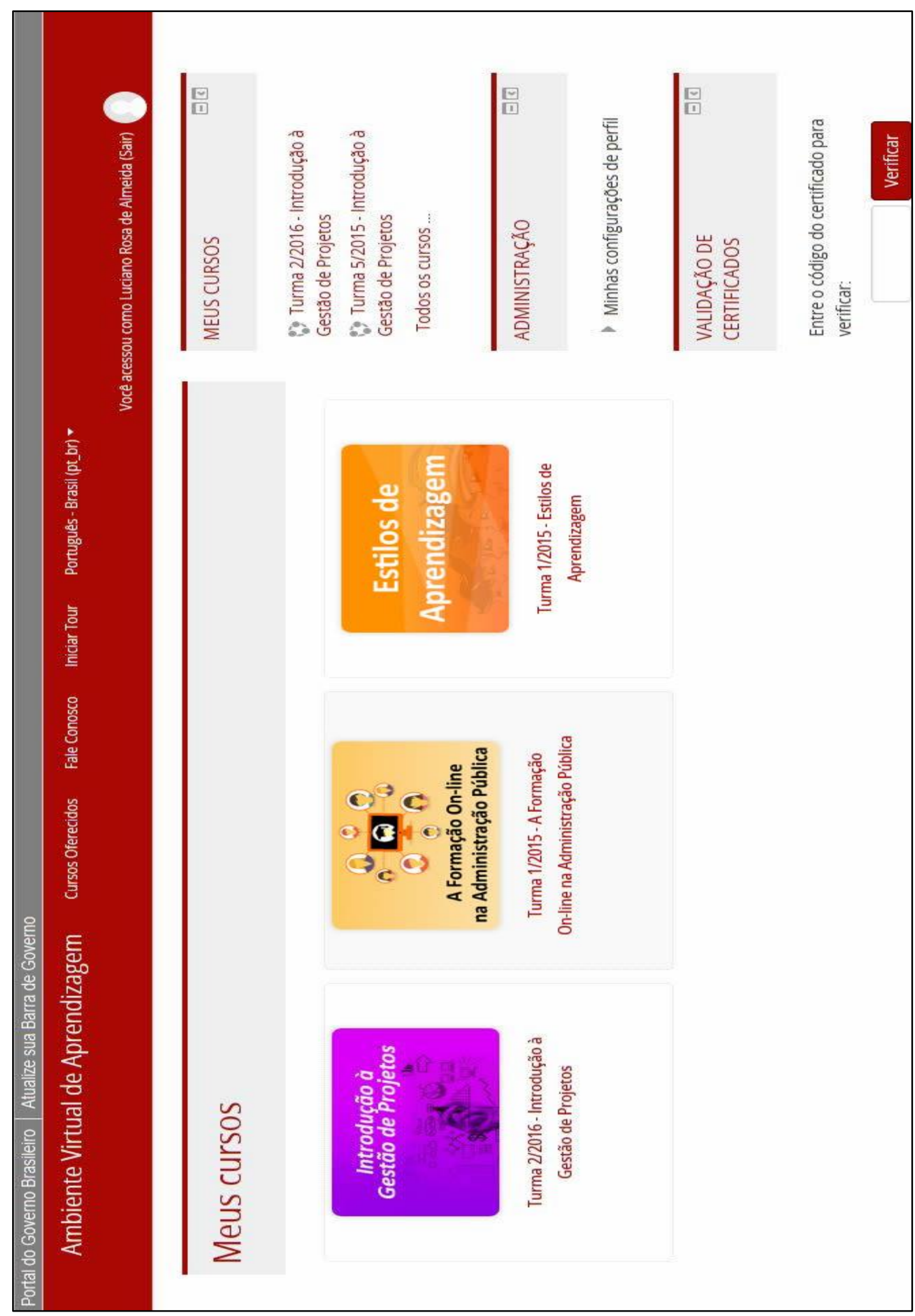

Figura 3 - Tela inicial com histórico de cursos do aluno. Fonte: Enap Virtual (2016). 
Com a finalidade de demonstrar a evolução do layout é apresentado na figura 4 o layout antigo e o novo layout desenvolvido na figura 5, onde é possível visualizar as diferenças de cores, banners, menus e outros elementos visuais. 


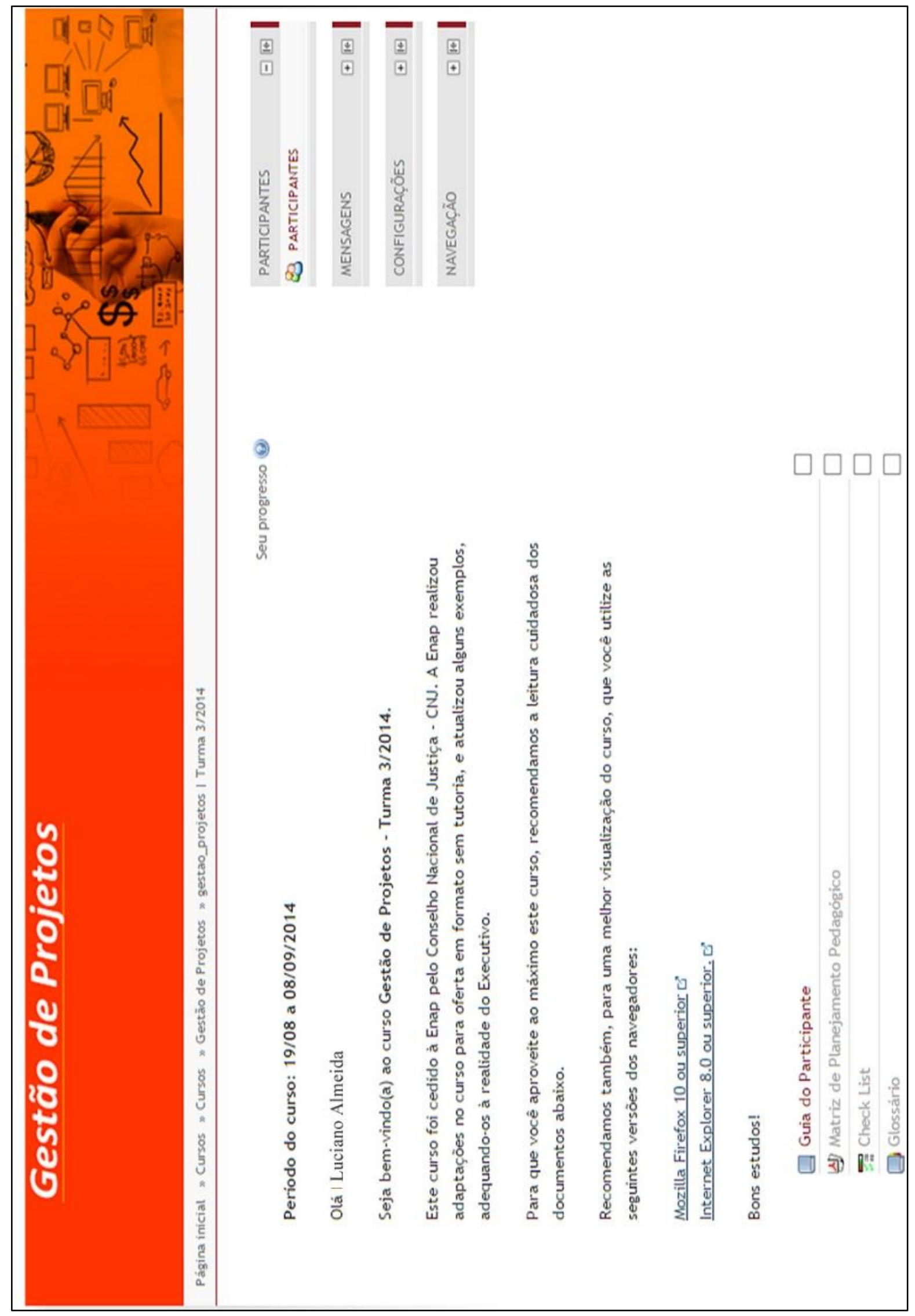

Figura 4 - Página inicial do layout antigo. Fonte: Enap Virtual (2016). 


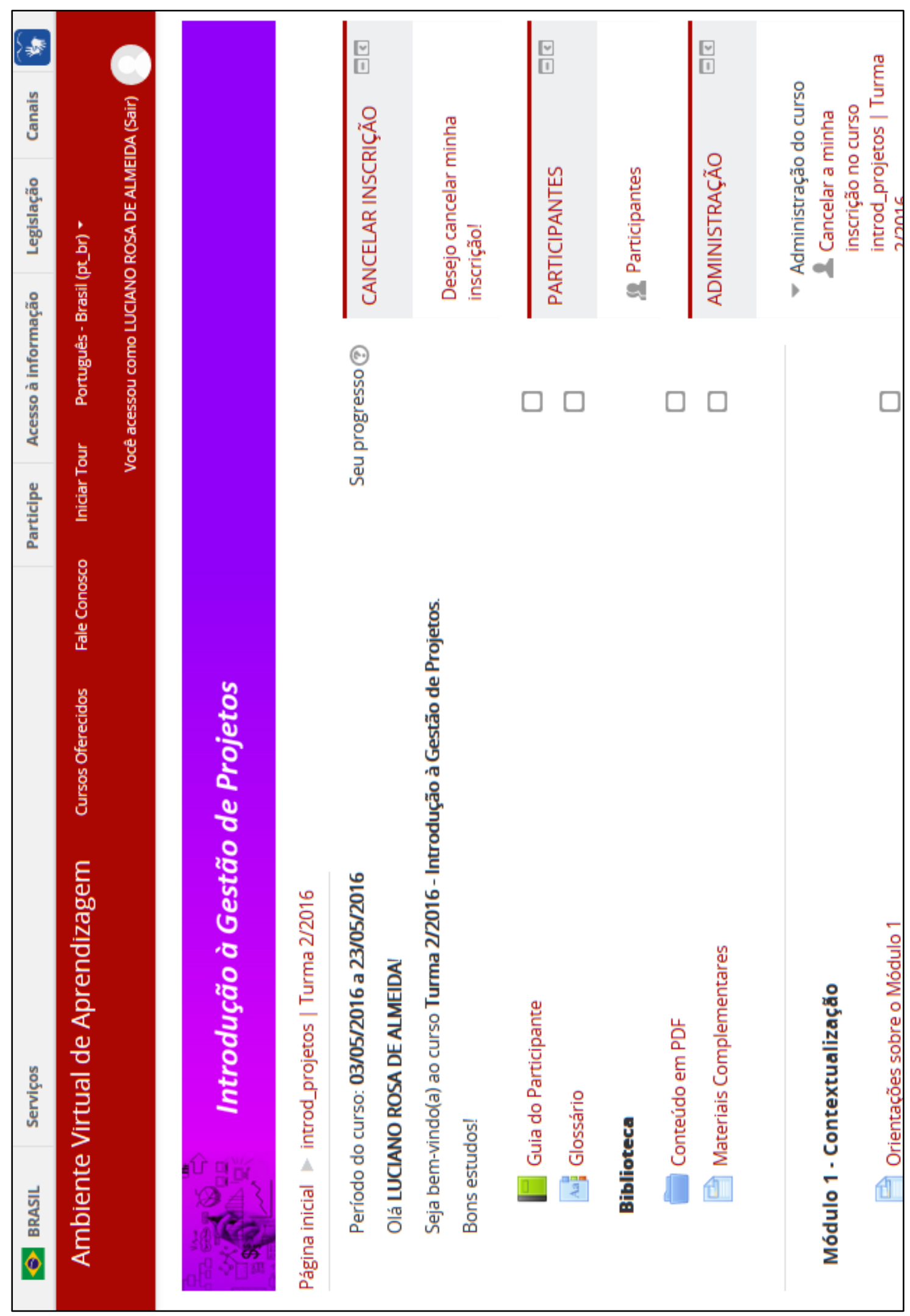

Figura 5 - Tela de abertura de curso com layout novo.

Fonte: Enap Virtual (2016). 
O sistema permite inserção de conteúdo em etapas, com inclusão de material de mídias variadas (textos, vídeos, links) e com diversas possibilidades de interação, como fóruns e chats.

A interface do curso é dividida em blocos modulares e é comum que os tópicos de inclusão de conteúdo fiquem na parte central, como podemos ver na figura 6 o layout antigo comparado com os blocos no layout novo na figura 7.

Bons estudios!

Guia do Participante

싱 Matriz de Planejamento Pedagógico

Check List

Glossário

BIBLIOTECA

Conteúdo em PDF

MÓdULO 1 - CONTEXTUALIZAÇÃO

Contextualizaçăo

Justificativa do Projeto

gू Questionário Avaliativo - Módulo 1

E. Material Complementar - Módulo 1

Q) Portfólio de Projetos

Contextualizaçào

MÓDULO 2 - CONCEITOS BÁSICOS

Conceitos básicos

Figura 6 - Módulos dos cursos no layout antigo. Fonte: Enap Virtual (2016). 


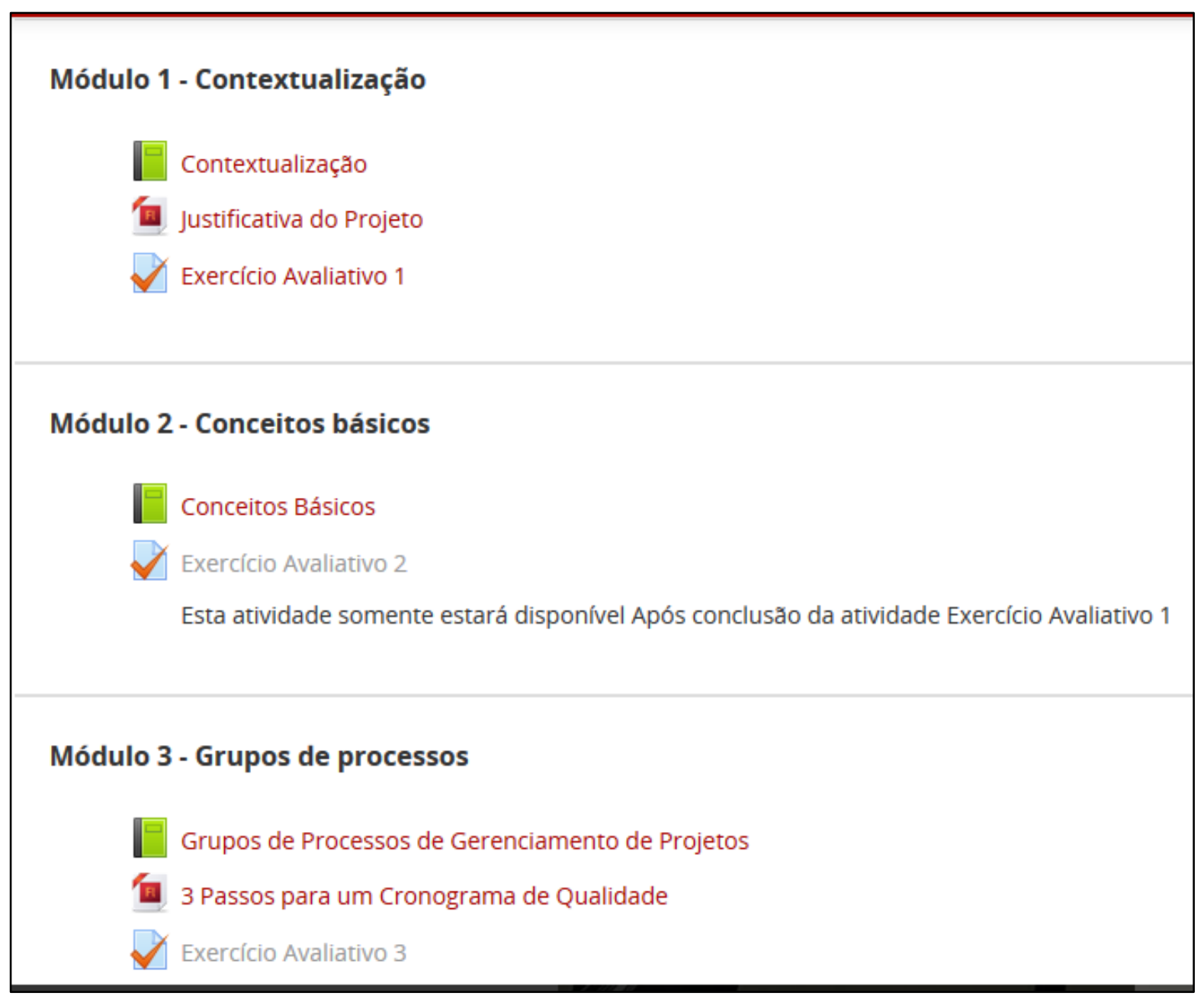

Figura 7 - Módulos dos cursos no layout novo. Fonte: Enap Virtual (2016).

As atividades a serem incluídas nos módulos são: chats, enquetes, fóruns, glossários, mapas conceituais, tarefas e wikis. Para os blocos, é possível incluir, por exemplo, videotecas, calendários, últimas notícias, mensagens e relatórios. E há ainda recursos como inclusão de páginas da web, inclusão de links, visualização de diretórios e definição de rótulos.

Destacamos também um item muito importante no ambiente virtual da Enap que é o guia do Participante. Esse guia é um recurso em formato livro, onde traz todas as informações importantes para o acompanhamento do curso e apresenta uma visão geral do curso e da sua estrutura.

$\mathrm{Na}$ figura 8, temos o guia do layout antigo e na figura 9 o layout novo onde podemos ver a divisão em módulos mais evidente por cores e cabeçalhos que destaca cada item da tela. 


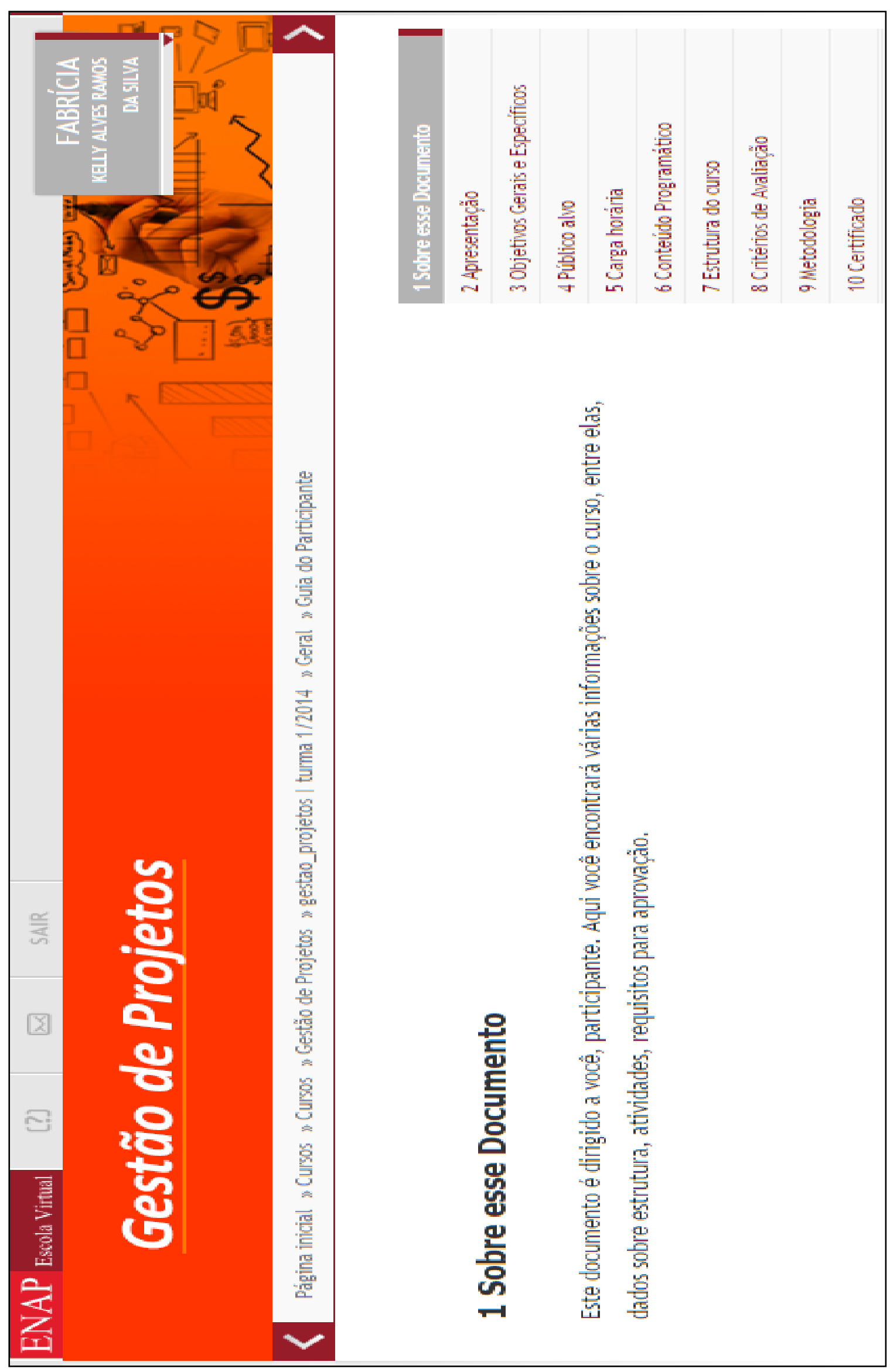

Figura 8- Guia do participante layout antigo. Fonte: Enap Virtual (2016). 


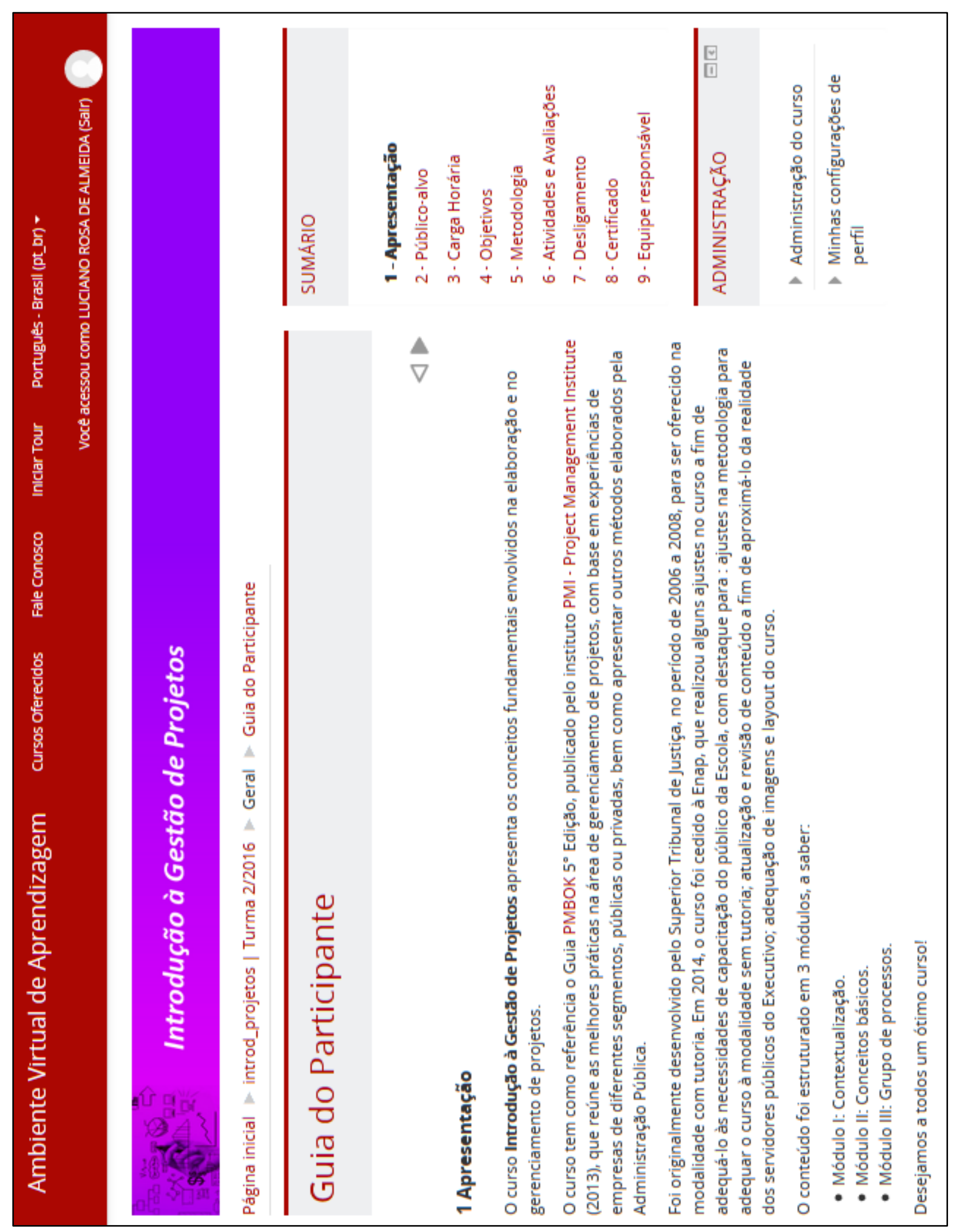

Figura 9 - Guia do participante no layout novo.

Fonte: Enap Virtual (2016). 
A principal contribuição neste capítulo foi o estudo e a análise do impacto da atualização de versão do Moodle 2.7 para a versão 2.9 na infraestrutura da escola, e ajustes necessários para correções de erros no novo layout desenvolvido, ocasionados pela troca de versão.

Enfim, o Moodle possui diversas vantagens, como uma enorme base de usuários, os principais recursos necessários à $\mathrm{EaD}$ e uma arquitetura de fácil integração. No entanto, é carente em ferramentas integradas ao ambiente que proporcionem interatividade contínua ou rápida retroação, principalmente para o desenvolvimento de conteúdos específicos com avaliação automática, tais como alguns tópicos da Matemática, como por exemplo a geometria.

\subsection{TOUR VIRTUAL}

Nesta seção apresentamos uma ferramenta que chamamos de Tour. O Tour auxilia na orientação e na usabilidade dos recursos e componentes do ambiente virtual da Enap. A referida ferramenta foi desenvolvida como um plugin para o ambiente de aprendizagem virtual Moodle.

A motivação para implementar o plugin com a função de tour decorre do estudo das dificuldades vivenciadas pelos participantes da Enap, dificuldades encaradas pelos participantes que acessam pela primeira vez o ambiente virtual do Moodle, incluindo as dificuldades de navegação em conteúdos curriculares, que freqüentemente afetam a motivação e o desempenho dos participantes do curso e até mesmo resultando no seu abandono.

As dificuldades mencionadas também têm consequências na coordenação e gestão da Enap, já que o participante atingido gera um grande volume de solicitações de informação, seja por e-mail, por telefone e até mesmo por conversas privadas. A finalidade do Tour é especificada como uma ferramenta para auxiliar o participante e consequentemente contribuir para que não haja uma demanda maior por assistência extra fora do AVA.

Além disso, o Tour virtual responde à tendência de participantes da modalidade de ensino a distância, em usar o ambiente virtual a qualquer momento, incluindo fins de semana. Esse recurso aborda a necessidade de ajuda rápida e ágil nessas situações.

O sistema virtual executa um processo de múltiplas etapas que começa com a apresentação dos cursos em que o aluno está registrado apresentado na figura 10. 


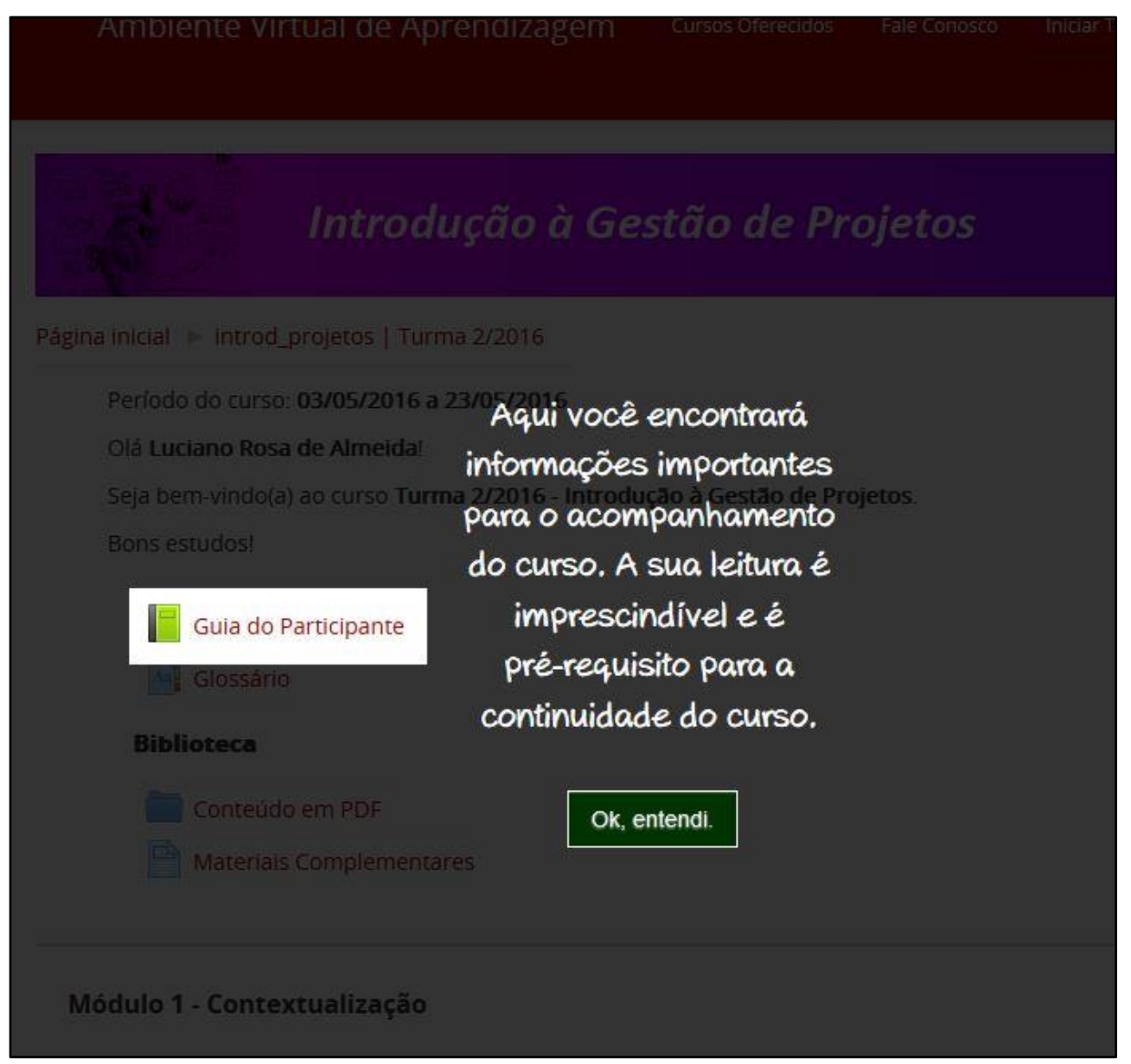

Figura 10 - Apresentação do guia do participante. Fonte: Enap Virtual (2016).

Na figura 11, temos um exemplo da apresentação de um componente, nesse caso a biblioteca, onde o Tour descreve sua finalidade e forma de uso.

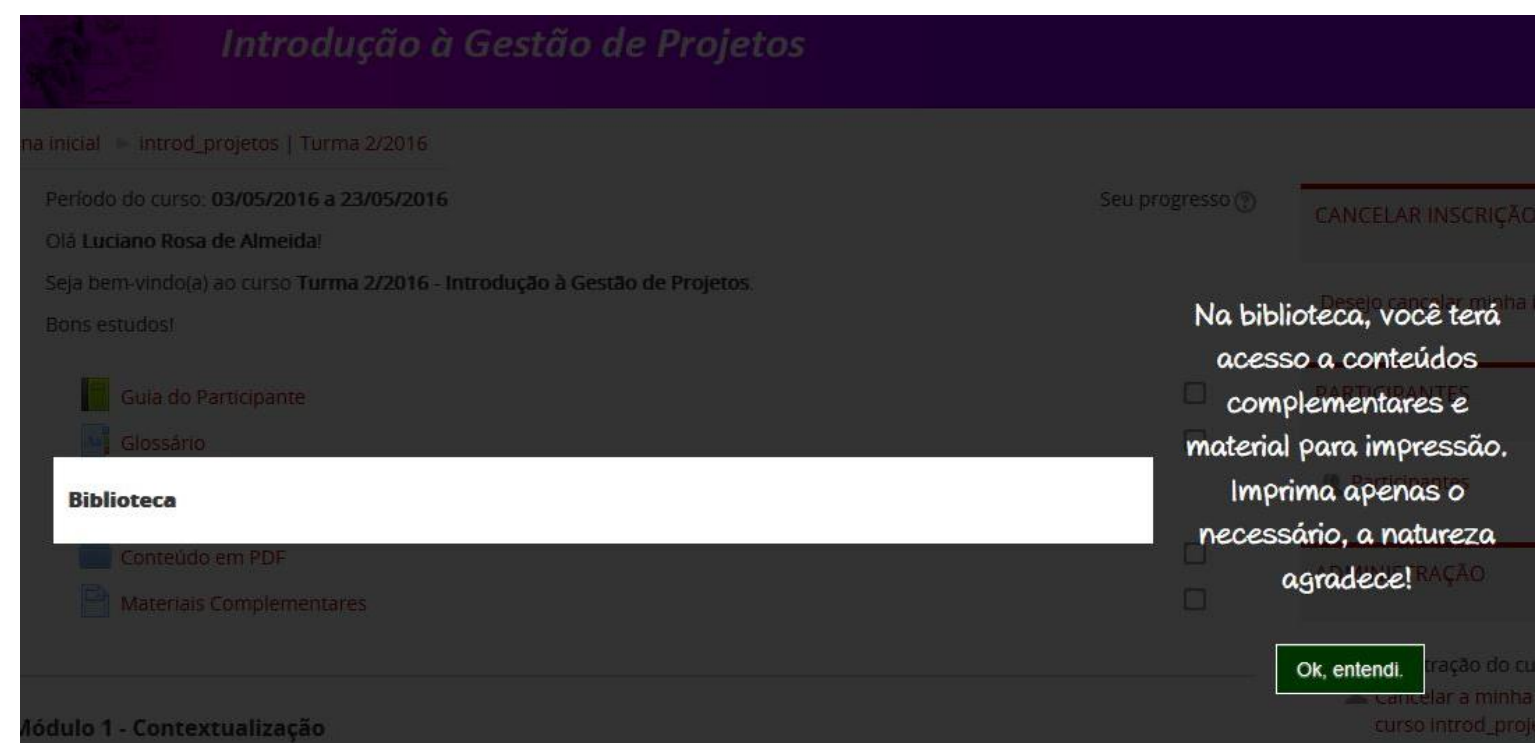


Figura 11 - Descrição do item biblioteca do curso. Fonte: Enap Virtual (2016).

Na figura 12, vemos outra característica é que o Tour virtual pode ser personalizado para cada curso e pode ser adaptado ao conteúdo programático específico dos cursos, onde apresenta os módulos.

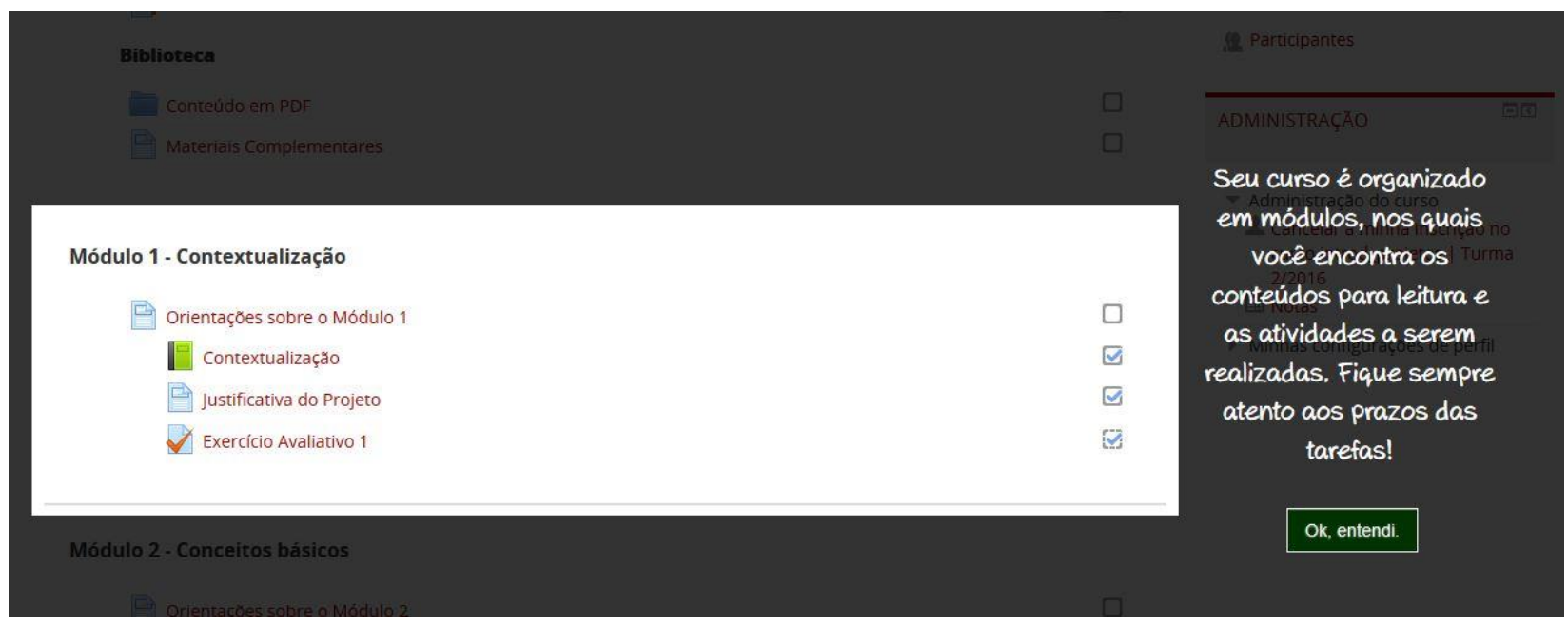

Figura 12 - Apresentação dos módulos dos cursos. Fonte: Enap Virtual (2016).

Logo após, o assistente virtual apresentado na figura 13 faz a introdução do curso e explica brevemente o que o participante vai aprender, um resumo detalhado do curso, e ainda outros itens, como referências bibliográficas e a descrição dos módulos do curso.

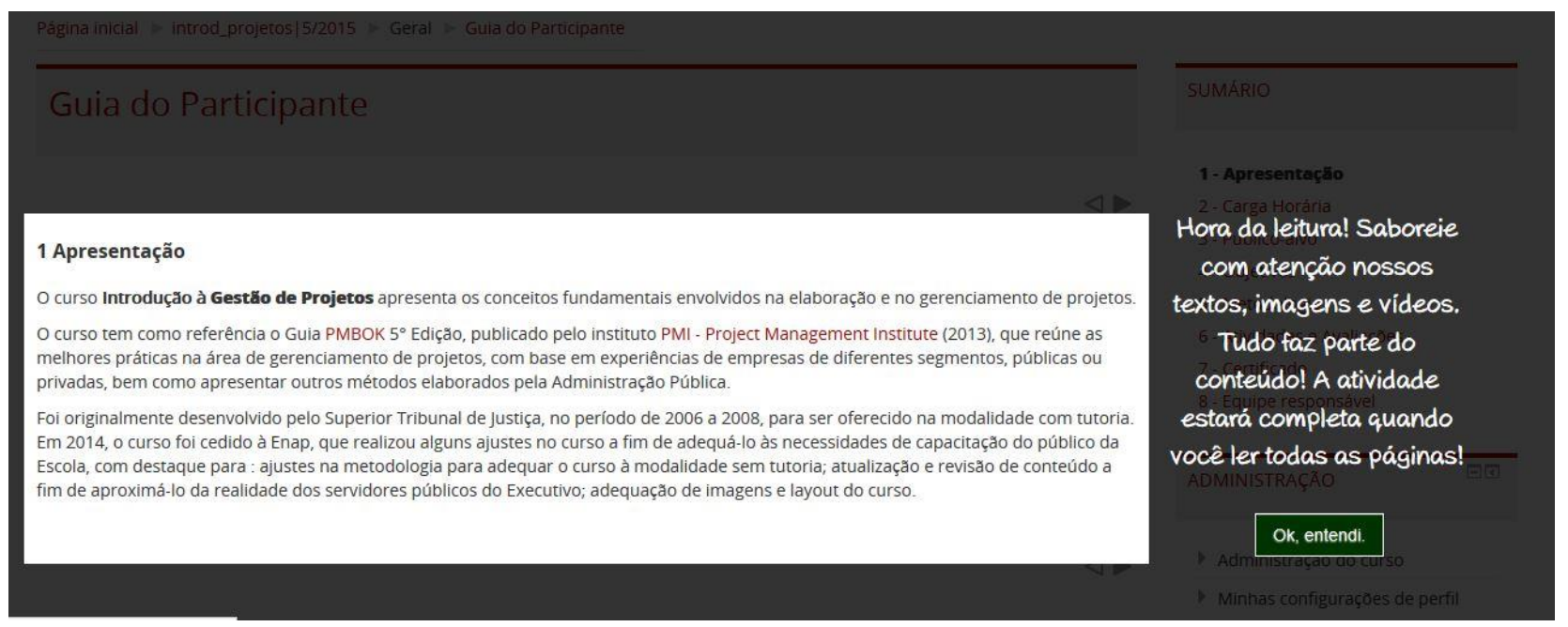

Figura 13 - Apresentação do guia do participante. Fonte: Enap Virtual (2016).

A ferramenta também apresenta os comandos que devem ser usados para a navegação do curso e os formulários de resposta para os exercícios do curso estão apresentados na figura 14. 


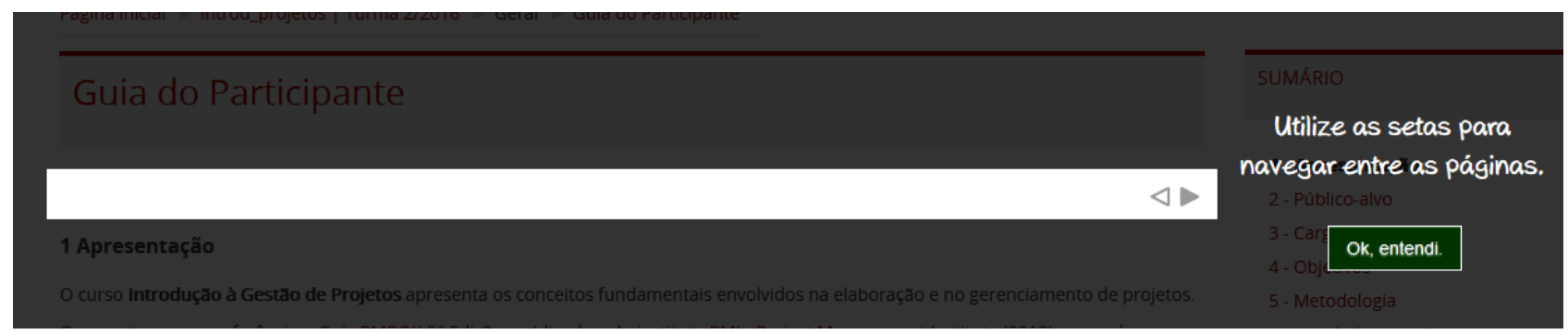

Figura 14 - Apresentação dos comandos de navegação do guia. Fonte: Enap Virtual (2016).

\subsection{FERRAMENTA DE MONITORAMENTO DO COMPORTAMENTO E DO DESEMPENHO DOS ALUNOS}

Em uma plataforma de educação a distância os relatórios são ferramentas importantes para a mediação pedagógica e gestão de cursos. Os relatórios da plataforma Moodle vêm melhorando bastante a cada nova versão, mas ainda não atendem necessidades específicas da CGEAD.

O relatório de Desempenho e comportamento do aluno foi concebido de forma a atender essa demanda da CGEAD em extrair dados do Moodle de forma consolidada. Gestores e professores frequentemente precisam de dados analíticos ou sintéticos para tomada de decisões e infelizmente o Moodle não consegue satisfazer todas as necessidades em um único lugar. Partindo de um problema geral chegamos em uma solução simples e sintetizada.

O planejamento do relatório de Desempenho e comportamento é um documento que agrupa as informações seis fontes diferente de dados com a finalidade de agrupar outros relatórios que eram produzidos de forma manual e muitas vezes deficientes de informações. Com um trabalho conjunto entre as Equipes da UnB e CGEAD, foram levantadas quais informações seriam mais trabalhosas de ser extraídas de forma manual e quais seriam de maior importância sobre o comportamento dos alunos em uma turma.

Na figura 15 é possível ver os componentes que formam o relatório de desempenho e comportamento com a lista de informações dos alunos referentes as turmas de cursos de EaD da Enap. 


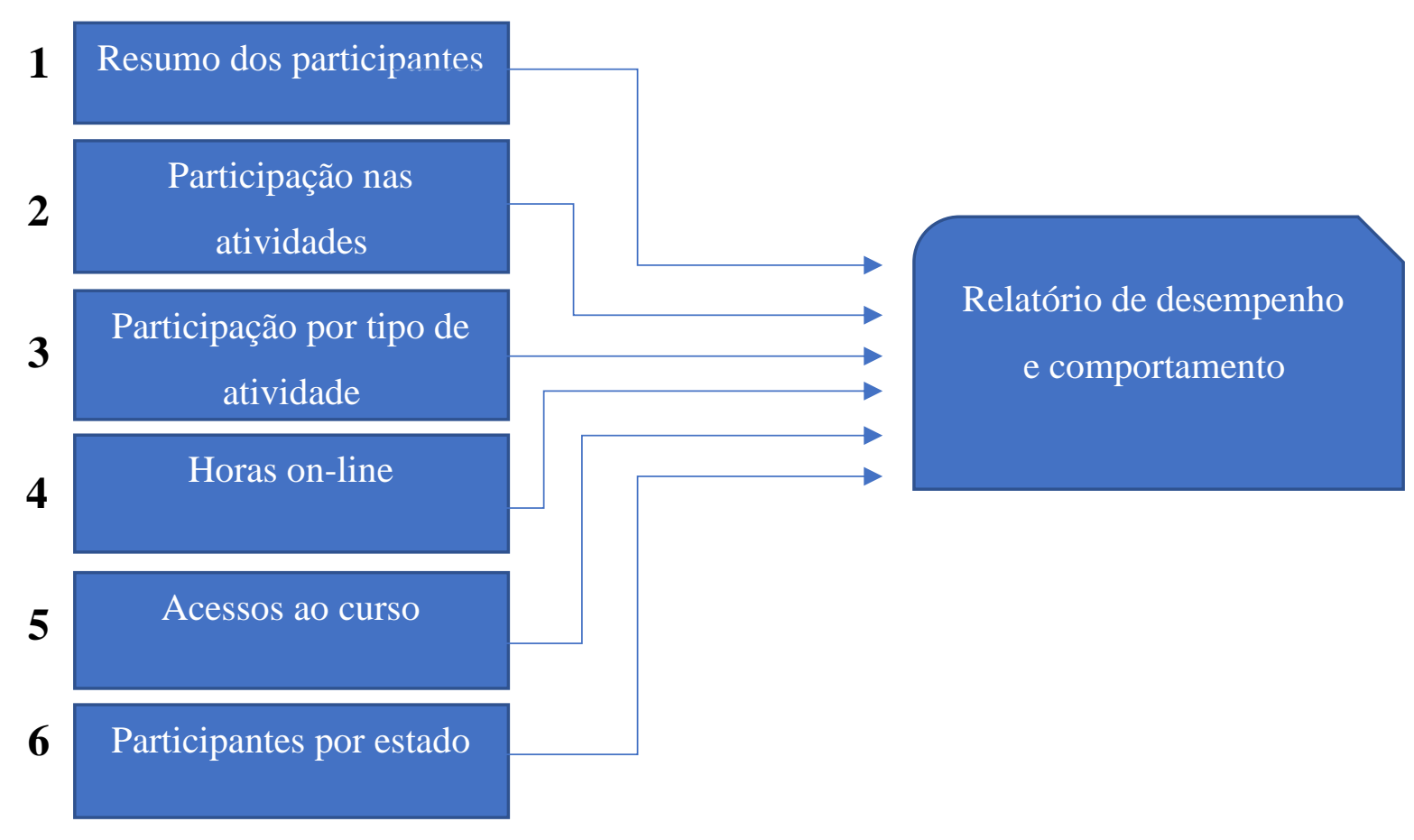

Figura 15 - Fluxo das informações que compõem o relatório de desempenho e comportamento dos alunos. Fonte: Próprio autor.

O item 1 da figura 15 que compõe o relatório que é representado na figura 16. Traz um resumo dos participantes onde é possível visualizar os totais de matriculados, inscrições canceladas, números de aprovados e reprovados, assim como a quantidade de desistentes e o índice de alunos concluintes.

\section{Turma 4/2015 - Gestão e Fiscalização de Contratos Administrativos - nível intermediário}

\section{Resumo dos participantes}

Participantes matriculados: 2360

Inscrições canceladas: 319

Aprovados: 687

Reprovados: 698

Desistentes: 656

Índice de conclusão: $29 \%$

Figura 16 - Resumo dos participantes. Fonte: Enap Virtual (2016). 
No item 2 da figura 15, temos um gráfico com as quantidades de acessos por dia de curso que é apresentado na figura 17. É possível também visualizar em quais dias o sistema envio mensagens e o histórico dessas mensagens por dia.

Esse gráfico é um exemplo de integração entre outros plugins, nesse caso o plugin de envio de mensagens automáticas descrito por Almeida (2016), o qual relaciona o envio de mensagens de estímulo para o aluno interagir e acessar o curso.

\section{Acessos ao curso}

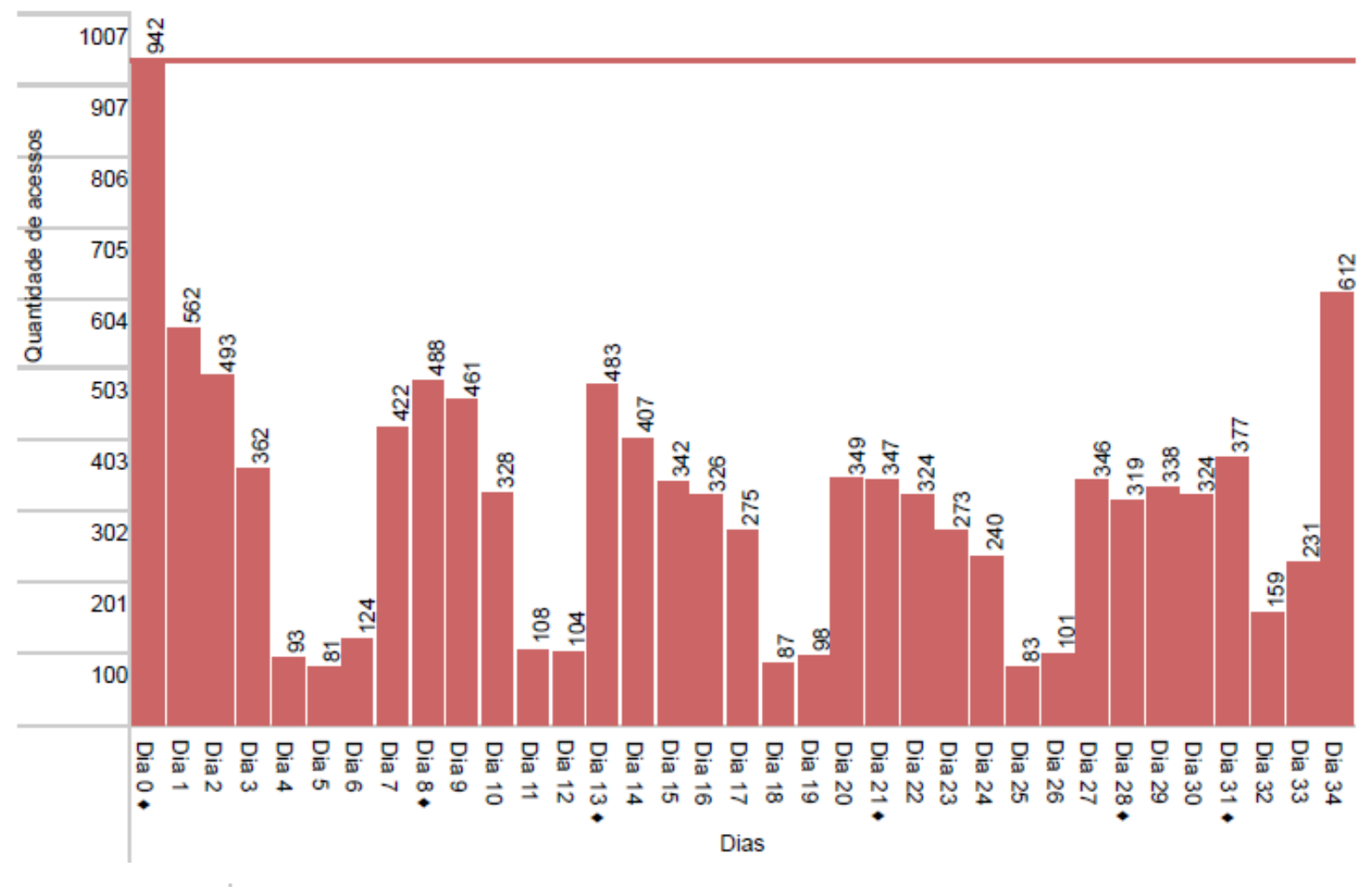

Nos dias marcados com $\bullet$ foram enviadas uma ou mais mensagens.

Mensagens

Dia 0

- Apresentação"

Dia 8

- Vamos começar as atividades...."

Dia 13

- Vamos realizar as atividades......"

Figura 17 - Gráfico com a quantidade de acesso por dia e histórico de mensagens enviadas. Fonte: Enap Virtual (2016). 
Os itens 3 e 4 da figura 15 são ilustrados respectivamente nas figuras 18 e 19 . Na figura 18 é possível ver no gráfico os índices de participação dos alunos em cada atividade dos cursos e no gráfico da figura 19 a quantidade e os percentuais de acessos por tipo de atividade.

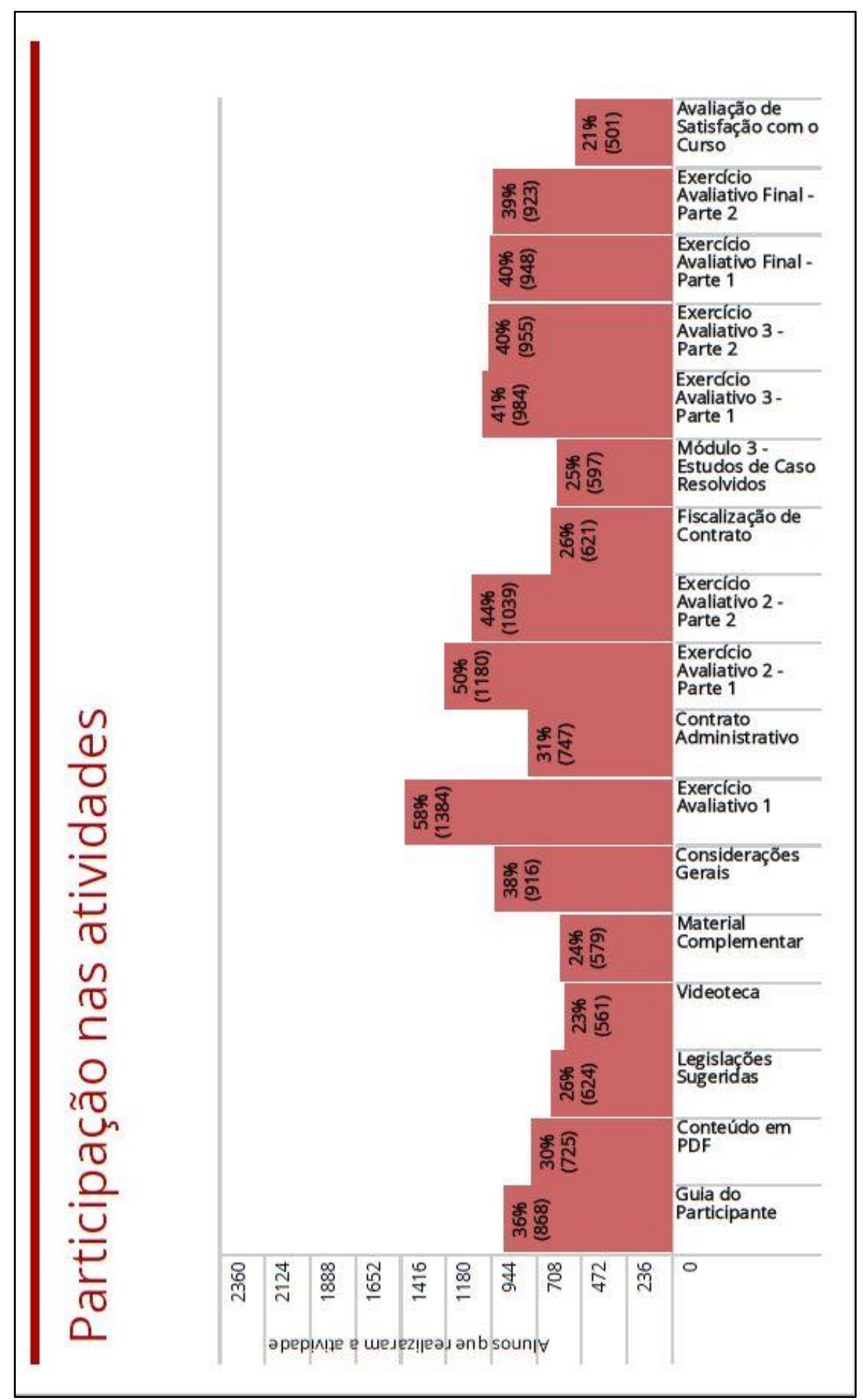

Figura 18 - Gráfico de participação por atividades. Fonte: Enap Virtual (2016). 


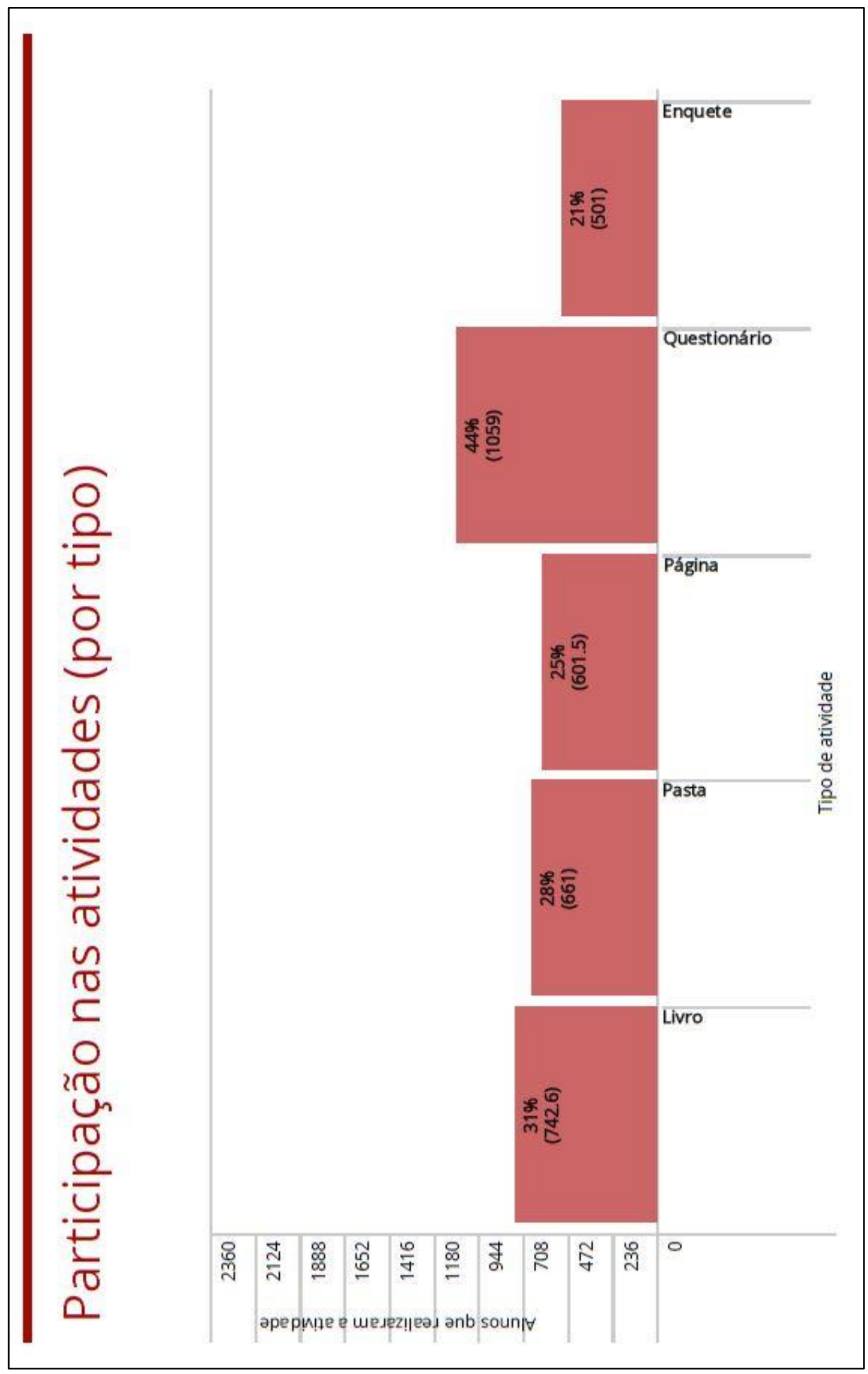

Figura 19 - Gráfico de participações por tipo de atividades. Fonte: Enap Virtual (2016). 
O componente 5 da figura 15 representa o gráfico de figura 20 que mostra o tempo de acesso dos alunos em relação ao status no curso. Podemos verificar por exemplo quanto tempo os alunos aprovados permaneçam conectados ao curso.

Esse gráfico é apoiado por outro plugin apresentado por Zacarias (2016), onde desenvolve um sistema para otimizar e registrar o tempo online dos alunos, sem a necessidade de percorrer o log do Moodle o que se torna inviável devido ao grande volume de informação de precisam ser percorridas.

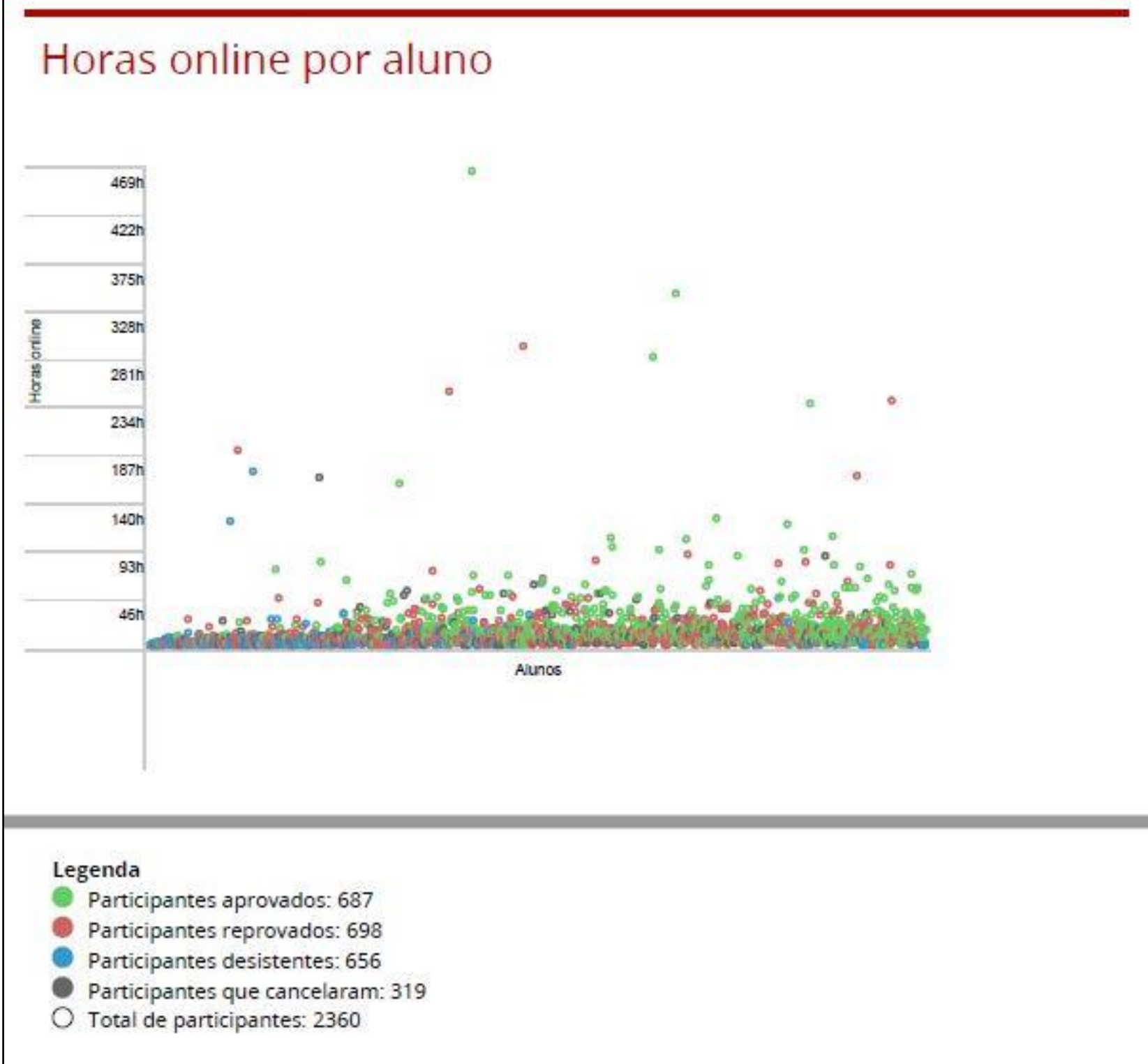

Figura 20 - Registro de tempo online por status do aluno. Fonte: Enap Virtual (2016). 
Por fim o item 6 da figura 15 temos uma lista com os totais de participantes por estados do pais que está ilustrada na figura 21 .

\section{Participantes por Estado (UF)}

\begin{tabular}{ccccccc} 
DF & SP & MG & RJ & RS & PR & BA \\
\hline 238 & 225 & 215 & 182 & 155 & 149 & 128
\end{tabular}

\begin{tabular}{ccccccc} 
PE & CE & PA & SC & MA & MT & RN \\
\hline 120 & 109 & 81 & 74 & 69 & 59 & 58
\end{tabular}

\begin{tabular}{lllllll} 
AM & ES & GO & MS & AC & PI & PB \\
\hline 56 & 48 & 48 & 47 & 44 & 40 & 40
\end{tabular}

\begin{tabular}{llllll} 
TO & AL & RO & SE & RR & AP \\
\hline 37 & 36 & 36 & 33 & 19 & 14
\end{tabular}

Figura 21 - Participantes por estados.

Fonte: Enap Virtual (2016).

\section{4 - IMPACTOS DA INTERFACE E DO MONITORAMENTO}

A Escola Nacional de Administração Pública (Enap) tem um grande fluxo de troca de informações e geração de dados, sejam dados gerados por humanos ou dados gerados por máquinas. Tais dados atualmente se encontram ocultos e distribuidos em diversas tabelas espalhadas pela base de dados. A base de dados contém dados estruturados em um banco e não estruturadas como planilhas, vídeos, imagens e arquivos de texto.

Uma pesquisa do IDC (2011) afirma que em torno de $90 \%$ dos dados do universo digital são classificados como dados não-estruturados. Dessa forma, é extremamente relevante que várias organizações atentem para qual tipo de dado vai aproveitar e como agregar valor com essas informações, visto que os dados não-estruturados têm uma representatividade considerável. Segundo Taurion (2012) os dados não estruturados são a imensa maioria. 
A tabela 3 listamos as fontes de informações as quais foram comparadas para comprovar as eficácias e impactos das ferramentas desenvolvidas.

Tabela 3 - Fontes de dados exploradas

\begin{tabular}{|c|c|c|c|}
\hline Fonte & Dado & $\begin{array}{l}\text { Período de } \\
\text { coleta }\end{array}$ & Significado do indicador a ser obtido \\
\hline $\begin{array}{l}\text { Informações de } \\
\text { mensagens } \\
\text { automáticas }\end{array}$ & $\begin{array}{l}\text { Tabela envolvidas } \\
\text { no sistema de } \\
\text { envio de } \\
\text { mensagens }\end{array}$ & $2015-2016$ & $\begin{array}{l}\text { Analisar o comportamento do aluno em } \\
\text { relação a essas interações e o impacto nas } \\
\text { taxas de evasão e acessos ao ambiente }\end{array}$ \\
\hline $\begin{array}{l}\text { Relatórios de } \\
\text { Desempenho e } \\
\text { Comportamento } \\
\text { do aluno }\end{array}$ & $\begin{array}{l}\text { Matriculados, } \\
\text { concluintes, taxas } \\
\text { de trancamento }\end{array}$ & $2015-2016$ & $\begin{array}{l}\text { Avaliar e sugerir soluções tecnológicas } \\
\text { para aumentar as taxas de conclusão e } \\
\text { diminuir ao máximo o cancelamento de } \\
\text { matrículas. }\end{array}$ \\
\hline Base de logs & $\begin{array}{l}\text { Tabela de } \log s \text { de } \\
\text { acessos dos alunos }\end{array}$ & $2015-2016$ & $\begin{array}{l}\text { Com essas informações poderemos medir } \\
\text { a periodicidade dos acessos e a interação } \\
\text { dos usuários na plataforma. }\end{array}$ \\
\hline $\begin{array}{l}\text { Google } \\
\text { analytics }\end{array}$ & $\begin{array}{l}\text { Informações de } \\
\text { acessos e } \\
\text { informações te } \\
\text { tempo }\end{array}$ & $2015-2016$ & $\begin{array}{l}\text { Acesso e configuração de indicadores do } \\
\text { analytics (Google). } \\
\text { Entender o comportamento do aluno em } \\
\text { relação a navegação ao portal e a } \\
\text { interação com os cursos. É um } \\
\text { complemento na análise dos } \log s\end{array}$ \\
\hline $\begin{array}{l}\text { Em Números } \\
\text { (2016) }\end{array}$ & $\begin{array}{l}\text { Informações } \\
\text { quantitativas de } \\
\text { cursos e } \\
\text { participantes }\end{array}$ & $2011-2016$ & $\begin{array}{l}\text { Bases histórica de informações } \\
\text { acadêmicas da Enap }\end{array}$ \\
\hline
\end{tabular}

A Tabela 4 apresenta o nome das tabelas da base de dados do Moodle selecionadas para o estudo, permitindo avaliar como cada usuário interage com o ambiente. A Tabela 4 apresenta os atributos selecionados, de acordo com os grupos de informações propostos. 
Tabela 4: Tabelas da base de dados do Moodle.

\begin{tabular}{|l|l|}
\hline \multicolumn{1}{|c|}{ Tabela } & \multicolumn{1}{c|}{ Especificação } \\
\hline mdl_course & Registro dos cursos. \\
\hline mdl_grade_grades & Registra as notas individuais das atividades \\
\hline mdl_grade_items & Registro de atividades que mantem vários itens \\
\hline mdl_report_automessage & Registros de mensagens enviadas e recebidas. \\
\hline mdl_report_avalreacao & Registros do relatório de avaliação e reação. \\
\hline mdl_log & Arquivo de log com dados referentes ao uso do sistema. \\
\hline
\end{tabular}

Com base nas informações apresentadas nas tabelas 3 e 4, podemos ver que as informações se encontram difusas em diversas tabelas e repositórios. Só após um tratamento manual dessas informações foi possível compilar e entender a dinâmica das relações do crescimento das ofertas, número de cursos e alunos para a realização deste estudo.

Segundo a Enap (2015) a meta inicialmente prevista para concepção desses cursos foi estabelecida com base em dois fatores: tendência histórica de oferta de cursos a distância na Enap e orçamento disponibilizado para o ano. Entretanto, com a redução do orçamento, houve uma dedicação maior na oferta de cursos a distância sem tutoria, abertos para servidores públicos e sociedade em geral, bem como investimento na divulgação dos cursos por meio de redes sociais.

O catálogo de cursos em EaD foi também ampliado por meio do desenvolvimento de eventos de capacitação realizados em parcerias com o Ministério do Planejamento, com a Controladoria Geral da União, com o Ministério da Previdência e com outras instituições, sem custos adicionais para a Enap. Para que esse aumento ocorresse, mostrou-se fundamental a automação de processos no âmbito do Termo de Cooperação firmado em 2013 com a Universidade de Brasília (Enap, 2015).

Dando prosseguimento a ações de ampliação do atendimento de demandas de capacitação por meio do ensino a distância, no ano de 2016 a Enap aumentou em 33\% o número de turmas, ampliando a oferta de 154 para 206 turmas em 48 cursos a distância. Esses eventos de aprendizagem são abertos e gratuitos aos agentes públicos dos três poderes, das três esferas de governo e, no caso dos cursos sem tutoria, também à sociedade. 
Por outro lado, em termos de capacitações realizadas (servidores atendidos), o incremento foi de 439 \% considerando que foram alcançadas 20.553 capacitações em 2012 ano antes da cooperação com a Enap e em 2016 registrou 110.936 capacitações.

A tabela 5 mostra os números de matriculados, capacitações concluídas e evadidos nos quatros anos anteriores ao termo de cooperação Enap - UnB.

Tabela 5 - Informações da demanda de 2009 a 2012

Fonte: Em Números (2016).

\begin{tabular}{|c|c|c|c|}
\hline Ano & Matriculados & Conclusões & Evadidos \\
\hline 2009 & 26.897 & 20.146 & 6.440 \\
\hline 2010 & 34.718 & 24.819 & 9.323 \\
\hline 2011 & 34.092 & 24.595 & 8.506 \\
\hline 2012 & 28.654 & 20.553 & 6.902 \\
\hline
\end{tabular}

Comparado com os quatro anos anteriores expostos na tabela 5 podemos ver que desde o início da parceria a evolução dos números na tabela 6 em relação a 2012.

Tabela 6 - Informações da demanda de 2013 a 2016

Fonte: Em Números (2016).

\begin{tabular}{|l|c|c|c|l|}
\hline Ano & Matriculados & Conclusões & Incremento & Comparativo \\
\hline 2013 & 42.073 & 27.331 & $33 \%$ & Ano 2012 \\
\hline 2014 & 68.922 & 35.627 & $73 \%$ & Ano 2012 \\
\hline 2015 & 148.840 & 74.601 & $263 \%$ & Ano 2012 \\
\hline 2016 & 192.545 & 110.936 & $439 \%$ & Ano 2012 \\
\hline
\end{tabular}

A figura 22 apresenta o gráfico com o total de matrículas por esfera de poder no ano de 2016. 


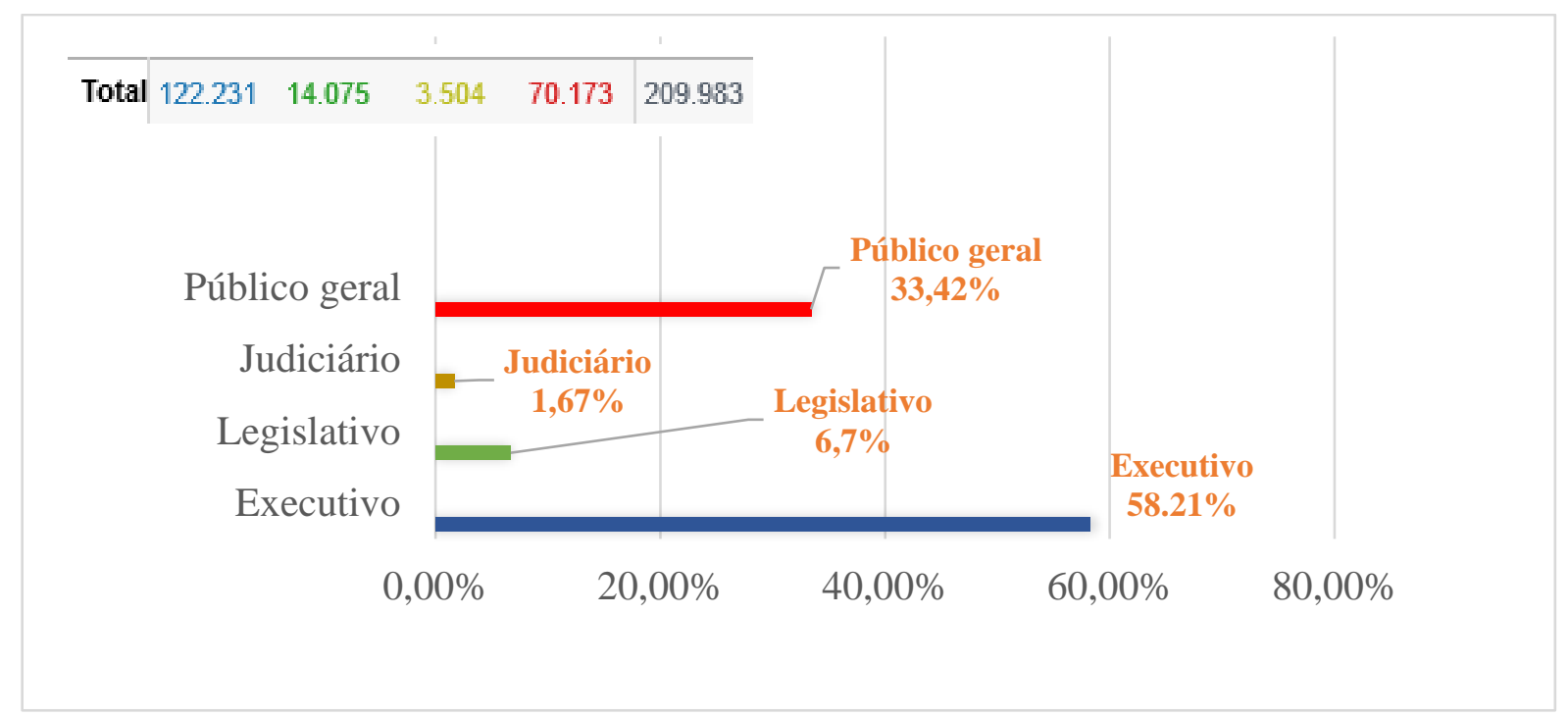

Figura 22 - Gráfico do total de matrículas por esfera de poder em 2016.

Fonte: Em Números (2016).

A maior parcela do público dos cursos de $\mathrm{EaD}$ é composta por servidores do poder executivo com 122.231 matrículas, em segundo com 70.173 matriculas aparece o público em geral. O poder legislativo compõe $6,7 \%$ que corresponde 14.075 inscritos e o poder judiciário com a menor parcela com 3.504 matrículas, em um total de todos os poderes 209.983 inscritos.

Em 2016 a Enap ampliou sua oferta de turmas em cursos a distância por meio de parcerias com a UnB e o Ministério do Planejamento (MP). Somente em cursos a distância, a Enap realizou cerca de 110.900 capacitações superando em 36.000 quando comparado com 2015, o que justifica a superação da meta da ação.

Nesse contexto, além da ampliação na oferta, a Escola tem também investido na melhoria tecnológica dos eventos de aprendizagem na modalidade a distância (infraestrutura de TI, atualização de versão do Moodle, aprimoramento das ferramentas voltadas para educação, etc.).

Para 2016, essas ações foram continuadas para conferir eficácia à plena oferta de cursos a distância e, ainda, foram disponibilizadas outras ferramentas de capacitação como as comunidades de prática. Ações essas que buscam construir e disponibilizar um ambiente de aprendizagem mais acessível e que possibilite uma maior interação para que seja possível atingir diferentes localidades em que a capacitação se faça necessária. 


\section{FERRAMENTA DE ENVIO DE MENSAGENS}

Neste capítulo apresentamos a ferramenta de envio de mensagens automáticas. Destacamos também sua finalidade, seu funcionamento e impacto nas turmas que recebem seu estímulo.

A proposta de análise da ferramenta de envio de mensanges automáticas buscou relacionar os comportamentos dos alunos registrados no AVA ( $\log$ de acesso, materiais acessados, atividades realizadas), em busca de padrões de acesso, de forma a traçar o perfil dos alunos que solicitam o trancamento da matrícula antes mesmo de qualquer atividade e que evadem ou reprovam por não atingirem o aproveitamento mínimo nas avaliações dos cursos na modalidade a distância, assim como auxiliar os coordenadores da CGEAD na identificação de estudantes com características que demonstram pouca atividade nos cursos $\mathrm{EaD}$.

Foram selecionadas turmas dos cursos realizados na modalidade à distância, que atendesse aos seguintes requisitos experimentais: maior quantidade de estudantes por turma, turmas concluídas com disponibilidade do status final do aluno, maior número de dados referentes aos recursos do AVA utilizados.

Com base nos critérios apresentados para essa experimentação, escolheram-se dados de Log dos alunos dos cursos Ética e Serviço Público - sem tutoria, Introdução à Gestão de Processos, atendimento ao cidadão, Gestão e fiscalização de contrato contabilizando um total de 60 mil matrículas.

A fase de identificação dos problemas e quais recursos deveriam ser incorporados ao ambiente virtual de ensino da Enap envolveu uma pesquisa da situação atual das tecnologias disponíveis, para identificar necessidades e oportunidades das ferramentas.

Esta fase proporcionou o levantamento dos principais recursos que poderiam integrar o ambiente virtual e quais informações deveriam ser enviadas pelo sistema de envio de mensagens (novos materiais postados, atividades pendentes, novas atividades postadas, mensagem do professor e tempo de inatividade) que geraram como resultado as especificações dos requisitos funcionais, não funcionais e casos de uso.

A plataforma Moodle é composta por uma estrutura cercada por plugins para prover funcionalidades específicas ao ambiente. Plugins são diretórios de códigos que podem ser simplesmente colocados 
dentro de qualquer instalação Moodle, instalado e automaticamente estará disponível como ferramenta dentro da interface do Moodle.

O plugin de mensagem automática proposto por Almeida (2016) foi desenvolvido com uma finalidade específica com a missão de substituir todo trabalho manual de comunicação que a escola virtual mantinha com os alunos e que ocasionava um intenso trabalho da equipe de suporte da escola.

O processo tem início com o fechamento das ofertas dos cursos e enturmação (tarefa de separar inscritos no curso em turmas) e prosseguia por todo tempo dos cursos. Para esse controle a equipe da CGEAD utilizava-se de tabelas no Excel com a listagem de alunos de cada turma, mensagens a serem enviadas e as datas para o envio. Na figura 23 é possível ver como as informações eram organizadas em um sistema de correio eletrônico que poderia ser o Microsoft Outlook ou outro similar, onde o coordenador do curso importava as informações das tabelas do Excel e organizava as mensagens de forma manual e selecionava para quais alunos deveriam ser enviadas as mensagens.

\begin{tabular}{|c|c|c|c|c|c|}
\hline \multicolumn{2}{|c|}{ 道 $00 \mathrm{De}$} & Assunto & Recebido em Ta... & Categorias & 8 \\
\hline की & Rodrigo ban... & RE: Aviso Importante - Regulamentaçăo da LAI nos Municípios & $\operatorname{seg} 20 / 04 / 2015 \ldots 15 \mathrm{~KB}$ & & P \\
\hline Q & Solange Car... & Emissāo de novo certificado_Tutoria on-line & $\operatorname{seg} 20 / 04 / 2015 \ldots .22 \mathrm{~KB}$ & & P \\
\hline Q & CLAUDETTE $_{. .}$ & RE: Aviso Importante - Mecanismos OGU PAC - Transferências Obrigat... & $\operatorname{seg} 20 / 04 / 2015 \ldots .18 \mathrm{~KB}$ & & P \\
\hline Q & EAD & Problema com a senha & $\operatorname{seg} 20 / 04 / 2015 \ldots . .7 \mathrm{~KB}$ & & $\checkmark$ \\
\hline ه & Vander Pinh... & Re: Aviso Importante - Regulamentaçăo da LAI nos Municipios & $\operatorname{seg} 20 / 04 / 2015 \ldots 83 \mathrm{~KB}$ & & $\checkmark$ \\
\hline S & COMPRASE... & RE: Conclusăo de Curso - Certificado! & $\operatorname{seg} 20 / 04 / 2015 \ldots 18 \mathrm{~KB}$ & & $\checkmark$ \\
\hline बे & Rarys Costa ... & RE: Aviso Importante - Último dia do curso! & $\operatorname{seg} 20 / 04 / 2015 \ldots 15 \mathrm{~KB}$ & & $\checkmark$ \\
\hline Q & eliane franklin & Re: RES: Convite para participar de turma piloto & $\operatorname{seg} 20 / 04 / 2015 \ldots 14 \mathrm{~KB}$ & & $P$ \\
\hline$\Leftrightarrow$ & EAD & Recuper aĀsāfo de sentia & sey 20/04/2015 ... 7 KB & & $\checkmark$ \\
\hline So & Ana Flávia C... & Re: Aviso Importante - Último dia do curso! & seg $20 / 04 / 2015 \ldots 16 \mathrm{~KB}$ & & $\checkmark$ \\
\hline a & Jucimara Sas.... & Re: Aviso Importante - Regulamentação da LAI nos Municipios & $\operatorname{seg} 20 / 04 / 2015 \ldots .20 \mathrm{~KB}$ & & $\checkmark$ \\
\hline 8 & EAD & Acesso ao Curso & $\operatorname{seg} 20 / 04 / 2015 \ldots .7 \mathrm{~KB}$ & & $\checkmark$ \\
\hline Q & EAD & nẤfo consigo acessar a escola virtual & $\operatorname{seg} 20 / 04 / 2015 \ldots .7 \mathrm{~KB}$ & & $\checkmark$ \\
\hline Q & Ingrid Moriy... & Re: Aviso Importante - Regulamentação da LAI nos Municipios & $\operatorname{seg} 20 / 04 / 2015 \ldots 19 \mathrm{~KB}$ & & $\checkmark$ \\
\hline Q & Assistencia & RES: Aviso Importante - Regulamentaçáo da LAI nos Municipios & $\operatorname{seg} 20 / 04 / 2015 \ldots 22 \mathrm{~KB}$ & & $\checkmark$ \\
\hline Q & LUCIANO M... & RE; Aviso Importante - Regulamentação da LAI nos Municípios & $\operatorname{seg} 20 / 04 / 2015 \ldots 18 \mathrm{~KB}$ & & $P$ \\
\hline S & Tito Carlos R... & Exércicios de Fixação & $\operatorname{seg} 20 / 04 / 2015 \ldots 21 \mathrm{~KB}$ & & $\varphi$ \\
\hline a & MARIA FER... & RE: Aviso Importante - Regulamentaçăo da LAI nos Municipios & $\operatorname{seg} 20 / 04 / 2015 \ldots 15 \mathrm{~KB}$ & & $P$ \\
\hline 8 & Heden Clazy... & Re: Convite para participar de turma piloto & $\operatorname{seg} 20 / 04 / 2015 \ldots 19 \mathrm{~KB}$ & & Y \\
\hline कि & Flávia GS & RE: Aviso Importante - Regulamentaçăo da LAI nos Municípios & $\operatorname{seg} 20 / 04 / 2015 \ldots 18 \mathrm{~KB}$ & & $\gamma$ \\
\hline Q & Hellynha Fsa & RE: Aviso Importante - Regulamentação da LAI nos Municípios & $\operatorname{seg} 20 / 04 / 2015 \ldots 18 \mathrm{~KB}$ & & $P$ \\
\hline Q & Alice Santos ... & RES: Certificado ENAP & $\operatorname{seg} 20 / 04 / 2015 \ldots 44 \mathrm{~KB}$ & & $\checkmark$ \\
\hline ब्रे & patricia caldas & RE: Convite para participar de turma piloto & $\operatorname{seg} 20 / 04 / 2015 \ldots 19 \mathrm{~KB}$ & & P \\
\hline Q & Paulo Rober... & RES: Aviso Importante - Início do Curso! & $\operatorname{seg} 20 / 04 / 2015 \ldots 24 \mathrm{~KB}$ & & $\checkmark$ \\
\hline$\Leftrightarrow$ & EAD & senha de acesso & $\operatorname{seg} 20 / 04 / 2015 \ldots 6$ KB & & $\checkmark$ \\
\hline बि & secretariaesc... & RES: $2^{3}$ Via Certificado & $\operatorname{seg} 20 / 04 / 2015 \ldots 14 \mathrm{~KB}$ & & $\checkmark$ \\
\hline a & EAD & Acesso ao site enap escola virtual & $\operatorname{seg} 20 / 04 / 2015 \ldots .7 \mathrm{~KB}$ & & $\checkmark$ \\
\hline B & EAD & Dificuldade de aresso no curso (TIC) e-MAG Conteudista & $\operatorname{sen} 20 / 04 / 2015 \quad 7 \mathrm{~KB}$ & & $\checkmark$ \\
\hline
\end{tabular}

Figura 23. Gerenciador de e-mail para envio manual de mensagens. Fonte: Próprio do autor. 
O Plugin proposto por Almeida (2016), tem a finalidade de auxiliar na motivação dos alunos em permanecerem conectados aos cursos e a interagir com o ambiente com maior frequência. Permite que os gestores programem o envio mensagens personalizadas e automáticas sempre que os alunos atingirem condições predefinidas.

A Figura 24 apresenta o fluxo de operação do plugin e as informações necessárias para enviar uma mensagem a um participante. No passo 1, o sistema passa por todos os cursos com classes em andamento. Na etapa 2, o sistema verifica as mensagens que estão registradas para um determinado dia de um curso. No passo 3, o sistema compara as condições de cada participante em relação à classe de dia correspondente do percurso. No passo 4, o sistema verifica se a condição está registada numa mensagem a ser enviada, enquanto que no passo 5 o sistema encaminha a mensagem para o servidor de mensagens. No passo 6, a mensagem é enviada para o e-mail do participante registrado.

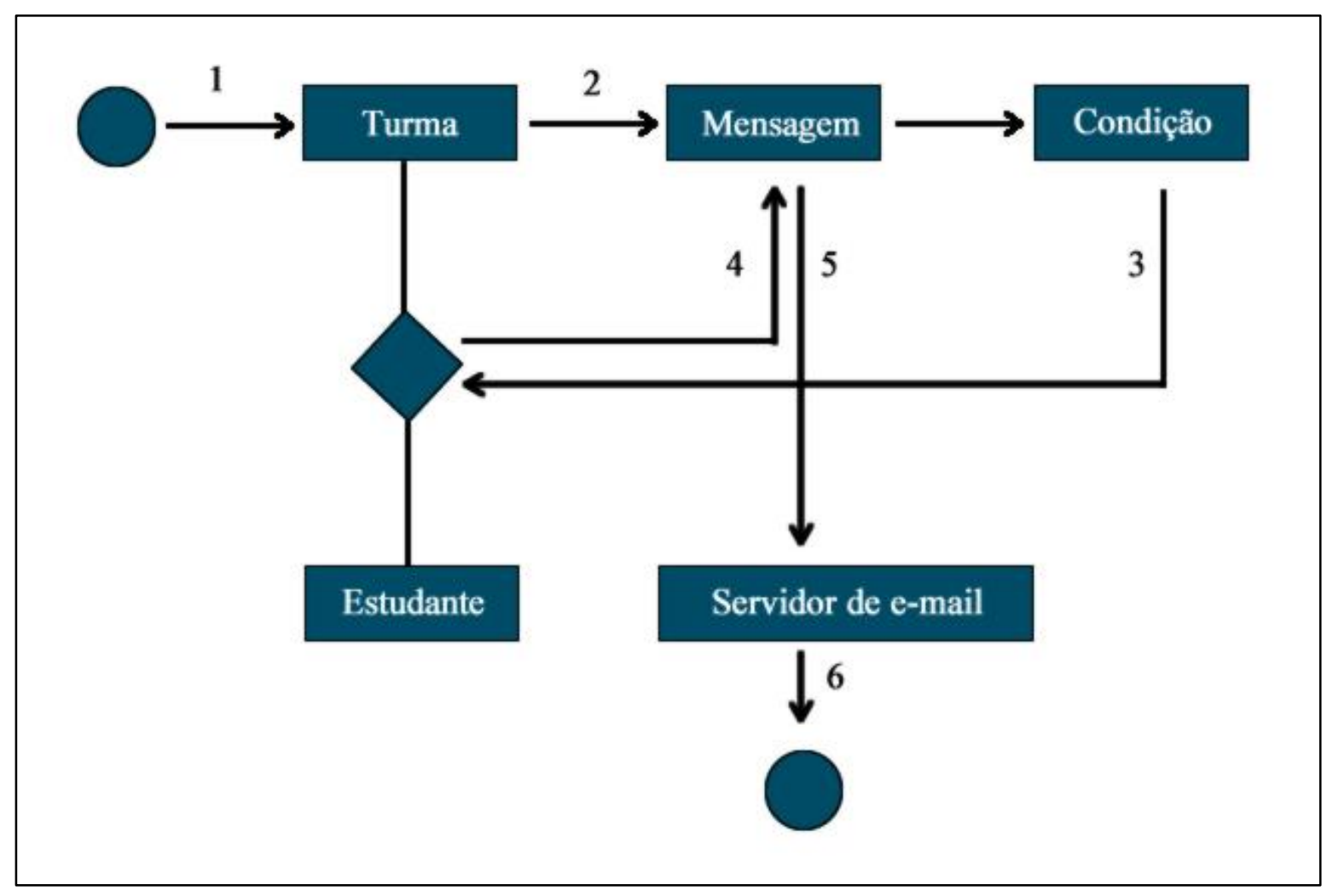

Figura 24: Fluxo de operação do plug-in de envio de mensagem. Fonte: Próprio do autor. 
Na figura 25, é representado o diagrama de blocos que apresenta o fluxo de informação dos processos de interação do utilizador. Observe que o fluxo principal e os três fluxos alternativos se complementam e têm o mesmo objetivo.

O fluxo principal da interface do sistema é uma ação de usuário que é executada através dos botões "Nova Mensagem / Editar / Apagar Mensagem" e, em seguida, os registros do sistema no arquivo as mensagens devem ser enviadas para os alunos em curso específico. No primeiro fluxo alternativo A1, o utilizador preenche os dados da mensagem que são inicialmente condições de envio, dia de expedição, assunto e corpo da mensagem e confirma a sua conclusão. Em seguida, os dados são gravados no banco de dados e o sistema exibe uma mensagem de confirmação e sai do fluxo alternativo A1. No fluxo alternativo A2, o utilizador modifica os dados e confirma a sua conclusão, e registra as alterações no banco de dados. Em seguida, o sistema exibe uma confirmação de mensagem e fecha o fluxo A2 alternativo. No fluxo alternativo A3, o sistema exibe uma pergunta, atualiza a mensagem e o banco de dados e exibe a mensagem de confirmação, finalizando o fluxo alternativo 3 com a exclusão do registro. Observe que o diagrama na figura 25 não apresenta exceção de fluxo. 


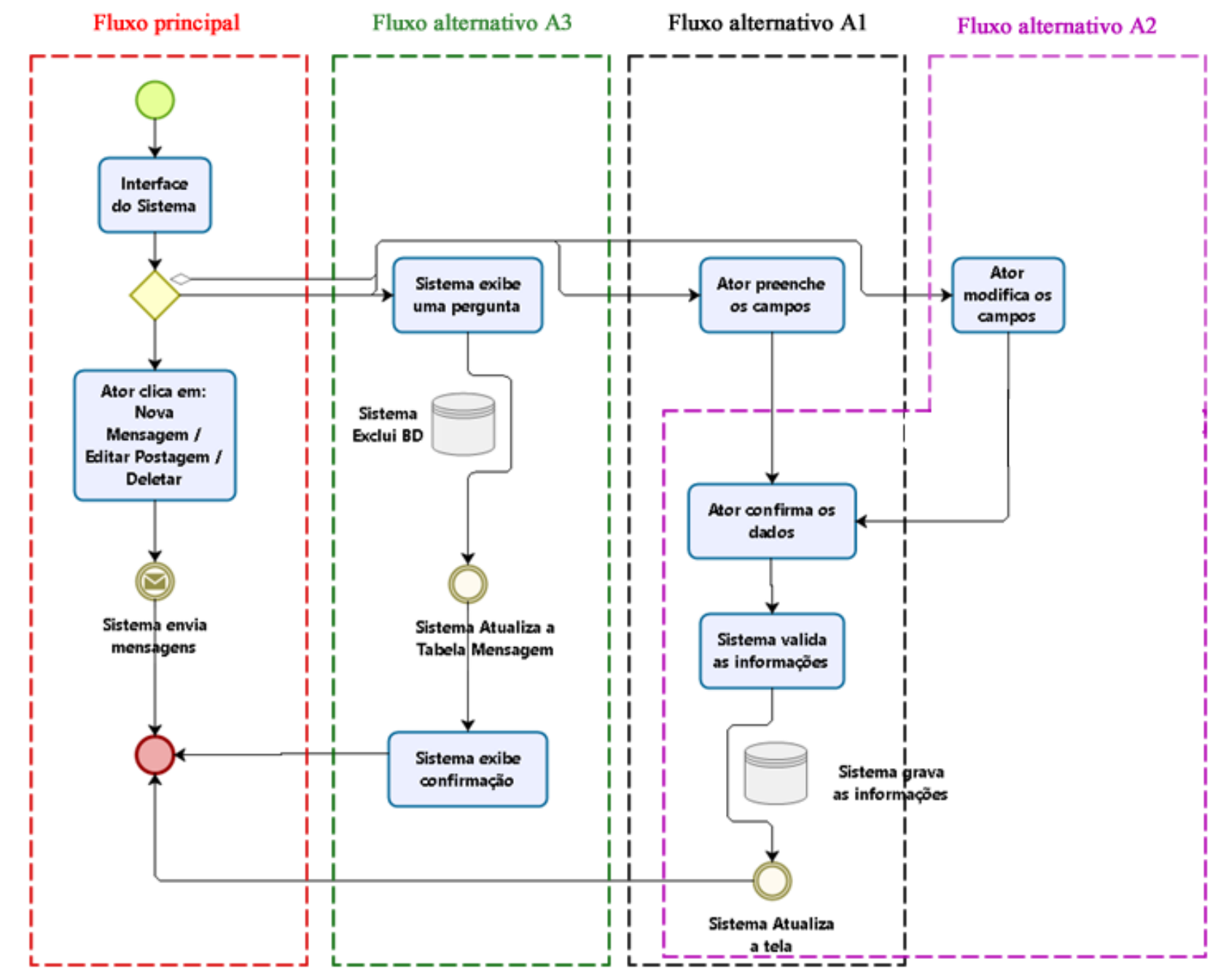

Figura 25. Processos de interação do usuário com o plugin de mensagem automática.

A figura 26 mostras nove tipos de condições predefinidas que são consideradas no plugin proposto:

- A primeira condição é o caso do usuário sem acesso ao sistema de e-learning.

- A segunda condição é quando o usuário já acessou e não tem nota em uma atividade de avaliação desde o início do curso.

- A terceira condição é quando o usuário não tem nenhum grau passado sete dias antes de uma data de envio de mensagem, embora tenha, na prática, concluída uma atividade.

- A quarta condição é quando o usuário obteve notas abaixo da pontuação mínima, mas ele ainda pode concluir o curso, melhorando suas notas nas próximas atividades.

- A quinta condição é quando o usuário não fez nenhuma atividade de avaliação.

- A sexta condição é quando o usuário falha em todas as atividades de avaliação.

- A sétima condição é quando o usuário passou com êxito as atividades. 
- A oitava condição é quando o usuário abandona o curso.

- Finalmente, a nona condição inclui todos os alunos de todas as condições.

Além da seleção de grupos de alunos por condições, os alunos podem, obviamente, ser selecionados com base em outros critérios educacionais que podem ser específicos para um determinado curso.

\section{Cadastrar / Editar Mensagem}

\section{Situaçāo do aluno:*}

\section{Inserir um valor.}

\section{Selecione uma situação para envio... \\ Usuário sem acesso \\ Usuário que já acessou e não possui nota em atividade avaliativa \\ Usuário sem nota na atividade avaliativa da semana, mas que fez alguma atividade, \\ Usuário que está abaixo da nota mínima e ainda pode obtê-la \\ Usuário reprovado que fez alguma atividade avaliativa \\ Usuário reprovado que fez todas as atividades avaliativas \\ Usuário aprovado \\ Usuário desistente \\ Todos \\ Selecione uma situação para envio...}

Figura 26: Tela de seleção com as condições para enviar mensagens para os alunos.

Fonte: Enap Virtual (2016).

Em vez de selecionar os alunos considerando uma condição específica, o gestor também pode selecionar os alunos pelo curso e, em seguida, observar o histórico de mensagens enviadas. A Figura 27 apresenta um exemplo de um quadro com o histórico de mensagens enviadas.

Na figura 27 o sistema mostra as mensagens configuradas no curso e em quais condições relacionadas a situação do aluno elas devem ser disparadas.

As mensagens possuem o critério ligados a três paramentos, dois paramentos ligado aos alunos e um ao andamento do curso. Quanto ao aluno o sistema avalia o desempenho e a interatividade e ao curso o seu andamento diário. 
A figura 27, também ilustra a forma como as mensagens são armazenadas por cursos. O gestor possui os recursos de visualizar, alterar e excluir as mensagens a partir dessa tela.

\section{Turma 2/2015 - Siconv para Convenentes 2 - Proponentes e Usuários}

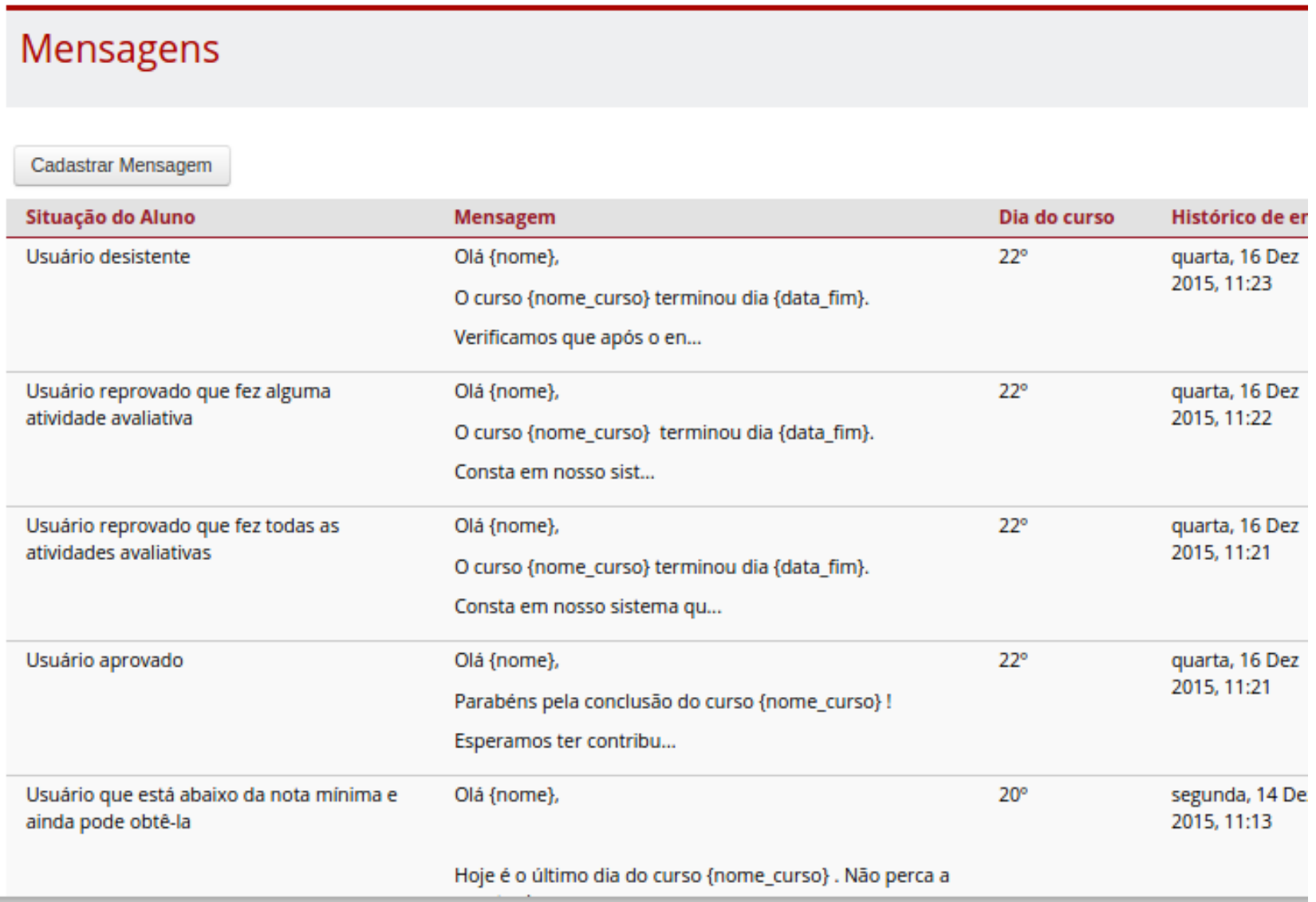

Figura 27: Listas de mensagens registradas em determinado curso.

Fonte: Enap Virtual (2016).

Na figura 28, é mostrado um exemplo de mensagem de modelo. Este exemplo aborda a situação em que o participante ainda não concluiu o curso. Note que a mensagem avisa que o curso está terminando com palavras motivacionais, onde incentiva o participante a terminar as tarefas e não deixar para a última hora. 


\section{Não perca tempo, o curso Introdução à Gestão de Projetos já está 宣 四 em andamento! Entrada $x$}

Escola Virtual Enap<ead_noreply@enap.gov.br>

06/05/2016

para mim

E aí, Luciano Rosa de Almeida! Tudo bem?

Estou entrando em contato mais uma vez para te lembrar de que o curso Turma 2/2016 Introdução à Gestão de Projetos começou no dia 03/05/2016 e já está quase terminando, porque possui três semanas de duração!

Aproveite essa oportunidade para realizar as atividades previstas sem correria. Não deixe para a última hora!

Esta é uma excelente oportunidade para adquirir novos conhecimentos. Que tal mais um certificado para o seu currículo?

Não sabe ou não se lembra de como acessar a Escola Virtual Enap? Não tem mistério.

Veja, abaixo, algumas orientações para te ajudar a entrar no curso:

Acesse 0 site: https://enapvirtual.enap.gov.br

Se você já fez algum curso a distância na Enap a partir de 2015, a senha que você já usava continua válida.

Caso contrário, seu usuário e sua senha correspondem ao seu CPF.

Em caso de dificuldades, entre em contato pelo e-mail: ead@enap.gov.br

Conte comigo sempre que precisar!

Coordenador de curso a distância

Coordenação-Geral de Educação a Distância

Diretoria de Desenvolvimento Gerencial

Escola Nacional de Administração Pública - Enap

Figura 28. Exemplo de mensagens recebidas pelo participante no final do curso.

Fonte: Próprio Autor.

\subsection{IMPACTO DA FERRAMENTA}

Para avaliar a eficácia do plugin proposto, comparamos o desempenho dos participantes do nosso sistema de e-Learningantes e depois do plugin. Para analisar o desempenho dos participantes, consideramos a quantidade de participantes que bloquearam sua inscrição nos anos de 2011 e 2012, 
quando ainda não era aplicado o plugin para o envio de mensagens. Por outro lado, os participantes foram motivados pelo envio automático de mensagens em 2013, 2014, 2015 e 2016.

Ao análisar os acessos, consideramos o mesmo período de tempo, mas agrupamos os participantes em duas categorias. Na primeira, consideramos turmas de diferentes cursos e analisamos os dias em os alunos não receberam mensagens, enquanto na segunda, consideramos turmas com recebimento de mensagens.

Os participantes do primeiro grupo são divididos em cinco classes, como mostrado na Tabela 7. Note que a quantidade média de participantes por dia foi de $23,11 \%$ para os dias em não foram disparadas mensagens automáticas. No entanto, como mostra a Tabela 8, para os cursos com mensagens automáticas, a percentagem médias de participantes por dia é de $37,1 \%$. Portanto, o ganho do plugin de mensagem automática proposto é bastante significativo.

Tabela 7 - Total e Porcentagem de acessos em dias em que não foram enviadas mensagens.

Fonte: Enap 2015.

\begin{tabular}{|c|c|c|c|}
\hline Turmas & $\begin{array}{c}\text { Quantidade } \\
\text { média de Alunos }\end{array}$ & Médias de acesso de alunos & \% \\
\hline Classe 1/2015 & 1,085 & 269 & $24.8 \%$ \\
\hline Classe 2/2015 & 1,208 & 289 & $23.9 \%$ \\
\hline Classe 3/2015 & 1,05 & 258 & $24.6 \%$ \\
\hline Classe 4/2016 & 1,371 & 279 & $20.4 \%$ \\
\hline Classe 5/2016 & 985 & 216 & $21.9 \%$ \\
\hline Total & $\mathbf{5 , 6 9 9}$ & $\mathbf{2 6 2 . 2}$ & $\mathbf{2 3 . 1 1 \%}$ \\
\hline
\end{tabular}

Tabela 8 - Total e Porcentagem de acessos em dias que foram enviadas mensagens automáticas pelo plugin.

Fonte: Enap 2015.

\begin{tabular}{|c|c|c|c|}
\hline Turmas & $\begin{array}{c}\text { Quantidade } \\
\text { média de Alunos }\end{array}$ & Médias de acesso de alunos & \% \\
\hline Classe 4/2015 & 1,371 & 349 & $35.5 \%$ \\
\hline Classe 5/2016 & 985 & 532 & $38.8 \%$ \\
\hline Total & $\mathbf{2 , 3 5 6}$ & $\mathbf{4 4 0 . 5}$ & $\mathbf{3 7 . 1 \%}$ \\
\hline
\end{tabular}


O gráfico do Google Analytics que monitora os acessos da escola mostra o pico de acessos em dias de envio de mensagens. A CGEAD tomou por padrão para todos os cursos o envio de mensagem no início dos cursos e no início de cada semana como podemos ver na figura 12.

Na figura 29 é possível visualizar os picos de acesso no dia do envio da mensagem e a progressão do dia posterior onde ocorre o maior número de usuários conectados. Foram selecionadas 4 turmas, duas turmas em 2015 e duas em 2016, em datas e períodos do ano diferentes.

O primeiro dia destacado em cada gráfico da figura 29 mostra a data de início do curso e apresenta um pico elevado de acesso em todos os períodos, indicando que a maior parte dos alunos acessam o ambiente nessa etapa inicial e os acessos seguem caindo até a próxima interação do sistema de envio de mensagem, repetindo a curva a cada semana. 


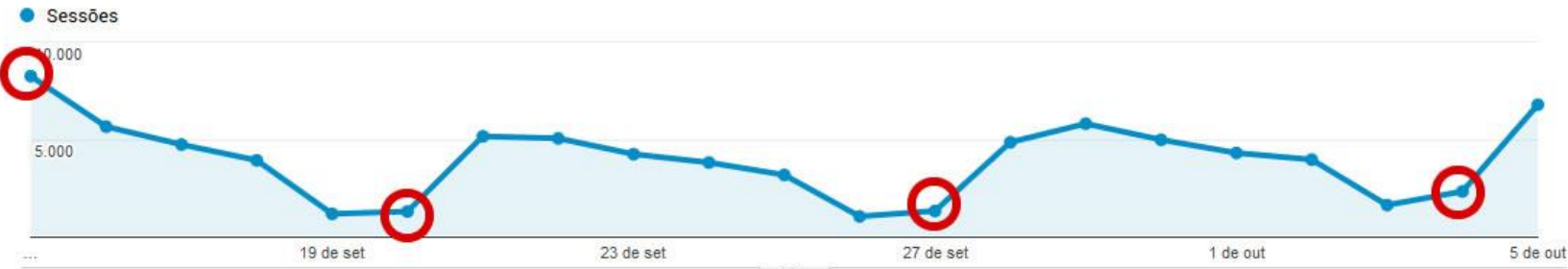

Visāo geral

Sessōes - x Selecione uma métrica 27 de out de $2015-16$ de nov de $2015 \vee$ Por hora Dia Semana Mês

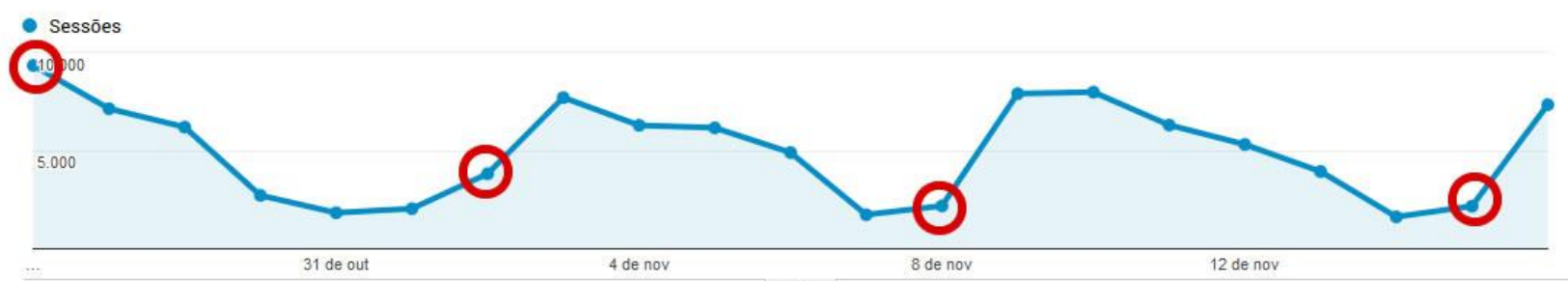

Visão geral

Sessōes - x Selecione uma métrica 8 de mar de 2016 - 28 de mar de 2016 Por hora Dia Semana Mês

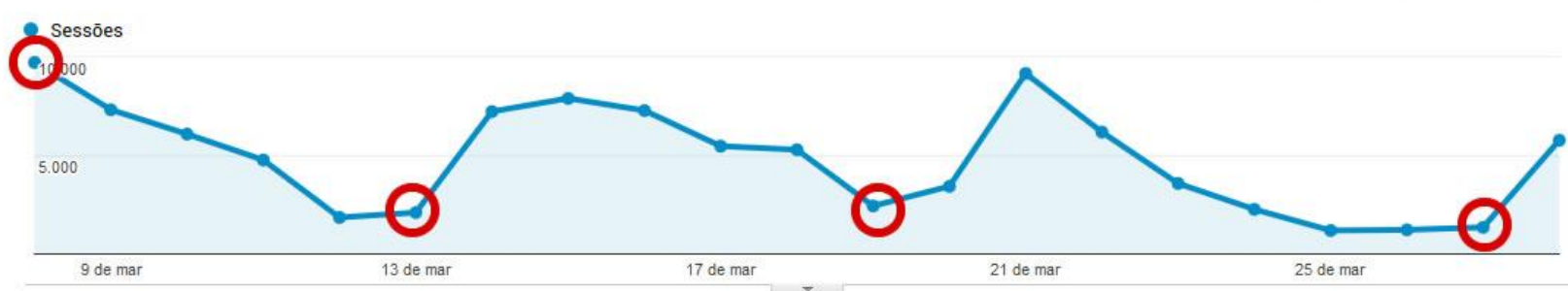

Visāo geral

Sessōes - x Selecione uma métrica 19 de abr de 2016 - 11 de mai de 2016 * Por hora Dia Semana Mês

- Sessōes

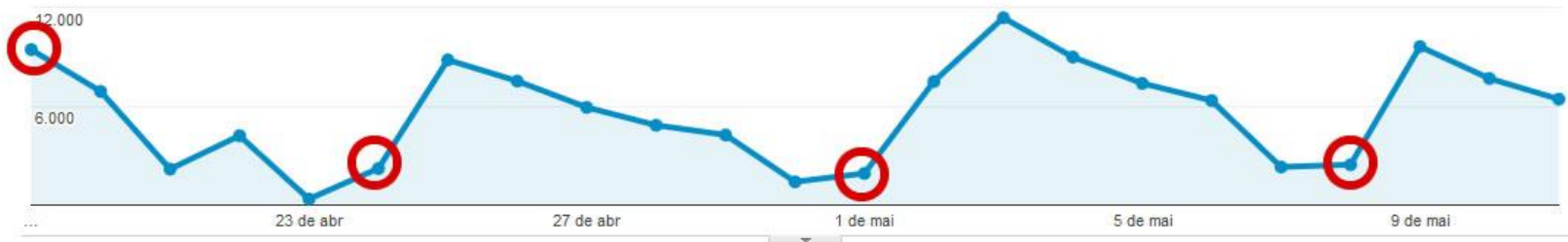

Figura 29 - Visualização dos picos de acesso do Google Analytics. Fonte: Próprio autor.

\section{Relação mensagens x notas médias}

Em meio às análises, foi verificado que o estímulo por mensagens, apesar de incentivar o acesso dos participantes dos cursos em interagir com o ambiente, não é um fator que influencia na nota do aluno.

Foram analisados três cursos distribuídos em 19 turmas em períodos diferentes e como podemos ver 
a média se manteve constante nos cursos que receberam mensagens e nos que não receberam. A tabela 9 mostra que as notas médias dos alunos dos cursos com e sem mensagens.

A tabela 9 notas dos cursos com e sem mensagens.

Fonte: Enap (2016).

\begin{tabular}{|c|c|}
\hline Cursos & Média das notas das avaliações \\
\hline Sem mensagens & 85,06 \\
\hline Com mensagens & 85,79 \\
\hline
\end{tabular}

\section{Relação mensagens $x$ concluintes}

Assim como as notas o número médio de concluintes não apresenta diferença significativa em turmas que receberam o estímulo do sistema e as turmas que não receberam qualquer mensagem.

A tabela 10 apresenta os dados da análise com uma pequena vantagem para as turmas que receberam mensagens.

Tabela 10 - Matrículas concluintes

\begin{tabular}{|c|c|}
\hline Cursos & Percentual médio de concluintes \\
\hline Sem mensagens & $65,56 \%$ \\
\hline Com mensagens & $68,08 \%$ \\
\hline
\end{tabular}

Durante a pesquisa, encontramos um fator fora do contexto do sistema de envio de mensagens. Conforme a tabela 11, foram analisadas 7 turmas com 20 dias de duração de curso e 7 turmas com 34 dias de duração. As turmas com 20 dias obtiveram $66 \%$ de conclusões contra $34 \%$ das turmas com 34 dias. Em relação a nota média das avaliações também existe diferença positiva para as turmas de 20 dias. As turmas de 20 dias apresentaram nota média de 85,09, enquanto as turmas com 34 dias obtiveram nota de 49,15 .

Tabela 11 - Relação entre turmas com 20 dias e turmas com 34 dias de duração de curso.

\begin{tabular}{|c|c|c|}
\hline Cursos & Concluintes \% & Notas médias \\
\hline Turmas com 20 dias & $66 \%$ & 85,09 \\
\hline Turmas com 34 dias & $34 \%$ & 49,15 \\
\hline
\end{tabular}




\section{CONCLUSÕES}

Nesta dissertação, foram apresentados os pontos positivos relativos as mudanças visuais da escola virtual da Enap e das ferramentas personalizadas desenvolvidas através da parceria entre a Universidade de Brasília em cooperação com a Escola Nacional de Administração Pública.

Com a revisão bibliográfica, puderam-se conhecer os fundamentos da educação a distância, em especial a educação corporativa que é o caso da Enap a qual tem como público alvo servidores públicos de instituições do poder executivo federal. Foram averiguadas diversas referências sobre a evasão e interatividade em cursos a distância fator de grande influência no sucesso desse modelo de ensino.

A reestruturação do ambiente virtual de aprendizagem, a construção de soluções com funções específicas e a busca por melhoria na elaboração de cursos possibilitou o atendimento de mais de 200 mil, em 206 turmas de 48 cursos diferentes em 2015 pela escola virtual da Enap.

O estudo também revelou a vantagem em desenvolver soluções sob medida para atender demandas especificas, em destaque os relatórios que possibilitam automatizar as tarefas e análises manuais das rotinas dos gestores da escola.

No contexto acima mencionado, a observação do comportamento do participante através de ferramentas de aprendizagem on-line, onde foi permitido visualizar que estímulos simples na comunicação podem ajudar a conectar os participantes ao ambiente escolar virtual, melhorando seu sucesso nos cursos seguidos.

Por fim, descreve uma das soluções desenvolvidas que é um plugin para o ambiente virtual de aprendizado (Moodle) que envia automaticamente mensagens aos participantes de acordo com condições pré-definidas durante sua participação nos cursos. Apresentau o resultado da investigação sobre os dados disponíveis e verificou-se a eficácia da solução quanto ao nível de participação e atração dos alunos para o ambiente de ensino, onde apresentou um aumento de $37,1 \%$ a mais de acessos nos dias em que os alunos rebem mensagens contra 23,11\% nos dias em que a ferramenta não é utilizada. 


\subsection{TRABALHOS FUTUROS}

Como sugestões para trabalhos futuros, os resultados obtidos permitem apontar algumas direções importantes para o decorrer do trabalho:

- Melhor integração do plugin proposto com ferramentas de análise, a fim de aumentar a automação e o controle.

- Promover inteligência ao sistema, através de técnicas de mineração de dados e aprendizados de máquina. Proporcionando ao sistema aprender com as experiencias dos usuários e tomar decisões autônomas em tempo real com base nesse conhecimento adquirido.

- Medir o nível de satisfação dos usuários através de quationários.

- Verificar a usabilidade do sistema através de mapas de interações ou gravação de tela.

Deste modo, é esperado que este trabalho possa contribuir significativamente para o crescimento da qualidade na gestão de informações e no apoio à decisão no auxílio aos alunos e colaboradores da Enap, visando o aperfeiçoamento e interatividade da Escola Virtual. 


\section{REFERÊNCIAS BIBLIOGRÁFICAS}

Abbad, Gardênia da Silva; ZERBINI, Thaís; SOUZA, Daniela Borges Lima de. Panorama das pesquisas em educação a distância no Brasil. In: Estudos de Psicologia, 15(3), setembrodezembro/2010. Disponível em: <http://www.scielo.br/epsic >. Acesso em: 11 nov. 2016.

Abbad, G. ; ZERBINI, T. ; SOUZA, D. B. L. . Panorama das pesquisas em Educação a Distância no Brasil. Estudos de Psicologia (UFRN), v. 15, p. 291-298, 2010.

Abed - ASSOCIAÇÃO BRASILEIRA DE EDUCAÇÃO A DISTÂNCIA Censo EAD.BR: Relatório Analítico da Aprendizagem a Distância no Brasil 2014 - Curitiba: Ibpex, 2015. Disponível em: <http://www.abed.org.br/censoEaD2014/CensoEAD2014_portugues.pdf. >Acesso:01 nov.2015.

Associação Brasileira de Educação a Distância. Informações do Anuário Brasileiro Estatístico de Educação Aberta e a Distância (AbraEaD/2015). Disponível em: http://www.abed.org.br/site/pt/midiateca/censo_EaD/1395/2016/09/censoEaD.br__2015/2016. Acessado em: 20/11/2016.

Adachi, A. A. C. T. "Evasão e evadidos nos cursos de graduação da Universidade Federal de Minas Gerais." Belo Horizonte: UFMG/FaE,(Dissertação de Mestrado) (2009).

Almeida, Ivana Carneiro; ILDETE, Maria. Educação a distância: Um estudo dos motivos de desistência de um curso a distância via Internet. $14^{\circ}$. Congresso Internacional da ABED de Educação a Distância, Santos/SP, 2008. Disponível em: http://www.abed.org.br/congresso2008/tc/ 54200862040PM.pdf. Acessado em: 25/07/2009.

Almeida, L. R. ; da Costa, J. P. C. L. ; DE SOUSA, JR., Rafael T. ; CANEDO, E. D. ; GALDO, G. ; PRETTZ, J. ; ZACARIAS, E. ; FREITAS, E. P. . Motivating Attendee's Participation in Distance Learning via an Automatic Messaging Plugin for the Moodle Platform. In: 2016 IEEE Frontiers in Education Conference, 2016, Erie. 2016 IEEE Frontiers in Education Conference Proceedings. Piscataway: IEEE, 2016. v. 1. p. 1570251129.

Andriola, 2006, Araújo, J.P. Capacitação docente para uso do Moodle: referência rápida para montagem de cursos. Apostila eletrônica utilizada no curso de extensão "Capacitação docente para uso do Moodle" ministrado na Faculdade de Letras da UFRJ, 2011. 
Bassani, Patrícia Brandalise Scherer. "Mapeamento das interações em ambiente virtual de aprendizagem: uma possibilidade para avaliação em educação a distância." (2006).

Behar, Patricia Alejandra. "Análise das interações em ambientes virtuais de aprendizagem: uma possibilidade para avaliação da aprendizagem em EAD Patrícia Scherer Bassani, Centro Universitário Feevale, patriciab@ feevale. br." (2006).

Berking, P., et al. "The Motif Project: Mobile Learning Survey Report." Advanced Distributed Learning (2013).

Bittencourt, Dênia F., and Alvaro GR LEZANA. "Avaliação do Ensino a Distância-utilizando a visão de Processo e do TQC." CONFERÊNCIA DE CIÊNCIAS DA EDUCAÇÃO. Vol. 4. 1997.

Neves JR, LT das. Aplicação dos conceitos de educação a distância ao treinamento: um estudo de caso em uma rede de farmácias. 2002. 121 f. Diss. Dissertação (Mestrado em Engenharia de Produção)-Programa de Pós-Graduação em Engenharia de Produção. Universidade Federal de Santa Catarina, Florianópolis. Disponível em:< http://www. eps. ufsc. br/defesa/pdf/5471. pdf> Acesso em: 10 abr, 2008.

Brasil. CDB. Lei de Diretrizes e bases da Educação Nacional. Lei no 9.394, de 20 de dezembro de 1996. Brasília - DF. $3^{a}$. ed. 2006.

Castro Filho, J. A.; Loureiro, R. C.; Paula, P. S.; Sarmento, W. W. F.; Peixoto, L. E.; Pequeno, H. S. L.; Rocha, B. T. S.; Viana Júnior, G. S. Portal Humanas: Um ambiente colaborativo para criação de projetos e comunidades virtuais para a área de Humanidades. In: Simpósio Brasileiro de Informática na Educação, 16. Juiz de Fora. Anais. 2005.

Charlot, Bernard. Relação com o Saber, Formação de Professores e Globalização: Questões para a educação hoje. Porto Alegre: Ed. Artmed, 2005.

Costa, José da. Modelos de Educação Superior a Distância e Implementação da Universidade Aberta do Brasil. Revista Brasileira de Informática na Educação - V. 15 N. 2 - Maio a Agosto de 2007.

Dibbela, Anthony J., and Edwin C. Nevis. Como as organizações aprendem: uma estratégia integrada voltada para a construção de capacidade de aprendizagem. Educator, 1999. 
Dillenbourg, Pierre. "Over-scripting CSCL: The risks of blending collaborative learning with instructional design." (2002): 61-91.

Dillenbourg, p.; Schneider, d.; Synteka, P. Virtual Learning environments. (A. Dimitracopoulou, Org.) Proceedings of the 3rd Hellenic Conference "Information \& Communication Technologies in Education”. Kastaniotis Editions: Greece, p. 3-18, 2002.

Dillenburg, D.J.\& Teixeira, A.C. Uma proposta de avaliação qualitativa em ambientes virtuais de aprendizagem. In: Simpósio Brasileiro de Informática na Educação (SBIE), 22. Aracaju. Anais. 2011.

Dougiamas, M. Improving the effectiveness of tools for Internet based education. In: HERRMANN, A; KULSKI, M.M. (Eds). Flexible Futures in Tertiary Teaching. Proceedings of the 9th Annual Teaching Learning Forum 2000 Perth: Curtin University of Technology, 2000. Disponível em http://lsn.curtin.edu.au/tlf/tlf2000/dougiamas.html Acesso em: maio 2013.

Duarte, Zalina Maria Cancela. "Educação à distância (EAD): estudos dos fatores críticos de sucesso na gestão de cursos da região metropolitana de Belo Horizonte." Belo Horizonte: Fumec (2011).

Eboli, Marisa. "Educação corporativa." Revista T\&D-Inteligência Corporativa 137.12 (2004): 48.

Em Números - Escola Nacional de Administração Pública. Acesso em: 10 de nov. 2016 < https://emnumeros.escolavirtual.gov.br >

Enap - Escola Nacional de Administração Pública. Acesso em: 10 de nov. 2016 < http://www.enap.gov.br/en/web/pt-br/a-distancia>

Enap Virtual - Escola Nacional de Administração Pública. Acesso em: 10 de nov. 2016 < https://enapvirtual.enap.gov.br>

Gallagher, Sandra, and Alan Sixsmith. "Engaging IT undergraduates in non-IT content: Adopting an eLearning information system in the classroom." Interactive Technology and Smart Education 11.2 (2014): 99-111.

Gdikian, Elizabeth Ayres, and Moisés Correia da Silva Silva. "Educação estratégica nas organizações: como as empresas de destaque gerenciam o processo de educação corporativa." Rio de Janeiro: Qualitymark (2002). 
Jensen, Jens F. "The concept of'interactivity'in digital television." Berco Beute, Claire Dorman, Jens F. Jensen, Henning Olesen, Michael Rose (1999).

Keegan, Desmond. Foundations of distance education. Psychology Press, 1996.

Lévy, Pierre. Cibercultura. São Paulo: Editora 34, 1999.

Lucena, C.J.P., Lucena, M., Fuks, H. e Filippo, D. (2005) “Extending Collaborative

Learning Coordination Support in the AulaNet LMS Using Mobile Devices”. In: IV International Conference on Multimedia and ICTs in Education, p. 846-850.

Machado, Armando. "Learning the temporal dynamics of behavior." Psychological review 104.2 (1997): 241.

Fernandes, Eugénia M., et al. "Dilemas implicativos e ajustamento psicológico: Um estudo com alunos recém-chegados à Universidade do Minho." (2005).

Mariotti, H. "Conceitos básicos." Organizações de aprendizagem-educação continuada e a empresa do futuro. São Paulo: Editora Atlas SA (1999): 17-38.

Mec/decreto. N. ${ }^{\circ}$ 2.494, de 10 de fevereiro de 1998. Disponível em: http://portal.mec.gov.br/seed/arquivos/pdf/tvescola/leis/D2494.pdf. Acessado em: 24/08/2008.

Mec - Ministério de Educação do Brasil. Relatório Final da Comissão Assessora para Educação Superior a Distância. Agosto, 2002. Disponível em: http://www.nEaD.ufma.br/arquivos/RELATORIO_FINAL_DA_COMISSAO DE_EAD_MEC.pdf. Acessado em: 30/08/2008.

Mec/Portaria No4.059, de 10 de dezembro de 2004 . http://portal.mec.gov.br/sesu/arquivos/pdf/nova/acs_portaria4059.pdf Acesso em: $10 / 10 / 2015$.

Meister, Jeanne C. "Educação corporativa: a gestão do capital intelectual através das universidades corporativas." (1999).

Moore, m.; Kearsley, G. Educação a Distância: uma visão integrada. São Paulo: Thomson Learning, 2007. 
Moore, Michael G.; Kearsley, Greg. Educação a distância: uma visão integrada. São Paulo: Thomson Learning, 2007.

Moran, José Manuel. Contribuições para uma pedagogia da educação online. Capítulo do Livro: SILVA, Marco. Educação online. São Paulo: Edições Loyola, 2003.

Oliveira, A. S. de, F. R. S. Feres, M. B. de Lima, E. D. Canedo, J. P. C. L. da Costa, R. T. de Sousa Júnior, "Inovação no design instrucional dos cursos a distância da escola nacional de administração pública e sua interface com a equipe interdisciplinar," $22^{\circ}$ CIAED - Congresso Internacional ABED de Educação a Distância, Águas de Lindóia, 2016.

Peres, Renata Cristina de Azevedo Borges. Uso da plataforma moodle em uma disciplina de graduação em letras: percepções de alunos e professora sobre a modalidade semipresencial. Diss. Universidade Federal do Rio de Janeiro, 2013.

Perry, B., Edwards, M. Creating a culture of community in the online classroom using artistic pedagogical technologies. In VELETSIANOS, G. Emerging technologies in distance education. Canada: Athabasca University. 2010, p. 129-152

Rodrigues, OB. "Aprendizagem organizacional: a mão única da educação corporativa." RH. com. br: offsite de referência sobre gestão de pessoas 26 (2006).

Rosenberg, Marc J. "E-learning: estratégias para a transmissão do conhecimento na era digital." Makron Books, ISBN 85 (2002): 1383-4. p 29

Royo, Enrique Rubio. "Proyecto colaborativo para la produccion de contenidos y desarrollo de cursos basados en Web." Universidade de Las Palmas de Gran Canária.

R. Tori, Educação sem Distância: as tecnologias interativas na redução de distâncias em ensino e aprendizagem. São Paulo: Senac, 2010.

Sale, D. G., et al. "Interaction between concurrent strength and endurance training." Journal of applied physiology 68.1 (1990): 260-270.

Sales, Patrícia de Andrade Oliveira. "Evasão em curso a distância: motivos relacionados às características do curso, do aluno e do contexto de estudo." (2011). 
Santos, E. M., Tomotake, M. E., Neto, J. D. O., Cazarini, E. W., Araújo, E. M., \& Oliveira, S. R. M. (2008). Evasão na educação a distância: Identificando causas e propondo estratégias de prevenção. Recuperado de: http://www.abed.org.br/congrsso/tc/511200845607PM.pdf

Sclater, N. "Cloud computing in education." Policy Brief, Unesco Institute for Information Technology in Education (2010).

Senge, Peter, et al. "The dance of change: The challenges to sustaining momentum in learning organizations." (1999): 55-58.

Senge, Peter. "Classic work: The 1EaDer's new work: Building learning organizations." Knowledge management: Classics and contemporary works (2000): 19-52.

Senge, Peter M. The fifth discipline: The art and practice of the learning organization. Crown Pub, 2006.

Sims, Roderick. "Interactivity and narrative: Strategies for effective learning." Proceedings of EdMedia. 1999.

Stewart, T. A. (1998) Capital intelectual: a nova vantagem competitiva das empresas. 4. Ed. Rio de Janeiro: Campus, 239p.

Tinto, V. Dropout from higher education: a theoretical synthesis of recent research. Washington, Review of Educational Research v. 45, n. 1, 1975, p. 89-125.

Vasconcellos, L; GUEDES, L. F. A. E-Surveys: Vantagens e limitações dos questionários eletrônicos via internet no contexto da pesquisa científica. X SEMEAD.

Vilarinho, Lúcia Goulart, and Emília Moreira Paro. "Evasão de alunos na educação superior a distância: A experiência do módulo de acolhimento." Voces y Silencios 2.2 (2011).

YIN, R. K. Estudo de caso: planejamento e métodos. 4. ed. Porto Alegre: Bookman, 2010.

Zacarias ,E., L. R. de Almeida, J. B. Prettz, J. P. C. L. da Costa, E. P. de Freitas, E. D. Canedo, and R. T. de Sousa Júnior, "Optimizing the Access Records of Students in the Moodle Virtual Learning Environment Database," 4th IFAC Symposium on Telematics Applications, 2016

Zanelli, José Carlos, and Narbal SILVA. "Interação humana e gestão: a construção psicossocial das organizações de trabalho." São Paulo: Casa do Psicólogo (2008).Acesso em: 03 mar.2013. 